Portland State University

PDXScholar

\title{
Modification of the $\mathrm{CA}^{2+}$ Release Channel from Sarcoplasmic Reticulum of Skeletal Muscle
}

Hui Xiong

Portland State University

Follow this and additional works at: https://pdxscholar.library.pdx.edu/open_access_etds Let us know how access to this document benefits you.

\section{Recommended Citation}

Xiong, Hui, "Modification of the $\mathrm{CA}^{2+}$ Release Channel from Sarcoplasmic Reticulum of Skeletal Muscle" (1991). Dissertations and Theses. Paper 1304.

https://doi.org/10.15760/etd.1303

This Dissertation is brought to you for free and open access. It has been accepted for inclusion in Dissertations and Theses by an authorized administrator of PDXScholar. Please contact us if we can make this document more accessible: pdxscholar@pdx.edu. 


\title{
MODIFICATION OF THE $\mathrm{Ca}^{2+}$ RELEASE CHANNEL FROM SARCOPLASMIC RETICULUM OF SKELETAL MUSCLE
}

\author{
by \\ HUI XIONG
}

A dissertation submitted in partial fulfiliment of the requirements for the degree of

\author{
DOCTOR OF PHILOSOPHY \\ IN \\ ENVIRONMENTAL SCIENCES AND RESOURCES: \\ PHYSICS
}

Portland State University

1991 


\section{TO THE OFFICE OF GRADUATE STUDIES:}

The members of the Committee approve the dissertation of Hui Xiong presented October 31, 1991.
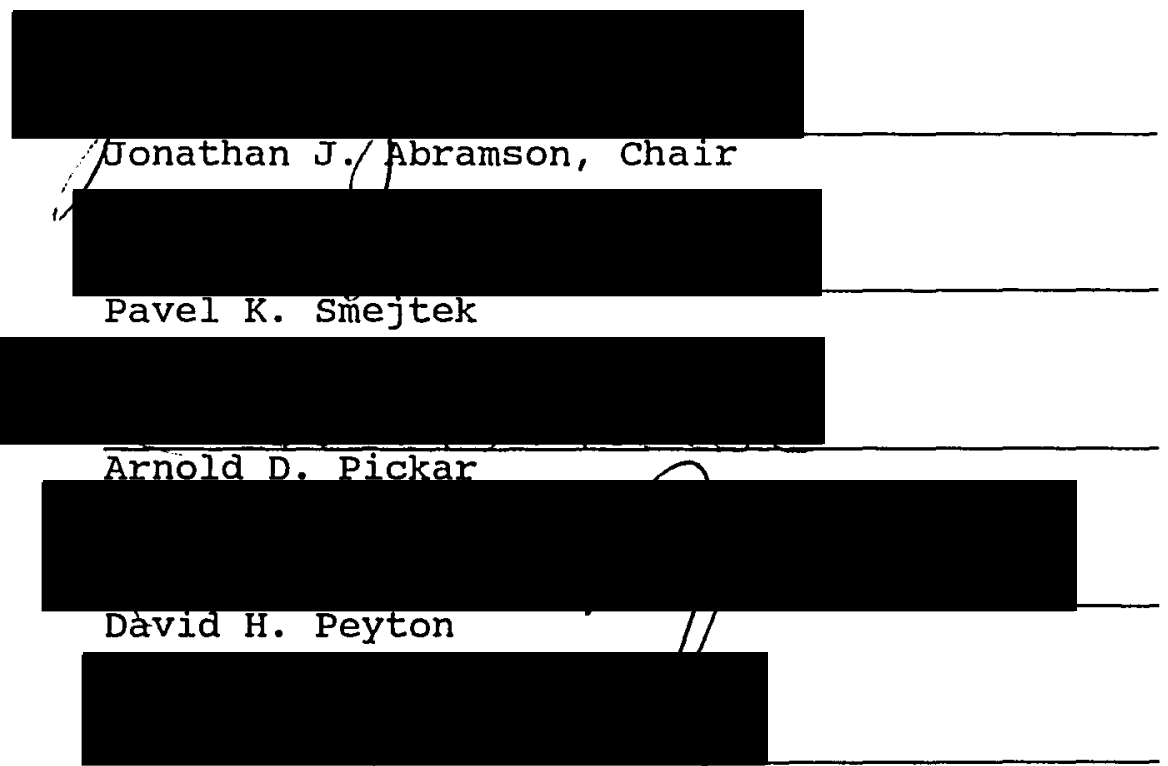

Robert L. Millette

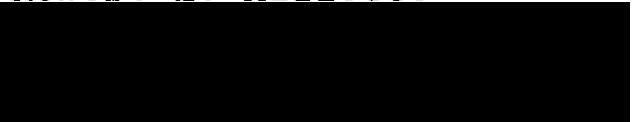

stanleýs. Hínimăn
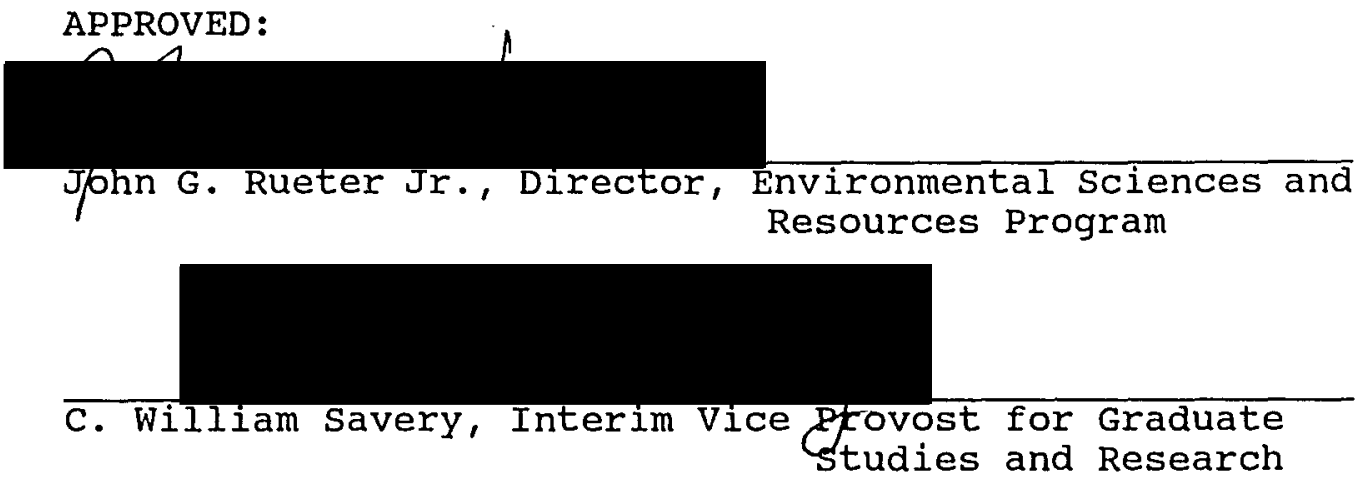
AN ABSTRACT OF THE DISSERTATION OF HUi Xiong for the Doctor of Philosophy in Environmental Science and Resources: Physics presented october $31,1991$.

Title: Modification of the $\mathrm{Ca}^{2+}$ Release Channel from Sarcoplasmic Reticulum of skeletal Muscle.

\section{APPROVED BY THE MEMBERS OF THE DISSERTATION COMMITTEE:}

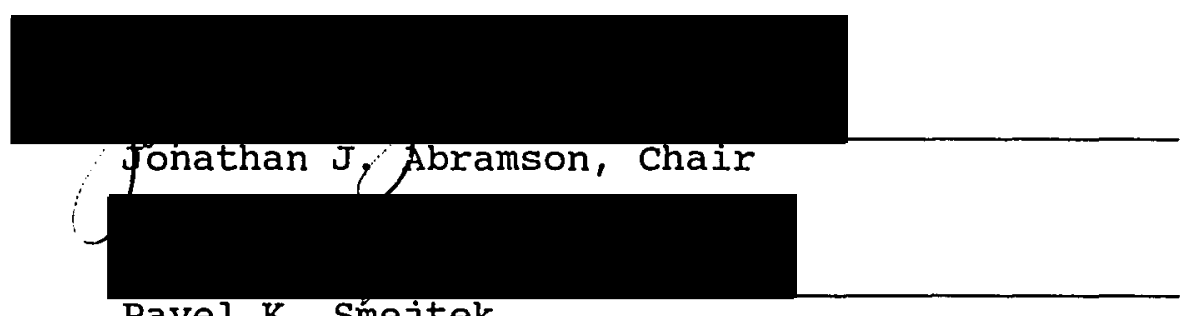

Pavel K. Smejtek

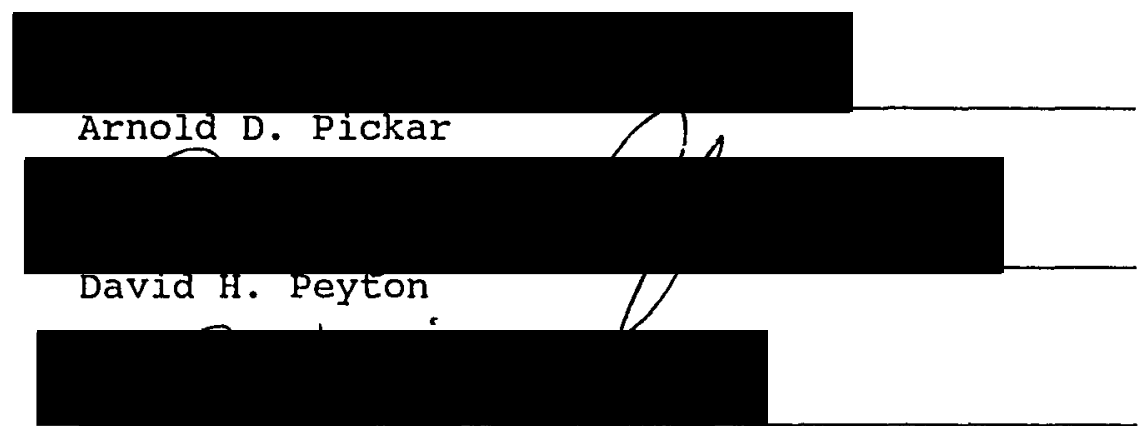

Robert L. Millette

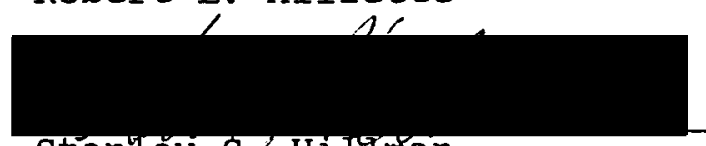

stanley s. Hiliman

Muscle contraction and relaxation are controlled by the intracellular free $\mathrm{Ca}^{2+}$ concentration. The sarcoplasmic reticulum (SR) is an intracellular membrane system which 
regulates this internal free $\mathrm{Ca}^{2+}$ concentration. Responding to an electrical excitation of the cell surface membrane, the $\mathrm{SR}$ releases $\mathrm{Ca}^{2+}$ through a specific $\mathrm{Ca}^{2+}$ release channel, thus elevating the $\mathrm{Ca}^{2+}$ concentration inside muscle cell and causing the muscle to contract. Subsequent sequestration of $\mathrm{Ca}^{2+}$ by the SR $\mathrm{Ca}^{2+}$ pumps restores the resting state of the muscle cell. This research focuses on the $\mathrm{Ca}^{2+}$ release channel from skeletal muscle SR. The planar lipid bilayer technique was used to study the channel at the single channel level.

The SR $\mathrm{Ca}^{2+}$ release channel was identified and isolated via its interaction with specific sulfhydryl oxidizing agents. This protein of a molecular mass of $106 \mathrm{kDa}$ was then incorporated into a planar lipid bilayer membrane (BLM). In an asymmetrical $\mathrm{Ca}^{2+}$ solution, the channel protein demonstrates a single channel conductance of $107 \pm 13 \mathrm{ps}$ and a permeability ratio of $\mathrm{Ca}^{2+}$ versus $\mathrm{Tris}^{+}$of $7.4 \pm 3.3$. In a symmetrical $250 \mathrm{mM} \mathrm{NaCl}$ solution, the channel protein displays a large single channel conductance of $400 \pm 20 \mathrm{pS}$, and a weak voltage-dependence. The channel is activated by millimolar ATP and inhibited by micromolar ruthenium red. Nanomolar concentrations of ryanodine modify the channel by changing it from a rapidly gating full conductance state to a long-lived subconductance state. These results demonstrate that the isolated $106 \mathrm{kDa}$ protein channel has properties similar to those observed following fusion of SR vesicles to a BLM. 
The bilayer system was also used to examine the effect of $\mathrm{Ag}^{+}$on the SR $\mathrm{Ca}^{2+}$ release channel. $\mathrm{Ag}^{+}(0.2-1.0 \mu M)$ activates the $\mathrm{SR} \mathrm{Ca}^{2+}$ release channel. Activation by $\mathrm{Ag}^{+}$does not require the presence of $\mathrm{Ca}^{2+}, \mathrm{Mg}^{2+}$, or ATP. $\mathrm{Ag}^{+}$activates the channel by increasing the open probability $\mathrm{P}_{0}$. $\mathrm{Ag}^{+}$ activation is always followed by a spontaneous inactivation. The channel is still sensitive to ruthenium red inhibition after exposure to $\mathrm{Ag}^{+}$.

Isolated SR vesicles were fused to a BLM to study the effect of the photooxidizing dye, rose bengal, on the gating characteristics of the reconstituted $\mathrm{SR} \mathrm{Ca}^{2+}$ release channel. Rose bengal activates the $\mathrm{Ca}^{2+}$ release channel in the presence of light by increasing the channel open probability and leaving the single channel conductance unchanged. This photoactivation is independent of the myoplasmic $\mathrm{Ca}^{2+}$ concentration, and can be achieved from either side of the membrane. In addition, the effect is inhibited by addition of 10-20 $\mu M$ ruthenium red. When modified to its subconducting state by ryanodine, subsequent addition of rose bengal reactivates the channel to a rapidly fluctuating full conducting state.

These studies carried out at the single channel level utilizing the planar lipid bilayer technique have not only enhanced our understanding of the $\mathrm{Ca}^{2+}$ release mechanism of skeletal muscle $S R$, but also provided information about the 
toxic effects on biological membrane systems caused by heavy metals and oxidizing agents. 


\section{ACKNOWLEDGEMENTS}

I would like to express my sincere appreciation to the individuals who have offered friendship and assistance during my study in this country and have made this dissertation possible. My advisor, Dr. Jon Abramson, has not only introduced me to the world of scientific research and guided me through the making of this thesis, but has also provided me with untiring encouragement and support during the course of this project. His integrity, his kindness, and his enthusiastic pursuit of truth has set an example of how to lead one's life. My thanks to the Physics Department and the Environmental Sciences Program for providing me the opportunity to study in this country by sponsoring my research. In addition, I would like to thank the members of my advisory committee (Drs. Pavel Smejtek and Arnold Pickar from Physics, Dr. David Peyton from Chemistry, and Drs. Robert Millette and Stanley Hillman from Biology) for their advice, suggestions and precious time which they committed in addition to their research endeavors and heavy academic duties. I would also like to thank Mrs. Dawn Dressler, Dr. Joel Nissen, Dr. Joe Walters, and all the current faculty, staff, and students of the Physics Department. Special thanks to Dr. Pavel Smejtek for providing equipment, lab space and constant 
comments on my project. I am especially grateful to all the co-workers in this lab: Ed Buck whose technical assistance and friendship helped me a great deal, Keith scott who prepared the purified protein for my experiments, Terry Favero whose friendship and jokes I'll miss, Jon Trimm, Joe Cronin, Jan stuart, Scott Milne, Tony Zable, and Margot Leonard. It is their presence, friendship, and assistance which made my study here a precious memory. I would also like to thank Garo Arakelian, Rudi Zupan, and Brian Mcloughlin of the Science support shop. Finally, I would like to thank my family in China, my American family here, the Kents, and my Chinese friends here. Above all, I thank my husband Jian Huang for his unconditional support and encouragement. To my husband and my parents, this dissertation is dedicated. 
TABLE OF CONTENTS

PAGE

ACKNOWLEDGEMENTS. • . . . . . . . . . . . . . . . . . . . iii

LIST OF TABLES. . . . . . . . . . . . . . . . . . . viii

LIST OF FIGURES . . . . . . . . . . . . . . . . . . . ix

TABLE OF ABBREVIATIONS. • . . . . . . . . . . . . . . . xii

CHAPTER

I INTRODUCTION . . . . . . . . . . . . . . 1

Muscle and Contraction . . . . . . . 1

Sarcoplasmic Reticulum . . . . . . . 7

Major Proteins of SR the Membrane System

Monovalent Channel Present in the SR

Hypotheses of EC Coupling . . . . . . 12

Preparations for Studying EC Coupling

Proposed Theories Describing EC Coupling

Calcium Channels . . . . . . . . 24

The $\mathrm{Ca}^{2+}$ Channel of T-tubule

The $\mathrm{Ca}^{2+}$ Release Channel of SR

Overview of Dissertation . . . . . . 28

Reconstitution and Characterization of SR $106 \mathrm{kDa}$ Protein

$\mathrm{Ag}^{+}$Modification of $\mathrm{SR} \mathrm{Ca}^{2+}$ Release Channel

Photooxidation of SR $\mathrm{Ca}^{2+}$ Release Channel 
II METHODS . . • . . . . . . . • . • . 32

Isolation of SR Vesicles . . . . . . 32

Isolation of $106 \mathrm{kDa}$ Protein . . . . . 33

Synthesis of SPDP-Biotin Conjugate Covalent Labeling of SR Protein with Biotin

Isolation of Biotin-Labeled SR Proteins by Biotin-Avidin Chromatography

Planar Lipid Bilayer Technique . . . . 35

Bilayer Chambers

Formation of Bilayer Membranes

Reconstitution of the Native SR $\mathrm{Ca}^{2+}$ Release Channel

Reconstitution of Purified $106 \mathrm{kDa}$ Protein

Signal Acquisition and Analysis

III RECONSTITUTION AND CHARACTERIZATION OF THE

$106 \mathrm{KDA} \mathrm{Ca}^{2+}$ RELEASE CHANNEL . . . . . . . 45

Summary . . . . . . . . . . . . . 45

Introduction . . . . . . . . . . . 45

Results . . . . . . . . . . . . 48

Discussion . . . . . . . . . . 60

IV SILVER MODIFICATION OF THE SR CALCIUM

RELEASE CHANNEL . . . . . . . . . . . . 66

Summary . . . . . . . . . . . . . 66

Introduction . . . . . . . . . . 67

Results . . . . . . . . . . 70

Discussion . . . . . . . . . . . 78

$\checkmark$ PHOTOOXIDATION OF THE SR CALCIUM RELEASE

CHANNEL . . . . . . . . . . . . . 87

Summary • . . . . . . . . . . . 87

Introduction . . . . . . . . . . 88 
vii

Results . . . . . . . . . . . . 93

Discussion . . . . . . . . . 108

VI CONCLUSION . . . . . . . . . . . . . . . 112

REFERENCES . . . . . . . . . . . . . . . . . 115

APPENDIX. . . . . . . . . . . . . . . . . . . . . . . . . . 


\section{LIST OF TABLES}

TABLE

PAGE

I Free ionic concentrations and equilibrium

potentials for mammalian skeletal muscle . . 6

II Modulators of $\mathrm{Ca}^{2+}$ release from isolated SR

vesicles of skeletal muscle . . . . . 16

III Different types of $\mathrm{Ca}^{2+}$ channels . . . . . . 25

IV The properties of the native $\mathrm{SR} \mathrm{Ca}^{2+}$ release

channel, the $106 \mathrm{kDa}$ channel, and the 400

kDa channel in the standard asymmetrical

$\mathrm{Ca}^{2+}$ solution . . . . . . . . . . 62 


\section{LIST OF FIGURES}

FIGURE

PAGE

1. The internal membrane system of a skeletal muscle fiber . . . . . . . . . . .

2. Electrical and mechanical responses of a single frog twitch muscle fiber to an electrical stimulus. . . . . . . . . . 7

3. A planar lipid bilayer setup. . . . . . . . 36

4. Fusion of a SR vesicle to a lipid bilayer. . 40

5. Structure of reactive disulfide compounds and reactions of SPDP. . . . . . . . . . . 47

6. Reconstituted $106 \mathrm{kDa}$ protein in the standard $\mathrm{Ca}^{2+}$ solution. . . . . . . . . . .

7. Reconstituted $106 \mathrm{kDa}$ protein shows monovalent cation conductance. . . . . . . . .

8. Reconstituted $106 \mathrm{kDa}$ protein shows monovalent cation conductance. . . . . . . . .

9. The properties of monovalent conductance of the $106 \mathrm{kDa}$ channel.

10. The native SR $\mathrm{Ca}^{2+}$ release channel conducts monovalent cations. . . . . . . . 56

11. Subconducting states of the reconstituted 106 kDa protein............ . . 57

12. ATP and ruthenium red modification of the reconstituted $106 \mathrm{kDa}$ channel. . . . . 59

13. Ryanodine modification of the reconstituted 106 kDa channel. . . . . . . . . .

14. $\mathrm{Ag}^{+}$dependence of $\mathrm{Ca}^{2+}$ release rate of isolated $\mathrm{SR}$ vesicles. . . . . . . . . . . . 
15. The current-voltage curve of a typical native

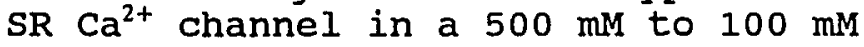

CsCl gradient. . . . . . . . . . . .

16. $\mathrm{Ag}^{+}$modification of a native $\mathrm{SR} \mathrm{Ca}^{2+}$ release channel under physiological conditions.

17. $\mathrm{Ag}^{+}$modification of the $\mathrm{SR} \mathrm{Ca}^{2+}$ channel in the absence of $\mathrm{MgCl}_{2}$. . . . . . . . .

18. $\mathrm{Ag}^{+}$modification of $\mathrm{SR} \mathrm{Ca}^{2+}$ release channel at a low $\mathrm{Ca}^{2+}$ concentration. . . . . .

19. Ruthenium red inhibition of the $\mathrm{SR} \mathrm{Ca}^{2+}$ channel after $\mathrm{Ag}^{+}$modification. . . . .

20. $\mathrm{Ag}^{+}$modification of the $\mathrm{Ca}^{2+}$ channel from the Iuminal face of the SR. . . . . .

21. The effect of high concentration of $\mathrm{Ag}^{+}$on the $\mathrm{SR} \mathrm{Ca}{ }^{2+}$ channel. . . . . . . . . . 80

22. The effect of $\mathrm{Ag}^{+}$on the purified $106 \mathrm{kDa} \mathrm{SR}$ $\mathrm{Ca}^{2+}$ release channel. . . . . . . .

23. The structure of rose bengal as $C-2 ', C-6$ potassium salt. . . . . . . . . . . . .

24. Rose bengal induced $\mathrm{Ca}^{2+}$ efflux from actively loaded SR vesicles. . . . . . . .

25. Rose bengal activation and ruthenium red inhibition of the SR $\mathrm{Ca}^{2+}$ release channel. . . . . . . . . . . .

26. Current-voltage curve of a single $\mathrm{Ca}^{2+}$ channel in the absence and presence of

$0.5 \mu M$ rose bengal with illumination. .

27. Open lifetime analysis of a $\mathrm{SR} \mathrm{Ca}^{2+}$ release channel upon photooxidation. . . . . .

28. Closed lifetime analysis of a SR $\mathrm{Ca}^{2+}$ release channel upon photooxidation. . . . . . 98

29. Light dependence of the rose bengal effect. . 100

30. Rose bengal activation of $\mathrm{SR} \mathrm{Ca}^{2+}$ release channel at low $\mathrm{Ca}^{2+}$ concentration. . . 101 
31. Rose bengal activation of channel activity is side independent. . . . . . . . 102

32. Ryanodine modification of the $\mathrm{Ca}^{2+}$ release channel is reversed by rose bengal. . . 103

33. Light dependent displacement of $\left[{ }^{3} \mathrm{H}\right]$-ryanodine from its binding sites by rose bengal. . 105

34. Rose bengal activation of the purified $\mathrm{Ca}^{2+}$ release channel and subsequent modification by ryanodine. . . . . . 106

35. Rose bengal activation of ryanodine modified $106 \mathrm{kDa} \mathrm{Ca}{ }^{2+}$ release channel. . . . . 107 


\section{TABLE OF ABBREVIATIONS}

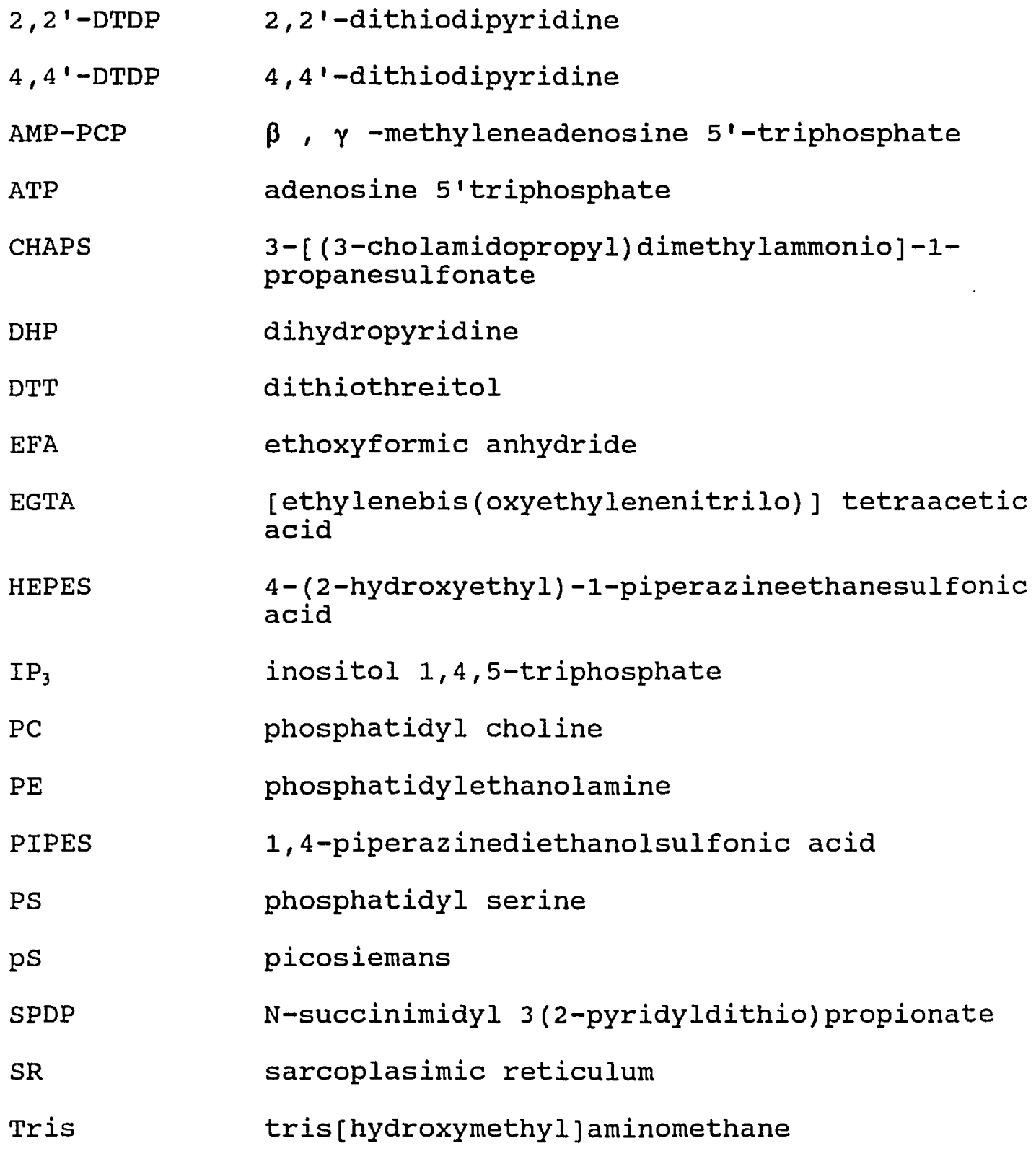


CHAPTER I

\section{INTRODUCTION}

In muscle cells, the chemical energy from the hydrolysis of ATP is transformed into the mechanical energy of contraction. Muscle contraction and relaxation are regulated by the cytoplasmic (myoplasmic) free $\mathrm{Ca}^{2+}$ concentrations. The sarcoplasmic reticulum (SR) of striated muscle cells is a highly specialized intracellular membrane system which controls intracellular $\mathrm{Ca}^{2+}$ concentration of muscle cells. This function is carried out mainly by two transport proteins in the SR membrane. The $\mathrm{Ca}^{2+}$ pump transports $\mathrm{Ca}^{2+}$ against electrochemical gradient into the lumen of the SR to maintain the low myoplasmic $\mathrm{Ca}^{2+}$ level of resting muscle cells. The $\mathrm{Ca}^{2+}$ release channel releases $\mathrm{Ca}^{2+}$ stored in $\mathrm{SR}$ and elevates the myoplasmic $\mathrm{Ca}^{2+}$ concentration. This research is focused on understanding the mechanism of $\mathrm{Ca}^{2+}$ release from $\mathrm{SR}$.

\section{MUSCLE AND CONTRACTION}

Vertebrate muscle cells are generally grouped into two categories, striated and smooth. Striated muscle makes up the tissue of the heart and skeletal muscles. The skeletal muscle cells are multinucleate and referred to as muscle fibers. In heart and smooth muscle, the cells are called myocytes. The 
response time of muscle contraction has a wide range in the different types of muscle, ranging from milliseconds in fasttwitch skeletal muscle to seconds in smooth muscle. The highly ordered structure of skeletal muscle cells has received the most attention and has led to the formulation of the sliding-filament model for muscular contraction.

Skeletal muscle fibers are 10 to $100 \mu m$ thick and up to a few centimeters on length. These fibers are multinucleate cells formed by the fusion of numbers of elongated uninucleate cells called myoblasts. Each cell is surrounded by an electrically excitable membrane known as the sarcolemma. Most of the interior of the fibre consists of the protein filaments termed myofibrils, which constitute the contractile apparatus. Along the axis of contraction, myofibrils are divided into repeating units about $2.5 \mu \mathrm{m}$ in length which are termed sarcomeres. The intracellular fluid bathing the myofibrils is termed sarcoplasm (myoplasm) and contains an elaborate system of intracellular membranes, the sarcoplasmic reticulum, as well as mitochondria, lipid droplets, and glycogen granules. The sarcoplasmic reticulum (SR) is an enclosed membrane system wrapping around the surface of myofibrils. It has a central role in controlling the myoplasmic $\mathrm{Ca}^{2+}$ concentration. The SR is broadly divided into two morphologically and functionally distinct regions: the junctional SR (also called the terminal cisternae), and the longitudinal SR (Peachey, 1965; Peachey et al. 1983). The junctional SR (JSR) are 
closely packed next to the transverse tubule (T-tubule) membrane, which is a continuous invagination of the sarcolemma extended into the interior of muscle cells (Figure 1). The association of one $T$ tubule and two apposed terminal cisternae forms the triadic junction. The longitudinal SR (LSR) connect with two terminal cisternae, forming SR compartments. Bridging the 12 to $14 \mathrm{~nm}$ gap between the junctional SR and the T-tubule membranes are regularly spaced structures termed feet (Franzini-Armstrong, 1975; 1980). The triad junction is involved in transmission of the excitatory stimulus from the surface membrane to the SR, causing $\mathrm{Ca}^{2+}$ release. How signal transmission occurs at the triad junction is one of the major unsolved problems of muscle biology.

In skeletal muscle, the signal for $\mathrm{Ca}^{2+}$ release is initiated at the neuro-muscular junction. This electrical signal, termed the action potential, spreads over the sarcolemma and down to the T-tubule as a depolarization of the membrane. Depolarization of the T-tubule membrane, by an unknown mechanism, causes an extremely rapid release of $\mathrm{Ca}^{2+}$ from the SR. The elevated myoplasmic $\mathrm{Ca}^{2+}$ concentration, in turn, triggers muscle contraction. subsequently $\mathrm{Ca}^{2+}$ uptake by the $\mathrm{SR} \mathrm{Ca}^{2+}$ pumps $\left(\mathrm{Ca}^{2+}-\mathrm{Mg}^{2+}\right.$ ATPase) decreases the intracellular $\mathrm{Ca}^{2+}$ concentration and causes relaxation. The process linking depolarization of the T-tubule and $\mathrm{Ca}^{2+}$ release from $S R$ is referred to as excitation-contraction coupling (EC coupling). The mechanism of EC coupling has been 


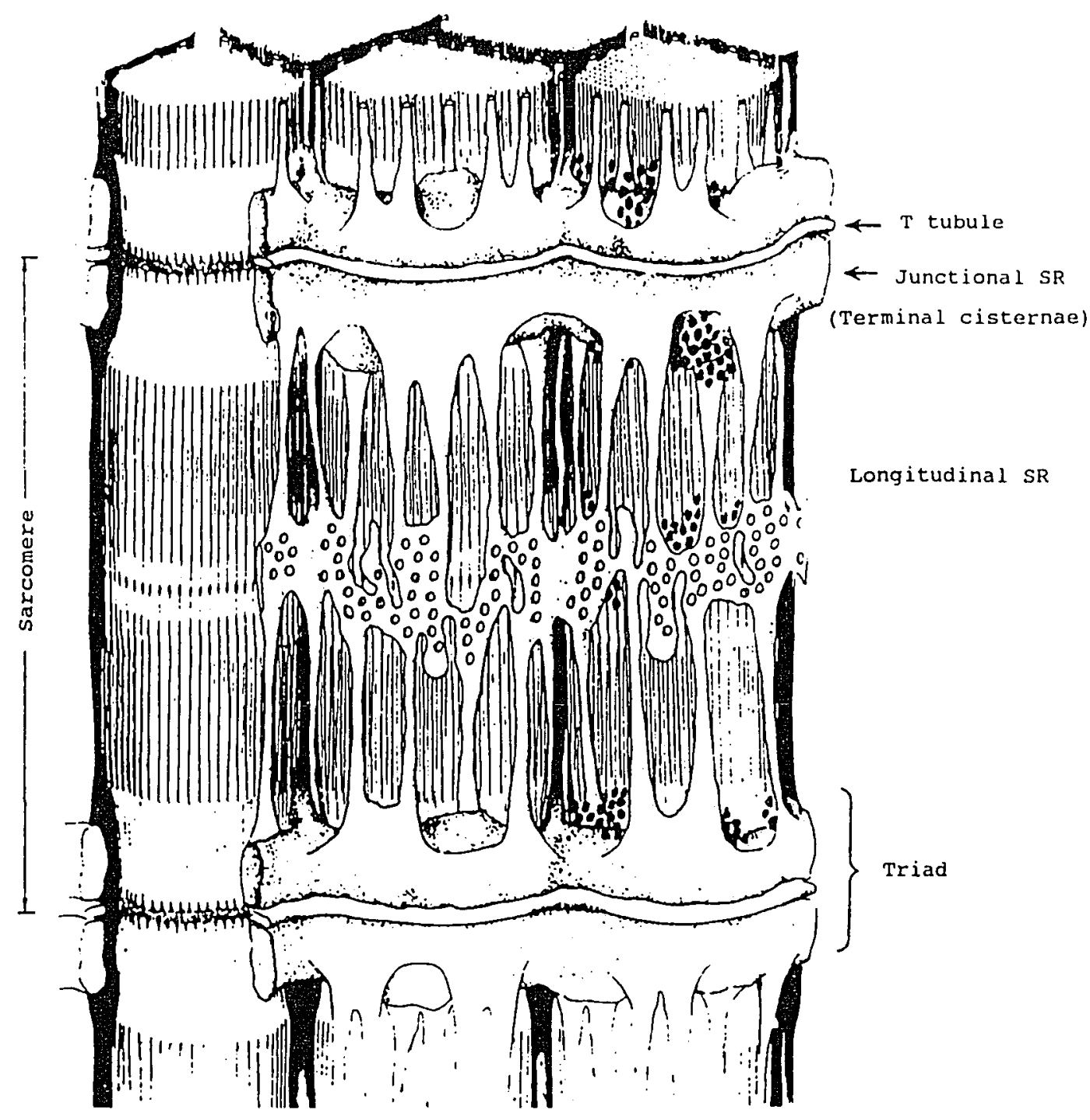

Figure 1. The internal membrane system of a skeletal muscle fiber. Reproduced from Peachey, 1965. 
extensively investigated over the last three decades. Although the exact mechanism is still unknown, remarkable progress has been made in characterizing the molecular machinery involved in EC coupling.

The molecular mechanism of reactions of contractile proteins has been worked out (Ebashi, 1975). Each myofibril contains tightly packed protein myofilaments, the thick and thin filaments. The thick filaments are made up of myosin. The thin filaments consist of two strands of fibrous actin with myosin binding sites at regular intervals and two smaller proteins, troponin, and tropomyosin. Under resting conditions the myoplasmic free $\mathrm{Ca}^{2+}$ concentration is low $(0.1 \mu \mathrm{M})$; the interaction of actin and myosin is blocked by the troponintropomyosin complex. When SR releases its stored $\mathrm{Ca}^{2+}$ in response to a neural stimulation, the elevated intracellular free $\mathrm{Ca}^{2+}$ level unblocks the troponin-tropomyosin complex and the interaction between actin and myosin occurs. The mechanism of action of $\mathrm{Ca}^{2+}$ on the contractile system is to remove an inhibition that has been exerted on actin molecules by troponin-tropomyosin complex in the absence of $\mathrm{Ca}^{2+}$. Thus, $\mathrm{Ca}^{2+}$ is the essential mediator of physiological contraction of muscle cells, and, in skeletal muscle, this $\mathrm{Ca}^{2+}$ is almost exclusively from the SR.

Table I lists the concentrations of ions when mammalian skeletal muscle is in a resting state (Hill, 1984). The resting potential ( $-90 \mathrm{mV}$ inside the cell) of muscle cells is 
TABLE I

FREE IONIC CONCENTRATIONS AND EQUILIBRIUM POTENTIALS FOR MAMMALIAN SKELETAL MUSCLE

\begin{tabular}{||l|l|l|l||}
\hline Ion & $\begin{array}{l}\text { Extracellular } \\
\text { concentration } \\
(\mathrm{mM})\end{array}$ & $\begin{array}{l}\text { Intracellular } \\
\text { concentration } \\
(\mathrm{mM})\end{array}$ & $\begin{array}{l}\text { Equilibrium } \\
\text { potential } \\
(\mathrm{mV})\end{array}$ \\
\hline $\mathrm{Na}^{+}$ & 145 & 12 & +67 \\
$\mathrm{~K}^{+}$ & 4 & 155 & -98 \\
$\mathrm{Ca}^{+}$ & 1.5 & $<10^{-7} \mathrm{M}$ & $>+128$ \\
$\mathrm{Cl}^{-}$ & 123 & $4.2^{\mathrm{c}}$ & $-90^{\mathrm{c}}$ \\
\hline
\end{tabular}

${ }^{a}$ Reproduced from Hille, 1984

${ }^{b}$ Calculated from $E_{X}=\frac{R T}{F} \ln \frac{[X]_{0}}{[X]_{i}}$

${ }^{c} \mathrm{Calculated}$ assuming a $-90 \mathrm{mV}$ resting potential for the muscle membrane and that $\mathrm{Cl}^{-}$ions are at equilibrium at rest.

due to the high $\mathrm{K}^{+}$permeability of the sarcolemma. The action potential of muscle cells is resulted from a transient increase in $\mathrm{Na}^{+}$permeability of the sarcolemma. Figure 2 illustrates the time course of the muscle action potential and the twitch contraction of a single fiber following an electrical stimulation. The action potential is almost completely finished in less than $4 \mathrm{~ms}$. The first signs of mechanical activity are detectable only 1 or $2 \mathrm{~ms}$ after the peak of the action potential (Hodgkin and Horowicz, 1957). $\mathrm{Ca}^{2+}$ release from SR begins a few milliseconds after the rising phase of the action potential, and is essentially complete before the development of tension. In the very fast toadfish swim bladder muscle, the whole cycle of release and reuptake of $\mathrm{Ca}^{2+}$ is accomplished within 3-5 ms (Martonosi, 1984). Each cycle of $\mathrm{Ca}^{2+}$ release and accumulation results in 


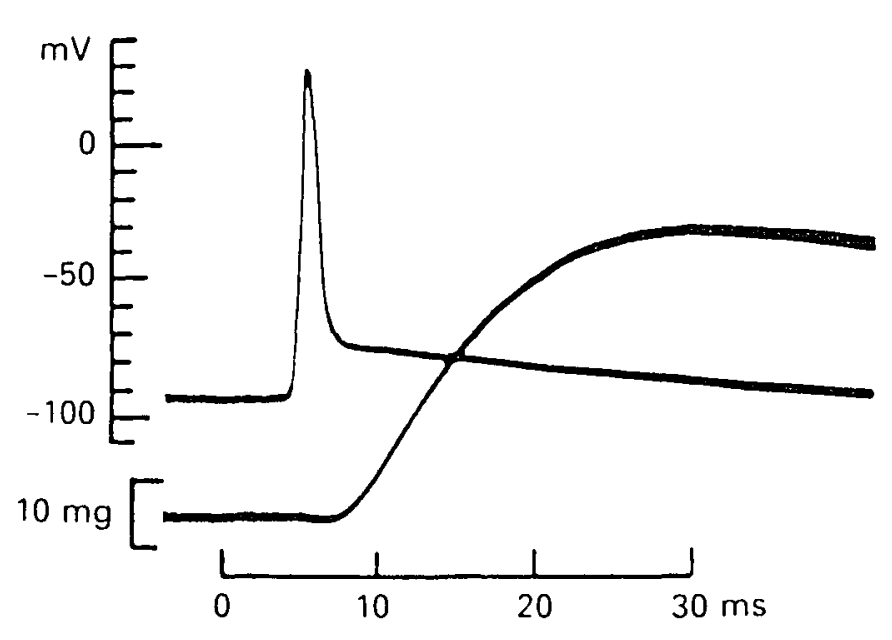

Figure 2. Electrical and mechanical responses of a single frog twitch muscle fiber to an electrical stimulus. The upper trace shows the action potential, recorded with an intracellular microelectrode, and the lower trace the isometric tension, recorded with a sensitive force transducer. Temperature $20^{\circ} \mathrm{C}$. Reproduced from Hodgkin and Horowicz, 1957.

a brief period of tension production called a twitch. The $\mathrm{Ca}^{2+}$ release and accumulation cycles can be repeated below a certain frequency termed the fusion frequency. Above the fusion frequency, characteristic for different types of fibers, the $\mathrm{Ca}^{2+}$ concentration in the myoplasmic space stays relatively high, the contractile apparatus is in a state of constant activation, and the contraction becomes a tetanus. The amount of $\mathrm{Ca}^{2+}$ released by a single action potential is about $30 \%$ of the amount of $\mathrm{Ca}^{2+}$ present in the SR in the resting state (Somlyo et al., 1981)

SARCOPLASMIC RETICULUM

The SR of muscle cells is a smooth-surfaced endoplasmic reticulum. During cell differentiation the SR is formed from 
the rough-surfaced endoplasmic reticulum and develops simultaneously with the formation of the myofibrils and $T$ tubules. Early SR forms irregular associations with the developing T-tubules, and later takes on the mature form of triads (Luff and Atwood, 1971; Kelly, 1980).

Autoradiographic evidence suggests that the $\mathrm{Ca}^{2+}$ release takes place primarily at the terminal cisternae part of SR (Winegred, 1968; 1970). On the other hand, the LSR contains the $\mathrm{Ca}^{2+}$ pump as its principal component and its major function is sequestrating $\mathrm{Ca}^{2+}$ into the $\mathrm{SR}$ during the relaxation phase of the contraction cycle.

\section{Major Proteins of the SR Membrane system}

$\mathrm{Ca}^{2+}$ pump protein. The $\mathrm{Ca}^{2+}$ pump $\left(\mathrm{Ca}^{2+}-\mathrm{Mg}^{2+}\right.$ ATPase) accounts for approximately 60 to $70 \%$ of the total SR protein and is evenly distributed throughout LSR. It was first purified with high ATPase activity from rabbit skeletal muscle SR in 1970 (MacLennan). The purified pump possesses all of the properties of its native state. When reconstituted into phospholipid vesicles it transports $\mathrm{Ca}^{2+}$ against a concentration gradient (Racker,1972). The $\mathrm{Ca}^{2+}$ pump actively transports two moles of $\mathrm{Ca}^{2+}$ into the $\mathrm{SR}$ lumen for each mole of ATP hydrolyzed. The concentration of the $\mathrm{Ca}^{2+}$ pump of the $\mathrm{SR}$ is correlated with the rate of relaxation of a specific muscle type (Martonosi, 1984). The pump consists of a single polypeptide chain of 105,000 daltons (105 kDa). 
$\mathrm{Ca}^{2+}$ binding protein. Calsequestrin is the second major protein constituent of the SR. It was first isolated in 1971 and has a molecular mass of 63,000 daltons (MacLennan and Wong, 1971). It is a $\mathrm{Ca}^{2+}$ binding protein with high capacity (43 mol $\left.\mathrm{Ca}^{2+} / \mathrm{mol}\right)$ and low affinity $\left(\mathrm{K}_{\mathrm{D}}=1 \mathrm{mM}\right)$ for $\mathrm{Ca}^{2+}$ (Reviewed by MacLennan et al., 1983). It appears that calsequestrin is responsible for $\mathrm{Ca}^{2+}$ storage in the SR. Meissner (1970) proposed that the calsequestrin was located in the lumen of the terminal cisternae, based on his studies with LSR and HSR vesicles. He suggested that the electron-dense material within the HSR vesicles was calsequestrin and/or the $53 \mathrm{kDa}$ glycoprotein. Using immunofluorescence stain, the localization of calsequestrin to the terminal cisternae has been proven (Jorgensen et al., 1983).

$\mathrm{Ca}^{2+}$ release protein-- $\mathrm{Ca}^{2+}$ release channel. The $\mathrm{Ca}^{2+}$ release channel is a minor protein component of the SR. Before its purification, the channel was studied mostly at the level of isolated membrane vesicles. The development of the planar lipid bilayer fusion technique made it possible to characterize the $\mathrm{SR} \mathrm{Ca}^{2+}$ release channel at the single channel level.

Ion channels are extremely efficient enzymes with turnover numbers approaching $10^{9} \mathrm{sec}^{-1}$. The high rate of ion translocation across membrane means that individual channels conduct currents in the range of picoamperes. In the late 1970 s and early 1980s, electrophysiological and biophysical 
techniques were developed which have sufficient resolution to record currents through a single ion channel. The patch clamp technique permits single channel currents to be observed in the native cell membranes. Two German scientists, Bart Sakmann and Erwin Neher, won this year's Nobel Prize in medicine for their important roles in developing this technique. On the other hand, the planar lipid bilayer technique allows recording of single ion channels of $\mathrm{T}$ tubules, SR, and other intracellular organelles which are inaccessible to glass microelectrodes required for patch clamping.

The fusion method of Miller and Racker (1976) was used to incorporate the SR $\mathrm{Ca}^{2+}$ channel into planer lipid bilayer. Current fluctuations through a single $\mathrm{Ca}^{2+}$ release channel of $S R$ was first recorded in 1985 (Smith et al.). This channel has characteristics different from $\mathrm{Ca}^{2+}$ channels isolated from other cell membranes (as described in the next section). The unit conductance of the channel is large. In a solution of 53 $\mathrm{mM} \mathrm{Ca}{ }^{2+} / 125 \mathrm{mM} \mathrm{Tris}^{+}$(the standard asymmetrical $\mathrm{Ca}^{2+}$ solution), the single channel conductance is $100 \mathrm{ps}$. The permeability ratio $\left(\mathrm{P}_{\mathrm{Ca}} / \mathrm{P}_{\text {Tris }}\right)$ is 11.4 . Unlike other types of $\mathrm{Ca}^{2+}$ channels, the SR $\mathrm{Ca}^{2+}$ channel does not inactivate. The SR $\mathrm{Ca}^{2+}$ channel is modulated by known effectors of $\mathrm{Ca}^{2+}$ release from skinned fibers and isolated SR vesicles. Myoplasmic $\mathrm{Ca}^{2+}$, in the range of 2-950 $\mu \mathrm{M}$ activates the channel by increasing its open probability $\left(P_{0}\right)$, without affecting channel open lifetime. 
Millimolar ATP also activates the channel activity. Submillimolar $\mathrm{Mg}^{2+}$ or micromolar ruthenium red inhibits the channel.

Monovalent Channels Present in the $S R$

The permeability of SR to other ions has been studied to understand the parameters involved in the regulation of the physiological $\mathrm{SR} \mathrm{Ca}^{2+}$ release mechanism. Light scattering measurements of $S R$ vesicles showed the membrane is permeable to small uncharged molecules (Selser et al. 1976, Kometani and Kasai, 1978). This may allow for an exchange of metabolic intermediates between the SR lumen and the myoplasm. Radioisotope flux measurements demonstrated that the $S R$ vesicles are highly permeable to monovalent cations and anions (reviewed by Meissner, 1986). These findings suggested the existence of other cation and anion channels in the SR membrane.

$\underline{\mathrm{K}^{+}}$channel. The existence of monovalent ion channels in the SR were confirmed by the planar lipid bilayer technique. In mammalian skeletal SR preparations, $\mathrm{a}^{+}$channel and a $\mathrm{Cl}^{-}$ channel have been studied (Miller et al., 1984; Rousseau et al., 1988). Miller and Racker (1976) successfully developed a technique for fusing $S R$ vesicles into an artificial membrane and studying the characteristics of channel proteins of the SR membrane. Vesicles were added to the aqueous solution bathing an planar phospholipid bilayer, and the increase of bilayer conductance was monitored. In searching for the SR 
$\mathrm{Ca}^{2+}$ channel, a $\mathrm{K}^{+}$channel was found (Miller, 1978). The SR $\mathrm{K}^{+}$channel has a unit conductance of $120 \mathrm{pS}$ (in $100 \mathrm{mM} \mathrm{K}{ }^{+}$), and a slow (seconds) kinetics. The channel is selective for $\mathrm{K}^{+}$over $\mathrm{Cl}^{-}$and for $\mathrm{K}^{+}$over $\mathrm{Ca}^{2+}$. In symmetrical $1 \mathrm{M}$ solutions, the single channel conductance (in ps) falls in the order: $\mathrm{K}^{+}(214)>\mathrm{NH}_{4}^{+}(157)>\mathrm{Rb}^{+}(125)>\mathrm{Na}^{+}(72)>\mathrm{Li}^{+}(8)>\mathrm{Cs}^{+}(0)$. $\mathrm{Cl}^{-}$channel. The behavior of single $\mathrm{Cl}^{-}$channels of SR was also examined by fusing isolated SR vesicles into planar lipid bilayers bathed in choline chloride solution (Rousseau et al., 1988). The channel exhibited a full open state with a unit conductance of $65 \mathrm{ps}$ (in $100 \mathrm{mM} \mathrm{Cl}^{\circ}$ ). $\mathrm{Cl}^{\circ}$ channel activity was not affected by variations of $\mathrm{Ca}^{2+}$ concentration on either side of the membrane. Neither millimolar ATP or millimolar $\mathrm{Mg}^{2+}$ affects the channel activity. Open probability of the channel is $60 \%-95 \%$ for membrane potentials ranging from -60 to $+60 \mathrm{mV}$.

The role of these monovalent channels may be to minimize osmotic and potential changes during $\mathrm{Ca}^{2+}$ uptake and release. Rapid movement of monovalent ions would prevent the development of a retarding membrane potential during electrogenic $\mathrm{Ca}^{2+}$ release and uptake by the SR.

\section{HYPOTHESES OF EC COUPLING}

\section{Preparations for studying EC Coupling}

The mechanism of coupling between depolarization of the T-tubule membrane and $\mathrm{Ca}^{2+}$ release from the SR (EC coupling) 
has been under extensive investigation over the last three decades. Physiological and biochemical information has been obtained from studies on various preparations.

Isolated muscle fiber. Isolated intact muscle fibers have been used to study the temporal sequence in muscle excitation. The $\mathrm{Ca}^{2+}$ transients (the change of myoplasmic free $\mathrm{Ca}^{2+}$ concentration during contraction cycle) can be monitored by measuring tension development or by observing $\mathrm{Ca}^{2+}$-sensitive dyes microinjected into the fiber (Baylor, 1983; Blinks et al., 1982). A new generation of $\mathrm{Ca}^{2+}$ sensitive dyes such as quin-2 and fura-2 have facilitaied such studies (Baylor and Hollingworth, 1988). In a more electrophysiological approach, intracellular $\mathrm{Ca}^{2+}$ fluxes have been studied in cut fiber segments under voltage clamp conditions. With this method, the potential of the sarcolemma and $T$ tubule can be precisely controlled and changed at will. This system also has been used to study charge movement across the surface membrane, and within the membrane. The isolated muscle fibers are complicated systems which can provide information, in addition to regulation, about temporal and spacial coordination during EC coupling. However, the results of a fiber system require very careful interpretation.

Skinned muscle fiber. Skinned fibers are fibers from which the surface membrane has been removed or made permeable, so that the $S R$ is accessible. Properly prepared skinned fibers have functional SR systems. $\mathrm{Ca}^{2+}$ can be taken up by 
$\mathrm{Ca}^{2+}$ pump and the $\mathrm{Ca}^{2+}$ release mechanism can be studied. $\mathrm{Ca}^{2+}$ release from $S R$ can be assayed by tension, ${ }^{45} \mathrm{Ca}^{2+}$, and spectrophotometric methods. In Natori-type skinned fiber (Natori, 1954; Donaldson, 1985) the sarcolemma is mechanically peeled off. The disrupted T-tubule membrane is likely to be sealed off and the voltage across the T-tubule membrane (which resembles the resting state) reestablished with the aid of active $\mathrm{Na}^{+}$transport (Natori, 1965; Costantin and Podolsky, 1967). Depolarization of the T-tubule can be achieved by ionic substitution. These fibers appear to have an operationally coupled T-tubule and SR system. The real physiological stimulus to cause $\mathrm{Ca}^{2+}$ release, depolarization of the T-tubule, can still be effective in this preparation. Chemically skinned fibers are made by treatment with the detergent saponin which reacts with cholesterol (Endo and Iino, 1988). Saponin creates holes in the sarcolemma and Ttubule, which have high contents of cholesterol, yet leaves the SR membrane intact. In chemical skinning, no potential gradient can be established across the $T$ tubule membrane. In skinned fiber systems most of the machinery of muscle function is still intact, but any change of solution in the immediate environment of $\mathrm{SR}$ is slow due to diffusion limits.

Isolated SR vesicles. The isolation of subcellular membrane fractions from muscle is an important step in their functional characterization. The SR membrane can be isolated in considerable quantities by differential centrifugation of 
muscle homogenate (Martonosi and Feretos, 1964). Electron microscopic studies reveal the isolated SR membrane as a population of outside-out vesicles ranging from $100 \mu \mathrm{m}$ to $300 \mu m$ in sizes. SR vesicles are identified by their ability to accumulate $\mathrm{Ca}^{2+}$ from ATP containing solutions and by their $\mathrm{Ca}^{2+}$-dependent ATPase activity. SR from rabbit fast-twitch skeletal muscle has been subfractionated by density-gradient centrifugation into fractions originating from terminal cisternae (HSR) or longitudinal SR (LSR) (Meissner, 1975). The isolated $S R$ vesicle is a simplified, controlled in vitro system in which the $\mathrm{Ca}^{2+}$ release mechanism can be studied without interference from other influences normally present within the muscle cells. It has been found that these vesicles maintain much of their structural and functional characteristics (Campbell et al., 1980). Although the isolated SR vesicle preparation is less physiological than the $\mathrm{SR}$ in skinned fibers, it is easier to follow $\mathrm{Ca}^{2+}$ movement precisely and it allows relatively easy control of the environment in which experiments are carried out.

The $\mathrm{Ca}^{2+}$ release mechanism in $\mathrm{SR}$ has been studied most extensively with isolated SR vesicles. Table II lists stimulators and inhibitors of $\mathrm{Ca}^{2+}$ release in isolated $\mathrm{SR}$ vesicles from skeletal muscle (Fleischer and Inui, 1989). These results qualitatively agree with those obtained with skinned fiber (Endo, 1985). Among these compounds, $\mathrm{Ca}^{2+}, \mathrm{ATP}$, and caffeine are commonly used as specific stimulators, while 
TABLE II

MODULATORS OF $\mathrm{Ca}^{2+}$ RELEASE FROM ISOLATED SR VESICLES OF SKELETAL MUSCLE ${ }^{a}$

\begin{tabular}{|c|c|c|c|}
\hline Activators & $\begin{array}{l}\text { Effective } \\
\text { concentra- } \\
\text { tion }\end{array}$ & Inhibitors & $\begin{array}{l}\text { effec- } \\
\text { tive } \\
\text { concen- } \\
\text { tration }\end{array}$ \\
\hline $\begin{array}{l}\mathrm{Ca}^{2+} \mathrm{b} \\
\text { ATP or ATP analogs } \\
\text { AMP } \\
\text { Caffeine } \\
\text { Ryanodine } \\
\text { Doxorubicin } \\
\mathrm{Ag}^{+} \\
\mathrm{Cu}^{2+} / \text { cysteine }\end{array}$ & $\begin{array}{l}1 \mu M \\
1-5 \mathrm{mM} \\
10 \mathrm{mM} \\
>0.5 \mathrm{mM} \\
10-20 \mathrm{nM} \\
15 \mu M \\
0.1-15 \mu M \\
2 \mu M / 10 \mu M\end{array}$ & $\begin{array}{l}\mathrm{Mg}^{2+} \\
\text { Ruthenium red } \\
\text { Procaine } \\
\text { Tetracaine } \\
\text { Ryanodine } \\
\text { Calmodulin }\end{array}$ & $\begin{array}{l}5 \mathrm{mM} \\
15 \mu M \\
10 \mathrm{mM} \\
0.6 \mathrm{mM} \\
>10 \mu M \\
0.2 \mu M\end{array}$ \\
\hline
\end{tabular}

"Adapted from Fleisher and Inui, 1989.

${ }^{b}$ These activators inhibit the $\mathrm{Ca}^{2+}$ release at higher concentration.

$\mathrm{Mg}^{2+}$ and ruthenium red are commonly used as specific inhibitors in studies of $\mathrm{Ca}^{2+}$ release.

Isolated triads. A fraction rich in triads (about 50\%)

can be prepared from rabbit fast-twitch muscle HSR by performing two sequential sucrose-gradient centrifugations (Caswell et al., 1976; Mitchell et al., 1983). Electron microscopic studies and other assays show that the purified triads consist terminal cisternae in junctional association with sealed, inside-out $\mathrm{T}$ tubules. The coupling of $\mathrm{T}$ tubules to the junctional SR can be disrupted mechanically by using a French press cell (Caswell et al., 1979) or by treatment with salt solution (Caswell and Brandt, 1981). Reassociation of triads is possible and is enhanced by potassium cacodylate or 
glyceraldehyde 3-phosphate dehydrogenase (Corbett et al., 1985).

An alternative preparation rich in triads was prepared and used for $\mathrm{Ca}^{2+}$ release studies (Kim et al., 1983). French press treatment to dissociate the $T$ tubules from SR eliminated depolarization-induced $\mathrm{Ca}^{2+}$ release from SR without affecting $\mathrm{Ca}^{2+}$-induced or caffeine-induced $\mathrm{Ca}^{2+}$ release. These results suggest that the T-tubule associated with SR is crucial in triggering rapid depolarization-induced $\mathrm{Ca}^{2+}$ release from $\mathrm{SR}$ and that $\mathrm{Ca}^{2+}$ and caffeine appear to stimulate $\mathrm{Ca}^{2+}$ release a direct interaction with the SR (Ikemoto et al., 1984; 1985). Isolated $\mathrm{SR} \mathrm{Ca}^{2+}$ release protein. To define the molecular machinery of the $\mathrm{Ca}^{2+}$ release channel, it is essential to identify and isolated the channel protein. Two specific ligands have been used to label the $\mathrm{Ca}^{2+}$ release protein, and two proteins have been purified.

The $400 \mathrm{kDa}$ protein is also called the ryanodine receptor complex. Ryanodine is a plant alkaloid known to interfere with EC coupling in cardiac and skeletal muscle. It binds specifically to $S R$ vesicles with high affinity. The conditions for ryanodine binding are similar to those for $\mathrm{Ca}^{2+}$-induced $\mathrm{Ca}^{2+}$ release. High affinity binding is stimulated by $\mathrm{Ca}^{2+}$, adenine nucleotide and caffeine. The $\mathrm{SR} \mathrm{Ca}^{2+}$ release channel is identified through its specific binding to ryanodine. The ryanodine receptor complex is purified from detergent-solubilized junctional SR as a high molecular mass 
$400 \mathrm{kDa}$ protein (Imagawa et al., 1987; Inui et al., 1987; Lai et al., 1988). When reconstituted into a planar lipid bilayer, the purified ryanodine receptor complex is shown to behave as a large conductance divalent cation channel, with electrophysiological properties identical to the channel that is detected with the use of intact $S R$ vesicles (Smith et al., 1988). The unit conductance is found to be $110 \mathrm{ps}$ in the standard asymmetrical $\mathrm{Ca}^{2+}$ solution with a permeability ratio $\left(\mathrm{P}_{\mathrm{C}_{\mathrm{a}}} / \mathrm{P}_{\text {Tris }}\right)$ of 14 . The channel activity of the purified receptor is activated by submicromolar $\mathrm{Ca}^{2+}$ and 1-2 $\mathrm{mM}$ ATP, and is inhibited by $1-4 \mathrm{mM} \mathrm{Mg}^{2+}$ and $30 \mu \mathrm{M}$ ruthenium red. Ryanodine at $7 \mu M$ brought the channel to a long lifetime subconducting state of about $40 \%$ full unit conductance. The data suggested that the ryanodine receptor and the $\mathrm{Ca}^{2+}$ release channel are contained within the same protein. Electron microscopy reveals that four ryanodine receptors compose a structure indistinguishable from the feet observed at the intact transverse tubule-SR junction (Inui et al., 1987). It is also believed that four ryanodine receptors form one functional $\mathrm{Ca}^{2+}$ release channel. The primary structure of the ryanodine receptor has been deduced from its CDNA sequence (Takeshima et al., 1989). It is a single polypeptide chain of $565 \mathrm{kDa}$. A predicted structure suggests that the $\mathrm{Ca}^{2+}$ release channel resides in the c-terminal region of the receptor molecule. The remaining region of the receptor constitutes the foot that spans the junctional gap between the SR and the T-tubule. 
We have identified a second protein, which has molecular mass of $106 \mathrm{kDa}$. The $106 \mathrm{kDa}$ protein is identified and purified based on its interaction with sulfhydryl reagents. The detailed characterization of this protein is described in Chapter III.

Proposed Theories Describing EC Coupling

As a result of these studies, several hypotheses have been proposed to describe E-C coupling--the communication between the 12 to $14 \mathrm{~nm}$ gap of junctional SR and T-tubule membranes. These hypotheses can be divided into three categories: electrical coupling, mechanical coupling and chemical coupling.

Electrical coupling. The electrical coupling hypothesis suggests that the depolarization of $T$ tubule causes $a$ potential change at the SR membrane by an ionic conduction (Mathias et al., 1980) or by capacitive coupling. The depolarization of $\mathrm{SR}$, in turn, opens the $\mathrm{SR} \mathrm{Ca}^{2+}$ release channel. As discussed by Eisenberg (1987), the transient opening of a conductive pathway between the T-tubule and $S R$ is highly unlikely. Also, the resting permeability of the SR to monovalent cations and anions is too high for any transport system to develop a significant membrane potential within the time scale required for EC coupling. In addition, the separation between the two membranes appears to be too large to provide efficient capacitive coupling between them (Rios and Pizarro, 1991). The other argument against this 
hypothesis comes from ionic substitution studies using SR vesicle and triad preparations (Meissner and McKinley, 1976; Ikemoto et al., 1984). While ionic depolarization of isolated triads (isolated $S R$ vesicles with sealed $T$-tubules attached) induces $\mathrm{Ca}^{2+}$ release, the same conditions fail to induce $\mathrm{Ca}^{2+}$ release from isolated SR vesicles. Despite the slight voltage dependence of the reconstituted single $\mathrm{SR} \mathrm{C \textrm {Ca } ^ { 2 + }}$ release channel in a bilayer membrane, the channel is not activated or inactivated by voltage across the membrane.

Mechanical coupling. Schneider and chandler reported detection of charge movement within the $\mathrm{T}$ tubule membrane upon depolarization by using voltage clamped muscle fibers (1973). They suggested the existence of charge groups and dipoles in T-tubule which can move within the membrane according to trans-membrane potentials. These charged groups (voltage sensor) may be mechanically linked, via the feet proteins, to the activation mechanisms of the SR $\mathrm{Ca}^{2+}$ channel. The voltage sensor was imaged as a plug to sense the depolarization of $\mathrm{T}-$ tubule which, in turn, to open the $\mathrm{SR} \mathrm{Ca}^{2+}$ channel (Chandler et al, 1976).

Using voltage clamp technique, intramembrane charge movement and $\mathrm{SR} \mathrm{Ca}^{2+}$ release can be regularly recorded just prior to contraction. Low concentrations of nitrendipine (a dihydropyridine) inhibit both $\mathrm{SR} \mathrm{Ca}^{2+}$ release and charge movement (Rios and Brum 1987). This indicates a possible role of the dihydropyridine receptor (DHP receptor) as a voltage 
sensor. Evidence for possible mechanical coupling is the electron microscopic study (Block et al., 1988), which shows the proximity and the fixed stoichiometry between the DHP receptors of $T$ tubule and the feet protein of $S R$. on the other hand, the direct binding study (Brandt et al., 1990) fail to show any direct interaction between the DHPR and the foot. The results indicate the involvement of glyceraldehyde 3-phosphate dehydrogenase, aldolase and a $95 \mathrm{kDa}$ protein in the triad junction.

Chemical coupling I: $\mathrm{Ca}^{2+}$-induced $\mathrm{Ca}^{2+}$ release. Using a skinned fiber preparation, Endo et al. (1970) and Ford et al. (1970) reported that $\mathrm{Ca}^{2+}$ release from the SR was facilitated by $\mathrm{Ca}^{2+}$ itself. Since then the $\mathrm{Ca}^{2+}$-induced $\mathrm{Ca}^{2+}$ release (CICR) has been extensively investigated in skinned fibers (Stevenson, 1981) and isolated SR vesicles (Ohnishi, 1981; Miyamoto and Racker, 1982; Meissner, 1984). $\mathrm{Ca}^{2+}$-induced $\mathrm{Ca}^{2+}$ release is modulated by myoplasmic $\mathrm{Ca}^{2+}$ concentration and stimulated by adenine nucleotides and caffeine. CICR is inhibited by ruthenium red, $\mathrm{Mg}^{2+}$, and local anesthetics. Single channel studies of $S R$ vesicle fused into planar bilayers showed similar properties (Smith, 1986). The studies of CICR greatly enhanced our understanding of the SR $\mathrm{Ca}^{2+}$ release channel. These studies also conclude that $\mathrm{Ca}^{2+}$, at a concentration that is subthreshold for contraction, is able to trigger $\mathrm{Ca}^{2+}$ release from $\mathrm{SR}$. It is possible that extracellular $\mathrm{Ca}^{2+}$ ions enter through T-tubules during 
depolarization and cause $\mathrm{Ca}^{2+}$ release from SR. Additional fiber studies have been conducted to investigate the physiological role CICR plays in EC coupling. The main argument against the physiological role of CICR is from experiments which show that $\mathrm{Ca}^{2+}$ entry through surface membrane $\mathrm{Ca}^{2+}$ channels is not necessary to trigger contraction (Mccleskey, 1985; Beaty et al., 1987). Most data is consistent with the hypothesis that $\mathrm{Ca}^{2+}$-induced $\mathrm{Ca}^{2+}$ release amplifies an initial process of release elicited by other means (Rios et al., 1991; Endo, 1985).

Chemical coupling II: Inositol 1,4,5-triphosphate-induced $\mathrm{Ca}^{2+}$ release. Inositol 1,4,5-triphosphate $\left(\mathrm{IP}_{3}\right)$ is involved in intracellular signal transduction controlling a variety of cellular functions in different cell types (Berridge, 1987). $\mathrm{IP}_{3}$ regulates intracellular $\mathrm{Ca}^{2+}$ in smooth muscle and nonmuscle cells. $\mathrm{IP}_{3}$ may play an important role in EC coupling of smooth muscle (Somlyo and Somlyo, 1986). Thus, it is reasonable to consider whether $\mathrm{IP}_{3}$ is a chemical messenger for EC coupling in skeletal muscle cells. The biochemical machinery for the synthesis, release, and hydrolysis of $\mathrm{IP}_{3}$ is present in the skeletal muscle. Although some laboratories failed in their attempts, Volpe et al. (1985) and Vergara et al. (1985) demonstrated that $\mathrm{IP}_{3}$ induces $\mathrm{Ca}^{2+}$ release from $\mathrm{SR}$ of skinned fiber and SR vesicles. They proposed that the depolarization of $\mathrm{T}$-tubule membrane facilitates the production of $\mathrm{IP}_{3}$, which then migrates across the junctional gap and 
stimulates $\mathrm{Ca}^{2+}$ release from $\mathrm{SR}$. It was also reported that $\mathrm{IP}_{3}$ activates $\mathrm{SR} \mathrm{Ca}^{2+}$ channels reconstituted into lipid bilayers (Suarez-Isla et al, 1988). However, it is questionable that $\mathrm{IP}_{3}$ (at concentration needed) can be regulated near the $\mathrm{SR}$ membrane at a time scale comparable to EC coupling. Furthermore, blocker of $\mathrm{IP}_{3}$-induced $\mathrm{Ca}^{2+}$ release failed to block the $\mathrm{Ca}^{2+}$ transient invoked by depolarization of the skeletal muscle fiber (Pape et al., 1988). In another comparative study of skeletal and smooth muscle fibers using caged $\mathrm{IP}_{3}$ (its release was precisely controlled by laser pulse photolysis), only in smooth muscle were the $\mathrm{IP}_{3}$ concentration and activation rate compatible with the in vivo physiological response (Walker et al., 1987).

Chemical coupling III: Sulfhydryl oxidation-induced $\mathrm{Ca}^{2+}$ release. In this laboratory, we have been investigating sulfhydryl oxidation induced- $\mathrm{Ca}^{2+}$ release from SR. Heavy metals such as $\mathrm{Hg}^{2+}, \mathrm{Ag}^{+}$, and $\mathrm{Zn}^{2+}$ were found to induce rapid $\mathrm{Ca}^{2+}$ release from SR vesicles. The potency of these heavy metals to induce $\mathrm{Ca}^{2+}$ release is similar to their relative binding affinities to sulfhydryl groups (Abramson et al., 1983). In addition, mercaptans such as cysteine were found to cause $\mathrm{Ca}^{2+}$ release from junctional $\mathrm{SR}$ in the presence of $\mathrm{Cu}^{2+}$ (1-2 $\mu M)$. The $\mathrm{Cu}^{2+}$ plus mercaptan effect appears to be due to a $\mathrm{Cu}^{2+}$-catalyzed oxidation reaction which results in the formation of a mixed disulfide bond between the exogenous mercaptan and a sulfhydryl on the release mechanism. 
Reduction of the disulfide bond with dithiothreitol (DTT) reverses the effect and results in $\mathrm{Ca}^{2+}$ re-uptake by the SR vesicles (Trimm et al., 1986). More recently, a group of compounds called reactive disulfides (dithiopyridines) such as 2,2'-DTDP, 4,4'-DTDP, and N-succinimidyl 3-(2-pyridyldithio) propionate (SPDP) were tested and found to cause $\mathrm{Ca}^{2+}$ release from SR vesicles (Zaidi et al., 1989a). Dithiopyridines are known to oxidize free $\mathrm{SH}$ sites specifically via a thioldisulfide exchange reaction with the stoichiometric production of thiopyridone. The increase of $\mathrm{SR} \mathrm{Ca}^{2+}$ permeability caused by oxidation is reversed by reducing the mixed disulfide bond with reducing agents, such as glutathione or DTT.

\section{CALCIUM CHANNELS}

$\mathrm{Ca}^{2+}$ channels are ubiquitous. They help regulate a wide range of cellular functions, including secretion, contraction, and excitability (Tsien et al., 1983; Hagiwara, 1983). $\mathrm{Ca}^{2+}$ channels are the most diverse group of channels. They are not as well characterized as the $\mathrm{Na}^{+}$and $\mathrm{K}^{+}$channels. $\mathrm{Ca}^{2+}$ channels can play two important roles. First, they are responsible for prolonging depolarization of cell surface membranes, because they do not inactivate as quickly as $\mathrm{Na}^{+}$ channels. Second, $\mathrm{Ca}^{2+}$ channels serve as pathways for the secondary messenger $\mathrm{Ca}^{2+}$ ions to enter cells.

$\mathrm{Ca}^{2+}$ channels from cell membrane are loosely divided into three types according to their kinetics (activation and 
TABLE III

DIFFERENT TYPES OF $\mathrm{Ca}^{2+}$ CHANNELS $^{\mathrm{a}}$

\begin{tabular}{|c|c|c|c|}
\hline & T-type & N-type & L-type \\
\hline $\begin{array}{l}\text { Single channel } \\
\text { conductance } \\
\text { Inactivation } \\
\text { range }\end{array}$ & $\begin{array}{l}8-10 \mathrm{ps} \\
-100 \mathrm{mV} \text { to } \\
-60 \mathrm{mV}\end{array}$ & $\begin{array}{l}13 \mathrm{ps} \\
\begin{aligned}-100 \mathrm{mV} \text { to } \\
-40 \mathrm{mV}\end{aligned}\end{array}$ & $\begin{array}{l}25 \mathrm{ps} \\
-60 \mathrm{mV} \text { to } \\
-10 \mathrm{mV}\end{array}$ \\
\hline $\begin{array}{l}\text { Activation } \\
\text { range }\end{array}$ & $-70 \mathrm{mV}$ & & $-10 \mathrm{mV}$ \\
\hline $\begin{array}{l}\text { Inactivation } \\
\text { rate }\end{array}$ & $20-50 \mathrm{~ms}$ & $20-50 \mathrm{~ms}$ & $>700 \mathrm{~ms}$ \\
\hline
\end{tabular}

${ }^{a}$ Adapted from McCleskey, 1986)

inactivation) and unit conductance (Table III) (Mccleskey, 1986; Bean, 1989). T-type (also called fast, or lowthreshold) channels have transient currents which inactivate completely in about $50 \mathrm{~ms}$. They are activated by low voltages and have small unit conductance. In contrast, the L-type (also called slow, or high-threshold) channels have longlasting currents. They are activated by high voltages and have relatively large unit conductance. The kinetics and conductance of N-type channels (fast but high-threshold) are intermediate between the $\mathrm{T}-$ and L-type channels. N-type channels are only found in neurons. In fact, all three types of $\mathrm{Ca}^{2+}$ channels exist in neurons (Fox et al., 1987). A peptide from a marine snail, $\omega$-Connotoxin, blocks highthreshold current ( $\mathrm{N}$ - and L-type) of neurons without affecting currents of cardiac, smooth, or skeletal muscles (McCleskey et al., 1987). 
T- and L-type channels are best characterized in cardiac muscle (Bean, 1989). Using $\mathrm{Ba}^{2+}$ as the charge carrier, macroscopic current of $\mathrm{T}$ - and L-type channels are readily distinguished on the basis of inactivation kinetics. $T-$ and L-type channels can also be distinguished based on their different pharmacological properties. L-type channels are potently inhibited by dihydropyridine (DHP) $\mathrm{Ca}^{2+}$ channel blockers (e.g. nifedipine, and nitrendipine) and by phenylalkamine $\mathrm{Ca}^{2+}$ channel blockers (e.g. verapamil, and D 600). L-type channels are stimulated by the DHP $\mathrm{Ca}^{2+}$ channel agonist Bay $\mathrm{K} 8644$. On the other hand, T-type channels are not as sensitive to these drugs as that of L-type channels. The insecticide tetramethrin completely inhibits T-type current at $100 \mathrm{nM}$ without affecting L-type current (Hagiwara et al., 1988). The same $T$ - and L-type channels are also found in smooth muscle.

In developing skeletal muscle, only T-type current exists (Beam and Knudson, 1988a; 1988b). Its presence is thought to help initiate spontaneous activity. There are two current components in adult skeletal muscle. The predominant is Ltype current (also called slow $\mathrm{Ca}^{2+}$ current), which resembles the L-type current in cardiac muscle except with slower activation rates. Another component, only recently recognized, is T-type current (also called fast $\mathrm{Ca}^{2+}$ current), which is activated rapidly with a low threshold (Garcia and 
Stefani, 1987). This component does not inactivate and is not sensitive to DHPs. Both slow and fast $\mathrm{Ca}^{2+}$ current, as in cardiac muscle, is potentiated by $\beta$-adrenergic agonists or internal CAMP (Arreola et al., 1987). The slow $\mathrm{Ca}^{2+}$ channel (also called DHP receptor) in $\mathrm{T}$ tubule is proposed to act as a voltage sensor for EC coupling (Rios and Brum, 1987). No special functional role for fast $\mathrm{Ca}^{2+}$ channel in known.

The $\mathrm{Ca}^{2+}$ Channel of $\mathrm{T}$-tubule

The studies of dihydropyridine (DHP) $\mathrm{Ca}^{2+}$ channel antagonists have revealed the existence of a DHP-binding protein in T-tubule membranes. It was purified based on its specific binding to DHPs (Borsotto et al., 1984; Curtis et al., 1984). The purified protein is composed of five subunits: $\alpha_{1}(170 \mathrm{kDa}), \alpha_{2}(150 \mathrm{kDa}), \quad \beta(50-55 \mathrm{kDa}), \quad \gamma(30-$ $33 \mathrm{kDa})$, and $\delta(19-30 \mathrm{kDa})$. The subunit (often referred to as the DHP receptor) is thought to contain the DHP binding site, the voltage sensor, and the channel pore. The primary structure of the subunit has been deduced from its complementary DNA (Tanabe et al., 1987). It has a molecular mass of $212 \mathrm{kDa}$, and it has $66 \%$ sequence in common to that of the $\mathrm{Na}^{+}$channel.

However, Schwartz et al. (1985) showed that less than $5 \%$ of the specific DHP binding site in intact skeletal muscle are actually functional $\mathrm{Ca}^{2+}$ channels. This surprising fact is explained by assigning the role of voltage sensor to DHP receptors. The postulation that the DHP receptor is the 
voltage sensor is greatly enforced by the study with dysgenic skeletal muscle (Tanabe et al., 1988) which genetically lacks the DHP receptor. In skeletal muscle of mice with muscular dysgenesis, both EC coupling and slow L-type $\mathrm{Ca}^{2+}$ current are missing. Expression of CDNA for the DHP receptor restored EC coupling in the dysgenic myotubes in primary culture.

\section{The $\mathrm{Ca}^{2+}$ Release Channel of SR}

As described before, the $\mathrm{Ca}^{2+}$ release channel from the SR membrane has unique characteristics which are different than those of any other types of $\mathrm{Ca}^{2+}$ channels. This dissertation is about my research on some aspects of this channel using the planar lipid bilayer technique.

\section{OVERVIEW OF DISSERTATION}

\section{Reconstitution and Characterization of SR $106 \mathrm{kDa}$ Protein}

One crucial step in characterizing a membrane boundprotein is to isolate the target protein. In our collaborator, Dr. Salama's laboratory in University of Pittsburgh, a protein involved in the $\mathrm{SR} \mathrm{Ca}^{2+}$ release mechanism has been purified by labeling with a sulfhydryl reagent (Zaidi et al., 1989b). The first part of my research was to reconstitute this purified $106 \mathrm{kDa}$ protein into planar lipid bilayers and to study its electrophysiological and biochemical characteristics. This study helped to establish the identity of this protein and its relation with the SR $\mathrm{Ca}^{2+}$ release process. 


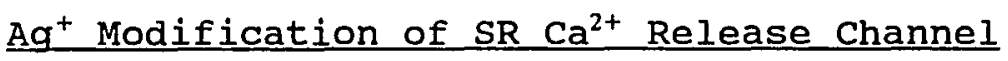

From data accumulated with $\mathrm{Ca}^{2+}$ flux measurements of isolated SR vesicles, our group proposed that sulfhydryl oxidizing reagents open the $\mathrm{SR} \mathrm{Ca}^{2+}$ release channel by interacting with critical sulfhydryl groups (Abramson et al, 1983; Trimm et al., 1986). Among the sulfhydryl reagents tested, $\mathrm{Ag}^{+}$is the most potent in inducing $\mathrm{Ca}^{2+}$ release from $\mathrm{SR}$ vesicles. $\mathrm{Ag}^{+}$induced $\mathrm{Ca}^{2+}$ release is optimal at physiological free $\mathrm{Mg}^{2+}$ concentration. Detailed flux measurements have shown that the initial $\mathrm{Ca}^{2+}$ release rate has an interesting $\mathrm{Ag}^{+}$dependence.

To study the SR $\mathrm{Ca}^{2+}$ release channel, the planar bilayer system has following advantages over the SR vesicle system: (1) a voltage can be applied across the channel; (2) ionic composition of either side of the channel can be changed; and (3) the behavior of a single channel can be observed in a long period of time (minutes) with high time resolution (milliseconds). The planar bilayer technique was applied to study how does $\mathrm{Ag}^{+}$interact with $\mathrm{SR} \mathrm{Ca}^{2+}$ release channel at the single channel level. Since heavy metals are potentially hazardous to the environment, this study contributes to a better understanding of the biological effects of heavy metals, specifically their toxic effects in muscle.

Photooxidation of SR $\mathrm{Ca}^{2+}$ Release Channel

In addition to the finding that oxidation of reactive thiols induces rapid $\mathrm{Ca}^{2+}$ release from $\mathrm{SR}$, modification of 
amino groups have also been shown to stimulate $\mathrm{Ca}^{2+}$ release from passively loaded SR vesicles (Shoshan-Barmatz, 1986; 1987). Work in our laboratory has shown that photooxidation of the SR vesicles (actively or passively loaded), using rose bengal as a sensitizer, resulted in rapid $\mathrm{Ca}^{2+}$ release (stuart et al., 1991). The molecular mechanism underlying rose bengal modification of the SR appears to involve modification of specific histidyl residues. In the presence of light, rose bengal appears to exert its effects by the generation of short-lived highly reactive oxygen intermediates. Production of singlet oxygen is directly measured in parallel with an increase in the $\mathrm{Ca}^{2+}$ permeability of the SR. Rose bengalinduced $\mathrm{Ca}^{2+}$ release is insensitive to $\mathrm{Mg}^{2+}$ or $\mathrm{Ca}^{2+}$. AMP-PCP (a non-hydrolyzable analog of ATP) or ruthenium red partially inhibit rose bengal induced release. In the last part of this dissertation I examine the effect of photooxidation on the SR $\mathrm{Ca}^{2+}$ release channel. This study shows that photooxidation acts directly on the SR $\mathrm{Ca}^{2+}$ channel and further describes how it modifies the channel.

Strong oxidizing agents are becoming increasingly significant as major health hazards in the environment. For instance, ozone now seems to be one of the most troublesome pollutants. The damaging effects of ozone in living systems are known to be partly mediated through free radical reactions. Rose bengal has been used in model systems in vitro to study the damaging actions of reactive oxygen 
intermediates on biological membranes. Studies on the interaction of reactive oxygen species with ion channel proteins will enhance our understanding of their toxic effects to biological systems. 
CHAPTER II

METHODS

ISOLATION OF SR VESICLES

$S R$ vesicles were isolated from rabbit white skeletal muscle according to the method of MacLennan (1970). Muscle was removed from the back and hind leg of a rabbit. The fat and connective tissue was trimmed off, and the muscl was put into ice-cold buffer A $(120 \mathrm{mM} \mathrm{NaCl}, 10 \mathrm{mM}$ imidazole, $100 \mu M$ dithiothreitol, $\mathrm{pH} 7.4)$. The muscle was then ground in a meat grinder and homogenized in a blender in three volumes of buffer A for 15 seconds on low speed, 45 seconds on high speed. The procedure was repeated once after waiting 30 seconds. The resulting suspension was then centrifuged at $1,600 \mathrm{~g}(3,100 \mathrm{rpm}$ in the large sorvall GSA rotor) for 10 minutes. The supernatant liquid (total $1500 \mathrm{ml}$ ) was filtered through four layers of cheesecloth and adjusted to $\mathrm{pH} 7.4$ with dry imidazole. The pelleted cell debris was discarded. The supernatant liquid was centrifuged at $10,000 \mathrm{~g}(8,000 \mathrm{rpm}$ in the GSA rotor) for 15 minutes. Again, the supernatant was filtered through four layers of cheesecloth and the brown mitochondrial pellet was discarded. The supernatant liquid was ultracentrifuged at $44,000 \mathrm{~g}$ for 70 minutes $(19,000 \mathrm{rpm}$ in 
the Beakman type 19 rotor). The pellet (without the brown mitochondrial ring) was scraped off, homogenized, and suspended at approximately $10 \mathrm{mg} / \mathrm{ml}$ in buffer A. This suspension was centrifuged at $7,500 \mathrm{~g}$ for 10 minutes $(11,000$ rpm in the Beckman Ti60 rotor, total volume $150 \mathrm{ml}$, or 7,500 rpm in the GSA rotor, two tubes containing $250 \mathrm{ml}$ each). The large myosin pellet was discarded. The supernatant liquid was centrifuged at $78,000 \mathrm{~g}(35,000 \mathrm{rpm}$ in the Ti60 for 30 minutes, or $19,000 \mathrm{rpm}$ in the type 19 rotor for 70 minutes). This pellet, which constitutes our SR preparation, was suspended in appropriate buffer, and stored in small aliquots in liquid nitrogen for later use. For vesicle fusion experiments, the $S R$ vesicles were suspended at about $1 \mathrm{mg} / \mathrm{ml}$ in $100 \mathrm{mM} \mathrm{KCl}, 0.7 \mathrm{M}$ sucrose, $10 \mathrm{mM}$ Tris-HEPES, $\mathrm{pH} \mathrm{7.4.} \mathrm{For}$ $106 \mathrm{kDa}$ protein isolation, the SR vesicles were suspended at 10-20 mg/ml in $0.9 \mathrm{M}$ sucrose, $20 \mathrm{mM}$ Tris-HEPES, $\mathrm{pH} 7.0$. All buffers were prepared with distilled, deionized water.

\section{ISOLATION OF 106 KDA PROTEIN}

The $106 \mathrm{kDa}$ protein was purified from isolated SR vesicles through the specific labeling by the reactive disulfide reagent N-succinimidyl 3-(2-pyridyldithio) propionate (SPDP) (Zaidi et al., 1989b). Biotin was linked to SPDP, and the resulting PDP-biotin conjugate was used to label detergent (CHAPS) solubilized SR vesicles. The labeled 
proteins were detained on a avidin column, and then eluted with sulfhydryl reducing agent dithiothreitol (DTT) .

\section{Synthesis of SPDP-Biotin Conjugate}

Equimolar concentrations $(10 \mathrm{mM})$ of SPDP and biotin hydrazide were mixed in dimethyl sulfoxide $(2 \mathrm{ml})$ and allowed to react in the dark at room temperature for 4 hours.

\section{Covalent Labeling of SR Protein with Biotin}

PDP-biotin hydrazide was used to covalently link biotin to $S R$ proteins. SR vesicles $(2 \mathrm{mg} / \mathrm{ml}$ ) were allowed to react with $100 \mu M$ PDP-biotin hydrazide in a pH 5.0 buffer $(100 \mathrm{mM}$ $\mathrm{NaCl}, 20 \mathrm{mM}$ Tris-HEPES, $1 \mathrm{mM} \mathrm{MgCl}_{2}$ ) at room temperature for 5 minutes. The reaction was terminated by diluting 25 -fold in a ice-cold pH 7.0 buffer (100 mM NaCl, $20 \mathrm{mM}$ Tris-HEPES, $1 \mathrm{mM}$ $\mathrm{MgCl}_{2}$ ). The dilution was centrifuged at 19,000 rpm (in the type 19 rotor) for 70 minutes to remove unreacted PDP-biotin hydrazide. The pellet was then washed with the $\mathrm{pH} 7.0$ buffer and centrifuged again. The pellet (biotinylated SR vesicles) was resuspended at about $15 \mathrm{mg} / \mathrm{ml}$ in the $\mathrm{pH} 7.0$ buffer.

Isolation of Biotin-Labeled SR Proteins by Biotin-Avidin Chromatography

Biotinylated SR vesicles were solubilized in $1 \mathrm{M} \mathrm{NaCl}, 20$ mM PIPES, $1.6 \%$ CHAPS, $0.5 \%$ phosphatidylcholine, $\mathrm{pH} 7.1$ at about $1 \mathrm{mg} / \mathrm{ml}$. The solubilization was done on ice with continuous stirring for two hours in the dark. The detergent- 
solubilized SR membrane was centrifuged at $49,000 \mathrm{rpm}$ (in Ti50 rotor) for 20 minutes, and the pellet was discarded, and the supernatant liquid was reacted with avidin beads (avidin conjugated to beaded agarose, Molecular Probes) for two hours on ice (in the dark with continuous stirring). The avidinconjugated beads were washed four times in wash buffer ( $1 \mathrm{M}$ $\mathrm{NaCl}, 20 \mathrm{mM}$ PIPES, 1\% CHAPS, $0.5 \%$ phosphatidylcholine) to remove non-biotinylated proteins. The beads were then loaded into a small column $(1 \mathrm{~cm} \times 8 \mathrm{~cm})$. Biotinylated proteins bound to the avidin-beads were selectively eluted with buffer containing sulfhydryl reducing agent dithiothreitol (1 $\mathrm{M} \mathrm{NaCl}$, $20 \mathrm{mM}$ PIPES, $5 \mathrm{mM}$ DTT, $0.3 \%$ CHAPS, $0.15 \%$ phosphatidylcholine, $\mathrm{pH} 7.1)$.

PLANAR LIPID BILAYER TECHNIQUE

In a planar bilayer system (Figure 3a), a phospholipid bilayer membrane was formed onto an aperture in a wall separating two aqueous compartments of milliliter-size dimensions. With two electrodes, each connected to the aqueous solution on one side of the membrane, a voltage was applied and the current across the membrane was measured. Under the right conditions, SR vesicles or isolated proteins added to the solution in one chamber were incorporated into the bilayer membrane and then electrical measurements could be made. The system had the following advantages: 1) the accessibility to both sides of the channel; 2 ) the ability to 

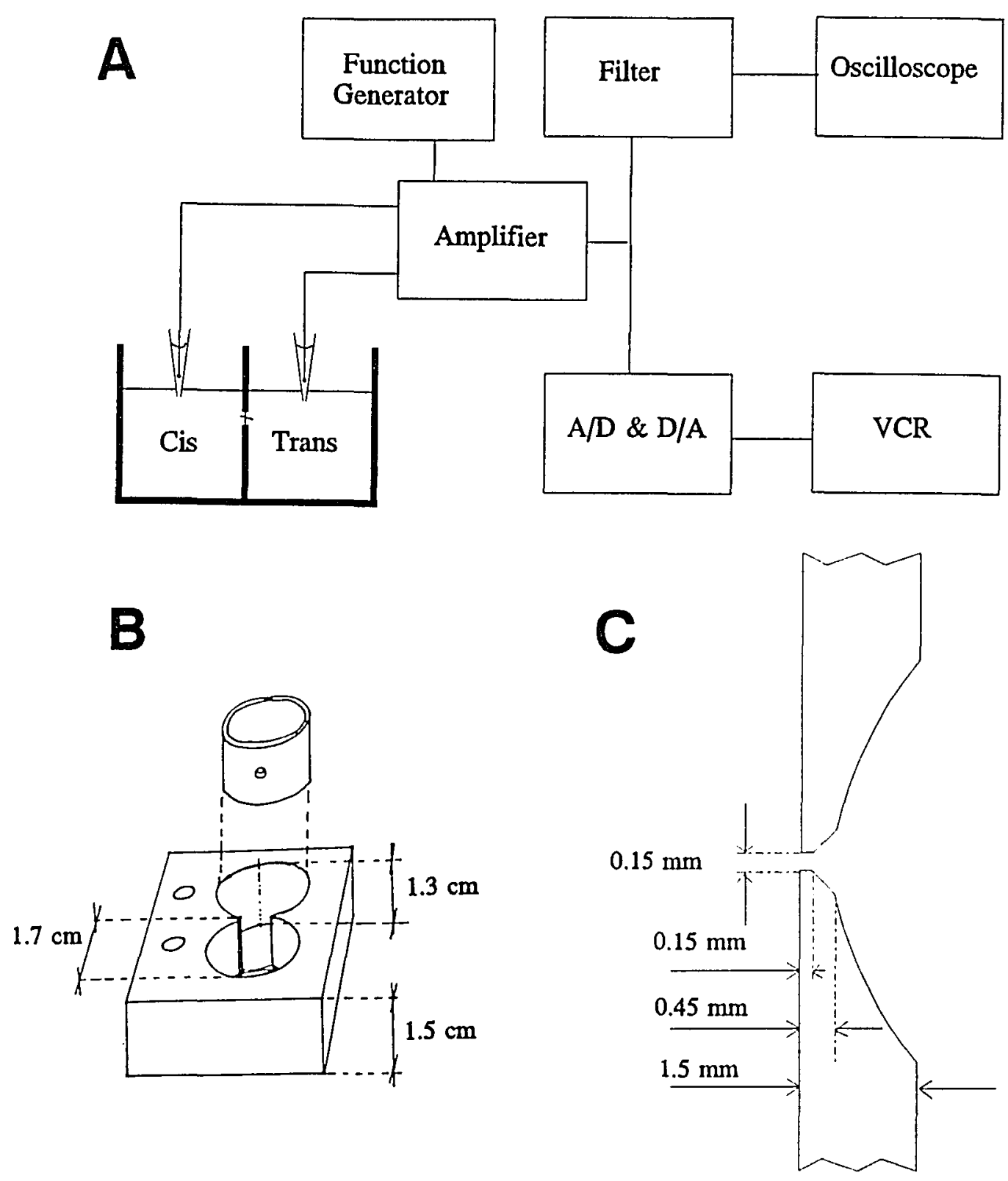

Figure 3. A planar lipid bilayer setup. (A) Schematic illustration of a bilayer system for single channel recording. (B) A bilayer chamber. (C) Cross-section view of a aperture for forming a lipid bilayer. 
control the ionic composition on both sides of the channel; and 3) the ability to control the voltage across the channel.

\section{Bilayer Chambers}

A bilayer chamber is shown in Figure 3b. A cylindrical polystyrene cup was fitted into a polyvinyl chloride holder. A small hole of $150 \mu \mathrm{m}$ diameter was drilled into a sector of the cup wall (Figure 3c). The cup was referred to as the trans chamber $(1.5 \mathrm{ml})$ which was held at virtual ground; the opposite side was defined as the cis chamber $(1.5 \mathrm{ml})$ to which SR vesicles or purified proteins were added.

The chambers were washed with running water to remove all salts. The chambers were then sonicated in the detergent JOY for 30 seconds to remove lipids and protein. After rinsing with running water, the chambers were sonicated in $1 \% \mathrm{HCl}$ for 30 seconds and then washed several times with distilled, deionized water. Chambers were stored in distilled, deionized water.

\section{Formation of Bilayer Membranes}

Phospholipid bilayers were made by the method of Mueller et al. (1962). A lipid film was formed by applying a lipid mixture to the aperture which connects two aqueous solution using a small camel hair brush. When an appropriate amount of lipid was applied, the film thined to a bilayer spontaneously to minimize the free energy of this lipid and aqueous solution system (White, 1986). Phospholipids dissolved in chloroform 
were purchased from Avanti Polar Lipids and stored at $-20^{\circ} \mathrm{C}$ to prevent decomposition. Lipids were freshly prepared each day by evaporating chloroform under nitrogen and dissolving the dry lipids with decane at a concentration of $50 \mathrm{mg}$ lipids/ $\mathrm{ml}$ decane. The lipid mixture used was phosphatidylethanolamine $(P E)$ : phosphatidyl serine (PS): phosphatidyl choline $(P C)=5$ : 3: 2 or PE: PS $=1: 1$. The presence of the negatively charged lipid PS in the mixture facilitated vesicle fusion (Miller and Racker, 1976).

The formation of a bilayer was a critical step in reconstitution experiments. To achieve easy membrane formation and stable membranes, the aperture was preconditioned with lipids. For membranes to thin spontaneously, the use of excess amounts of lipid was avoided. If a bilayer was not formed after three application of lipids, the chamber was cleaned to remove lipids on the aperture. It was important to use a clean brush to paint membranes. To clean a brush, salts were first washed off with distilled, deionized water, and then it was washed once in ethanol and once in chloroform.

The thickness of the membranes was determined by monitoring the capacitance. To measure the capacitance, a triangle wave of fixed period ( $t$ ) and amplitude (V) was applied across a membrane. The amplitude of the current acoss the membrane ( $i=c * d V / d t)$ was used to calculate the specific capacitance of a membrane, which should be in the range of 
$1 \mu F / \mathrm{cm}^{2}$ for a bilayer (Hille, 1984). The capacitance of the bilayer was constantly checked, in order to insure that the bilayer thickness remained the same throughout a reconstitution experiment. The noise level of a membrane was also a good indicator of the thickness of a membrane.

Reconstitution of the Native SR $\mathrm{Ca}^{2+}$ Release Channel

The native $\mathrm{SR} \mathrm{Ca}^{2+}$ release channel was reconstituted by the vesicle fusion technique. The ionic composition on both sides of the membrane was controlled to facilitate fusion. The following three conditions were generally used.

The standard asymmetrical $\mathrm{Ca}^{2+}$ solution. This protocol was first used by Smith et al. (1985) to characterize the native $\mathrm{Ca}^{2+}$ release channel. $\mathrm{SR}$ vesicle fusion was accomplished in a 5:1 choline chloride gradient (cis: $250 \mathrm{mM}$ choline chloride, $10 \mathrm{mM}$ Tris-HEPES, pH 7.4; trans: $50 \mathrm{mM}$ choline chloride, $10 \mathrm{mM}$ Tris-HEPES, pH 7.4). Vesicles were added to the cis chamber in the presence of $1 \mathrm{mM} \mathrm{CaCl}$. Fusion events (Figure 4) were monitored as an increase of $\mathrm{Cl}^{\text {. }}$ current. After one such event, $1 \mathrm{mM}$ EGTA was added to the cis chamber to prevent further fusion. Then, the cis chamber was perfused with three volumes of $125 \mathrm{mM}$ Tris-250 mM HEPES, pH7.4, and the trans chamber was perfused with three volumes

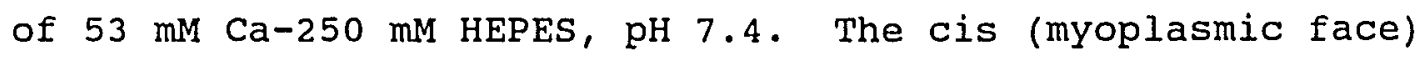
free $\mathrm{Ca}^{2+}$ concentration was controlled with a Ca-EGTA buffer. Monovalent cations such as $\mathrm{K}^{+}, \mathrm{Na}^{+}$, and the anion $\mathrm{Cl}^{-}$were avoided in this system to eliminate interference by SR $\mathrm{K}^{+}$ 


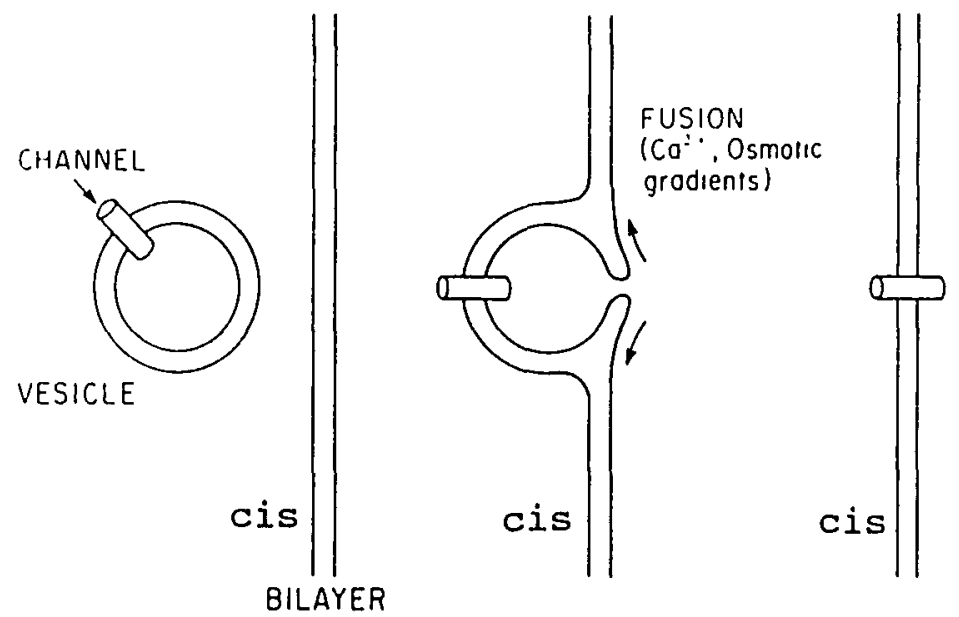

Figure 4. Fusion of a $S R$ vesicle to a lipid bilayer. A vesicle is incorporated into a bilayer by the method of Miller and Racker (1976). The fusion is controlled by $\left[\mathrm{Ca}^{2+}\right]_{\text {cist }}$ the presence of negatively charged lipid PS in the bilayer, and the osmotic gradient across the bilayer. The gradient across the bilayer ensures that vesicles incorporate into the bilayer with maintained orientation (outside facing cis). Adapted from White, 1986.

channels and $\mathrm{Cl}^{-}$channels. The permeability ratio of $\mathrm{Ca}^{2+}$ to Tris $^{+}$was obtained by determining the reversal potential of $\mathrm{Ca}^{2+}$ current (see appendix).

The CsCl gradient. It was convenient to characterize the $\mathrm{Ca}^{2+}$ channel in the same solution in which fusion was performed. This was achieved by using a Cscl gradient (cis: $500 \mathrm{mM} \mathrm{CsCl}, 10 \mathrm{mM}$ Tris-HEPES, pH 7.2; trans: $100 \mathrm{mM} \mathrm{CsCl,} 10$ MM Tris-HEPES, pH 7.2). These conditions, first reported by Fill et al. (1990), avoided the $\mathrm{K}^{+}$and $\mathrm{Cl}^{-}$currents normally found in SR preparations. $\mathrm{CS}^{+}$was chosen because it was reported (Coronado et al., 1980) that $S R \mathrm{~K}^{+}$channels are almost impermeable to $\mathrm{Cs}^{+}\left(<3 \mathrm{ps}\right.$ in $1 \mathrm{M}$ symmetrical $\left.\mathrm{Cs}^{+}\right)$. The 
high $\mathrm{Cs}^{+}$conductance of the $\mathrm{SR} \mathrm{Ca}^{2+}$ channel improved the signal to noise level. The effect of $\mathrm{Cl}^{-}$channels was minimized by monitoring the $\mathrm{Ca}^{2+}$ channel activity near the reversal potential of $\mathrm{Cl}^{-}$. The disadvantage of this method was the narrow voltage range (0 to $+40 \mathrm{mV})$ at which $\mathrm{Ca}^{2+}$ channel activity could be monitored. SR vesicles were added to the cis chamber at a final concentration of 2-10 $\mu \mathrm{g} / \mathrm{ml}$ in the presence of $0.35-0.7 \mathrm{mM} \mathrm{CaCl}$. Fusion events were monitored as an increase in the $\mathrm{Cl}^{-}$current. The osmotic gradient and the millimolar $\mathrm{cis} \mathrm{Ca}^{2+}$ were essential for vesicle fusion. $\mathrm{Cl}^{*}$ was also believed to be essential for fusion. After one such event, a two fold excess of EGTA (over $\mathrm{Ca}^{2+}$ ) was added to the cis chamber to prevent further fusion. The cis chamber was then perfused with three volumes of vesicle free solution. Solution perfusions were performed by using a back to back double syringe arrangement. Solution was pumped into the bottom of a chamber via a small tubing and simultaneously withdraw through another tubing positioned at the top of the chamber. The solutions in the two chambers were electrically shorted with a piece of silver wire to avoid buildup of static charge and breakage of the bilayer during the solution changing process.

The symmetrical $\mathrm{NaCl}$ solution. A symmetrical $\mathrm{NaCl}$ solution $\left(250 \mathrm{mM} \mathrm{NaCl}, 10 \mathrm{mM} \mathrm{NaOH}\right.$-HEPES, $0.5 \mathrm{mM} \mathrm{CaCl} \mathrm{Cl}_{2}, 0.5 \mathrm{mM}$ EGTA, $\mathrm{pH}$ 7.4.) was used to study the monovalent conductivity of the native $\mathrm{Ca}^{2+}$ release channel. The SR vesicle fusion was 
carried out in the presence of $0.7 \mathrm{mM} \mathrm{CaCl} \mathrm{Ca}_{2}$ and a $2: 1 \mathrm{NaCl}$ gradient (500 mM cis/250 mM trans) or with a symmetrical 250 $\mathrm{mM} \mathrm{NaCl}$ solution. The cis chamber was then perfused with a vesicle-free solution containing $250 \mathrm{mM} \mathrm{NaCl}$. After one fusion event, $0.7 \mathrm{mM}$ EGTA was added to prevent further fusions. The interference of $\mathrm{SR} \mathrm{Cl}$ channels was minimized by using SR vesicle preparations which contained only a few $\mathrm{Cl}^{\circ}$ channels per vesicle. The protocol was effective becsuse the conductivity of $\mathrm{SR}^{+}$channels to $\mathrm{Na}^{+}$is relative low $(\sim 40 \mathrm{pS}$ in $250 \mathrm{mM} \mathrm{NaCl}$ ), and the gating of the $\mathrm{K}^{+}$channel is much slower (on the second scale) than that of the $\mathrm{Ca}^{2+}$ release channel (on the millisecond scale). Generally, less than five $\mathrm{SR} \mathrm{K}^{+}$channels were incorporated after a single fusion event.

\section{Reconstitution of Purified $106 \mathrm{kDa}$ Protein}

The reconstitution of purified $106 \mathrm{kDa}$ channel protein into a planar lipid bilayer was carried out with two ionic conditions.

The standard asymmetrical $\mathrm{Ca}^{2+}$ solution. For comparison with the native $S R \mathrm{Ca}^{2+}$ release channel, the activity of the purified protein was monitored in the standard asymmetrical $\mathrm{Ca}^{2+}$ solution described above for the native channel. The incorporation of the purified protein to a bilayer was obtained in a symmetrical $\mathrm{NaCl}$ solution $(150 \mathrm{mM} \mathrm{NaCl}, 10 \mathrm{mM}$ Na-HEPES, $0.1 \mathrm{mM} \mathrm{CaCl} \mathrm{Ca}_{2}, 0.1 \mathrm{mM} \mathrm{EGTA,} \mathrm{pH} \mathrm{7.4)} \mathrm{by} \mathrm{adding} \mathrm{5-}$ $30 \mathrm{Hl}$ of purified $106 \mathrm{kDa}$ protein (at a protein concentration of about $20 \mu \mathrm{g} / \mathrm{ml}$ ). A bilayer was formed after the addition 
of purified protein to the vicinity of the aperture of a bilayer chamber. This often produced a bilayer with a few incorporated proteins. Breaking and reforming bilayers also seemed to assist protein incorporation. Generally these procedures were repeated until a bilayer was formed containing only one or two channel proteins. Sonication of protein prior to addition gave bilayers containing a fewer numbers of proteins. After a successful reconstitution, the solutions in both chambers were perfused to the standard asymmetrical $\mathrm{Ca}^{2+}$ solution.

The symmetrical NaCl solution. The lack of other SR channels in the purified protein preparation made it possible to use this convenient experimental procedure. symmetrical $\mathrm{NaCl}$ solution $(250 \mathrm{mM} \mathrm{NaCl}, 10 \mathrm{mM}$ Na-HEPES, $0.1 \mathrm{mM} \mathrm{CaCl}, 0.1$ mM EGTA, $\mathrm{pH} \mathrm{7.4)} \mathrm{was} \mathrm{used} \mathrm{in} \mathrm{most} 106 \mathrm{kDa}$ protein reconstitution studies. The incorporation of purified protein into a bilayer was as described above. Compared to the standard asymmetrical $\mathrm{Ca}^{2+}$ solution, the use of the symmetrical $\mathrm{NaCl}$ solution greatly improved the success rate of reconstitution of the $106 \mathrm{kDa}$ channel protein.

\section{Signal Acquisition and Analysis}

The planar lipid bilayer setup was enclosed in a Farady cage so that the system was isolated from electrical noise. A vibration-isolation table was used to protect the system from physical vibrations. A D.C. stirring motor was placed directly under the bilayer chamber to achieve fast mixing of 
solutions. As shown in Figure $3 a$, two agar bridges ( $1 \%$ agar in $100 \mathrm{mM} \mathrm{KCl}, 20 \mathrm{mM}$ Tris-HEPES, $\mathrm{pH} 7.0$ ) connected the solution of two chambers to two Ag/ AgCl electrodes. A patch clamp amplifier (List EPC-7), applied a known voltage across the bilayers. The amplifier also allowed measurement of the trans-membrane current and converted the picoampere current to a millivolt voltage reading. This signal was then passed through a $3000 \mathrm{~Hz}$ low pass filter inside the amplifier. Data were digitized with an VR-10 Digital Data Recorder (Instrutech) and stored on a VHS HQ video recorder. The signal was simultaneously passed through a low pass filter (Frequency Devices, model 902) and displayed on a digital storage oscilloscope (Kikusui; $20 \mathrm{MHz} 5020 \mathrm{~A}$ ). Data stored on VCR tapes were filtered at $400-1,500 \mathrm{~Hz}$ and digitized at 5004,000 $\mathrm{Hz}$ for later analysis on an IBM-PC using the software package pCLAMP (Axon Instruments). 
CHAPTER III

\section{RECONSTITUTION AND CHARACTERIZATION OF THE $106 \mathrm{KDA} \mathrm{Ca}^{2+}$ RELEASE CHANNEL}

SUMMARY

The purified $106 \mathrm{kDa}$ protein was reconstituted into a planar lipid bilayer membrane and the resulting channel activity was examined. In an asymmetrical $\mathrm{Ca}^{2+}$ solution, the channel demonstrated a single channel conductance of $107 \pm 13$ ps and a permeability ratio of $\mathrm{Ca}^{2+}$ versus Tris ${ }^{+}$of $7.4 \pm 3.3$. In a symmetrical $250 \mathrm{mM} \mathrm{NaCl}$ solution, the channel displayed a large single channel conductance of $400 \pm 20 \mathrm{ps}$, and a weak voltage-dependence of the open probability. The channel was activated by millimolar ATP and inhibited by micromolar ruthenium red. Nanomolar concentrations of ryanodine modified the channel by changing the channel from a fast gated full conductance state to a long-lived subconducting state. Thus, the $106 \mathrm{kDa}$ protein is a $\mathrm{Ca}^{2+}$ channel protein which has similar properties to the native $\mathrm{SR} \mathrm{Ca}^{2+}$ release channel.

\section{INTRODUCTION}

Previous work from our laboratory strongly indicated that $\mathrm{SH}$ groups are involved in the $\mathrm{SR} \mathrm{Ca}^{2+}$ release process 
(reviewed by Abramson and Salama, 1989). A group of disulfide compounds (Figure 5a) were examined in an effort to find ideal sulfhydryl oxidizing reagents which would label and help to purify the $\mathrm{Ca}^{2+}$ release protein (Zaidi et al., 1989a). These reactive disulfide compounds (RDSs) with a pyridyl ring adjacent to an S-S bond, include 2,2'-dithiopyridine (2,2'DTDP) , 4-4'-dithiopyridine (4,4'-DTDP), and N-succinimidyl 3(2-pyridyldithio) propionate (SPDP). These compounds are known specifically to oxidize free SH sites via a thiol-disulfide exchange reaction with the stoichiometric production of thiopyridone. The RDSs cause $\mathrm{Ca}^{2+}$ release from isolated SR vesicles at micromolar concentrations. This sulfhydryl oxidation-induced $\mathrm{Ca}^{2+}$ release can be reversed by addition of the reducing agents glutathione (GSH), or dithiothreitol (DTT). At micromolor concentrations, reactive disulfides displace $\left[{ }^{3} \mathrm{H}\right]$ ryanodine binding from $\mathrm{SR}$ vesicles, indicating further that the RDSs specifically interact with the $\mathrm{Ca}^{2+}$ release protein. It appears that the RSDs oxidize one or more sulfhydryl groups on the $\mathrm{Ca}^{2+}$ channel, resulting in a mixed disulfide between the release protein and the RSDs (Figure 5b).

Among the dithiopyridines causing release, SPDP is a heterobifunctional reagent. It can be covalently linked to another easily identifiable molecule which, in turn, can be attached to a column. Figure $5 \mathrm{c}$ shows the reaction of SPDP with biotin hydrazide to form PDP-biotin hydrazide. As 
A<smiles>c1ccc(SSc2ccccn2)nc1</smiles>
2,2' - Dithiodipyridine

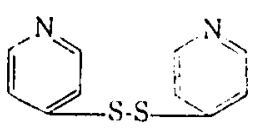

$4,4^{\prime}$-Dithiodipyridine<smiles>O=C(CCCCSc1ccccn1)ON1C(=O)CCC1=O</smiles>
N-Succinimidyl 3(2-pvridyldithio) propionate<smiles>CCC1CC(=O)N(C(=O)CCSc2cccc([Hg]Sc3ccccc3)n2)C1</smiles><smiles>O=C(CCCSc1ccccc1)ON1C(=O)CCC1=O</smiles>

C SPDP -Biotin Hydrazide conjugation<smiles>NNC(=O)CCC1SCC2NC(=O)NC21</smiles>

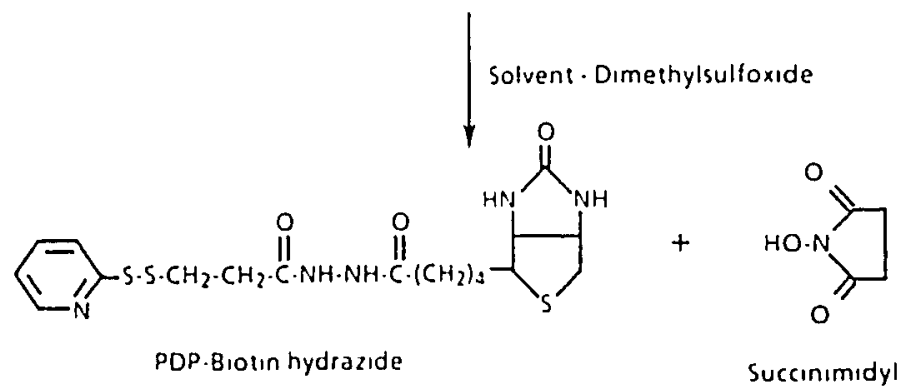

Figure 5. Structure of reactive disulfide compounds and reactions of SPDP. (A) structure of three reactive disulfide compounds. (B) Thioldisulfide exchange reaction between a free $\mathrm{SH}$ site on the SR and SPDP. (C) Synthesis of SPDP-biotin conjugate. 
expected, PDP-biotin hydrazide was effective in causing SR $\mathrm{Ca}^{2+}$ release, with characteristics similar to SPDP. PDPbiotin hydrazide covalently labeled one SR protein which was identified by biotin-avidin peroxidase reaction. This was an elegant method to link covalently the channel protein with an easily identifiable probe which facilitated isolation and purification. The reactive disulfide SPDP was first used successfully in our collaborator's laboratory to label and purify a single protein from solubilized SR (Zaidi et al., 1989b) . The biotinylated protein was isolated and purified by biotin-avidin chromatography. The purified protein consists of a single polypeptide of molecular mass about 106,000 dalton (106 kDa).

This chapter describes characterization of this $106 \mathrm{kDa}$ protein reconstituted in planar lipid bilayers. The purified $106 \mathrm{kDa}$ protein used in my early experiments was obtained from Dr. Salama's laboratory at the University of Pittsburgh. Keith scott, a fellow student in this laboratory, kindly provided the purified $106 \mathrm{kDa}$ protein for most of my experiments.

\section{RESULTS}

The purified $106 \mathrm{kDa}$ protein was first characterized in a standard asymmetrical $\mathrm{Ca}^{2+}$ solution. The purified $106 \mathrm{kDa}$ protein was first incorporated into a bilayer in a symmetrical $\mathrm{NaCl}$ solution, which was then changed to an asymmetrical 
calcium solution. The protein was added to the cis chamber at a final concentration of $50-500 \mathrm{ng} / \mathrm{ml}$ in the presence of CHAPS (2-20 $\mu M)$. The bilayer bathing buffer contained symmetrical $150 \mathrm{mM} \mathrm{NaCl}, 10 \mathrm{mM} \mathrm{NaOH} / \mathrm{HEPES}, 0.1 \mathrm{mM} \mathrm{CaCl} 2,0.1 \mathrm{mM}$ EGTA, pH 7.4. After the incorporation of proteins into the bilayer, the cis chamber was perfused with $125 \mathrm{mM}$ Tris, $250 \mathrm{mM}$ HEPES, $0.1 \mathrm{mM} \mathrm{CaCl} 2,0.1 \mathrm{mM} \mathrm{EGTA}, \mathrm{pH} 7.4$; the trans chamber was perfused with $53 \mathrm{mM} \mathrm{Ca}(\mathrm{OH})_{2}, 250 \mathrm{mM}$ HEPES, pH 7.4. Incorporation of the $106 \mathrm{kDa}$ protein into bilayer membrane was monitored through changes in the bilayer current. In the $\mathrm{NaCl}$ solution, about $20 \%$ of the bilayers showed discrete current fluctuation which is a characteristic feature of single channel activity. This may reflect the percentage of $106 \mathrm{kDa}$ proteins which were structurally intact after purification procedure and incorporated into bilayer membranes in the native conformation. The difficulty in studying channel behavior using this procedure lay in the fact that after changing solutions to a standard $\mathrm{Ca}^{2+}$ containing buffer, the thickness of bilayer membranes was likely to increase, and at this point channel activity was often lost. The increased thickness of the membranes might be caused by changes in the ionic environment or the interaction between high concentration of $\mathrm{Ca}^{2+}$ and the lipid component of the membranes. If the protein survived the solution changing, measurements such as shown in Figure 6 were recorded. Figure 6a shows a typical current fluctuation following incorporation 
of the isolated $106 \mathrm{kDa}$ protein into a bilayer. The corresponding current-voltage (I-V) curve (Figure 6b) reveals a single channel conductance of $107 \pm 13 \mathrm{ps}$. The reversal potential is $-27 \pm 7 \mathrm{mV}$, yielding a permeability ratio of $\mathrm{Ca}^{2+}$ to $\operatorname{Tris}^{+}\left(\mathrm{P}_{\mathrm{Ca}} / \mathrm{P}_{\text {Tris }}\right)$ of $7.4 \pm 3.3$. As a control, the detergent CHAPS without protein was added at higher concentration (200 $\mu M)$ and no current fluctuations were observed.

As mentioned above, the $106 \mathrm{kDa}$ protein also conducted current in a symmetrical $\mathrm{NaCl}$ solution. The ability of the $106 \mathrm{kDa}$ protein to conduct monovalent ions was investigated. The purified $106 \mathrm{kDa}$ protein was added to the cis chamber at a final concentration of $50-500 \mathrm{ng} / \mathrm{ml}$ in the presence of CHAPS (2-20 $\mu M)$. The bilayer bathing buffer contained symmetrical $250 \mathrm{mM} \mathrm{NaCl}, 10 \mathrm{mM} \mathrm{NaOH} /$ HEPES, $0.1 \mathrm{mM} \mathrm{CaCl})_{2} 0.1 \mathrm{mM} \mathrm{EGTA,} \mathrm{pH}$ 7.4. Figure 7 shows current fluctuation recorded at four different holding potentials. In this figure, $\mathrm{Na}^{+}$is transported through a single $106 \mathrm{kDa}$ protein molecule. The single channel current is large and the kinetics of opening and closing is fast (on the scale of $\mathrm{ms}$ ). The channel does not spontaneously inactivate. The other feature clearly demonstrated in Figure 7 is the weak voltage dependence of the open probability $\left(P_{0}\right)$, which is smaller at positive potentials $\left(P_{0}=3 \%\right.$ at $+40 \mathrm{mV} ; P_{0}=6 \%$ at $\left.+20 \mathrm{mV}\right)$, and larger at negative potentials $\left(\mathrm{P}_{0}=24 \%\right.$ at $-20 \mathrm{mV} ; \mathrm{P}_{0}=38 \%$ at $\left.-40 \mathrm{mV}\right)$. This voltage asymmetry of $P_{0}$ is evident in all experiments performed in symmetrical solution, where the channel can be 


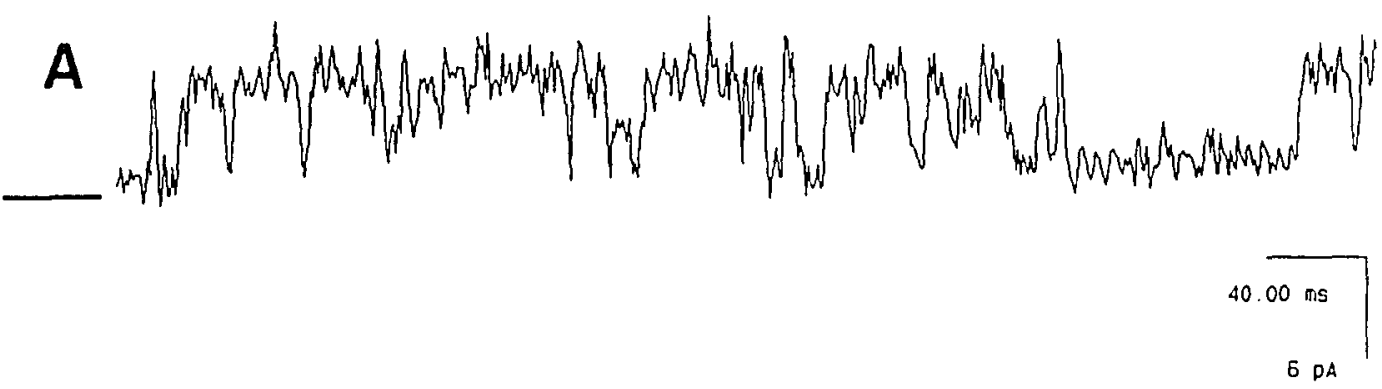

B

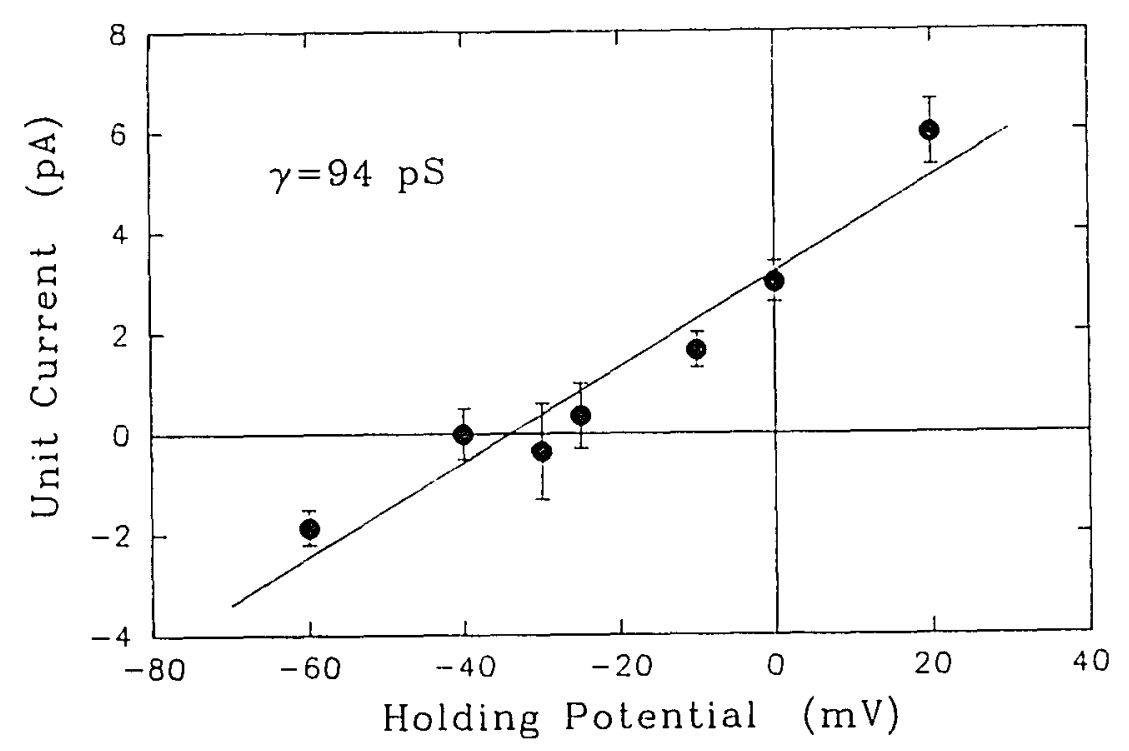

Figure 6. Reconstituted $106 \mathrm{kDa}$ protein in the standard $\mathrm{Ca}^{2+}$ solution. (A) $\mathrm{Ca}^{2+}$ current fluctuation through the reconstituted $106 \mathrm{kDa}$ channel. Holding potential (HP) is $20 \mathrm{mV}$. Number of experiments (n) is 3. The bar indicates the closed state of the channel. (B) The current-voltage curve of a single $106 \mathrm{kDa}$ channel. The straight line is determined by a least square fit. 


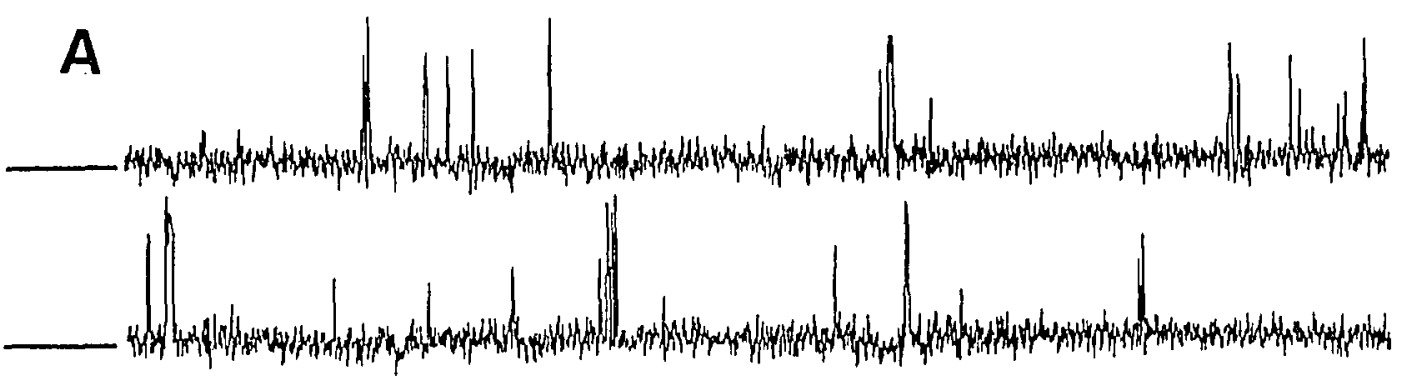
B

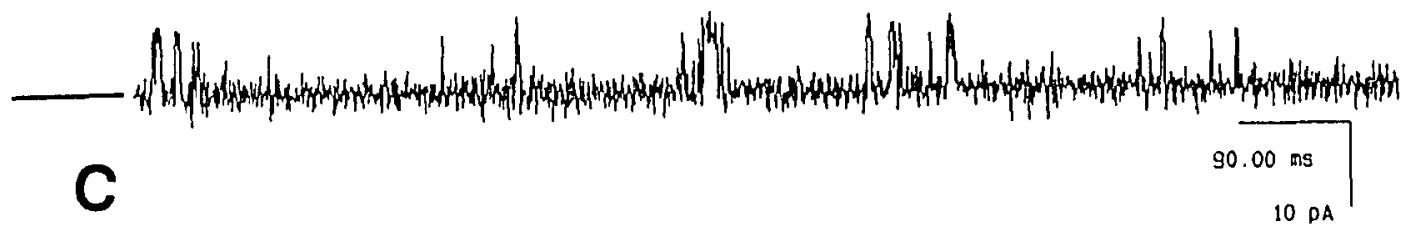
工 D

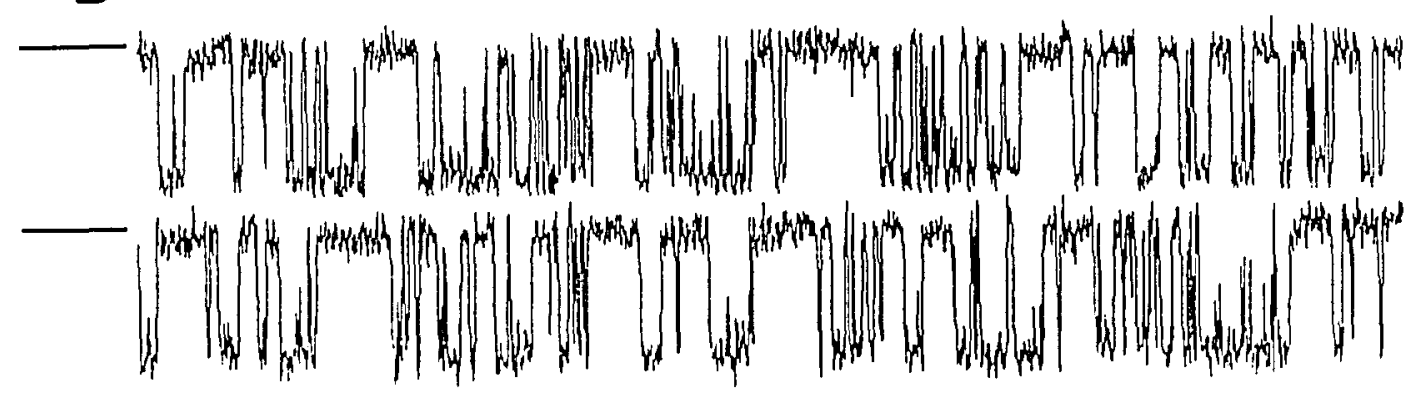

\footnotetext{
Figure 7. Reconstituted $106 \mathrm{kDa}$ protein shows monovalent cation conductance. Purified protein was incorporated into a bilayer in symmetrical 250 $\mathrm{mM} \mathrm{NaCl}, 10 \mathrm{mM} \mathrm{NaOH} / \mathrm{HEPES}, \mathrm{pH} \mathrm{7.4.} \mathrm{(} \mathrm{n}>10)$ The $\mathrm{Na}^{+}$current through the $106 \mathrm{kDa}$ channel was recorded under four different holding potentials. (A) $\mathrm{HP}=$ $40 \mathrm{mV}, \mathrm{P}_{0}=3 \%$. (B) $\mathrm{HP}=20 \mathrm{mV}, \mathrm{P}_{0}=6 \%$. (C) $\mathrm{HP}=$ $-20 \mathrm{mV}, \mathrm{P}_{0}=24 \%$. (D) $\mathrm{HP}=-40 \mathrm{mV}, \mathrm{P}_{0}=38 \%$. The bars indicate the closed state of the channel.
} 
observed under a large range of holding potential. Figure 8 displays the $\mathrm{Na}^{+}$current through the $106 \mathrm{kDa}$ protein channel at a higher time resolution (data from the same experiment as Figure 7). Here, the opening and closing of the channel (the gating of the channel) can be seen clearly. The channel open lifetime can be fit to a single exponential with a mean open lifetime ranging from 1.1-6.4 $\mathrm{ms}$, depending on the holding potential (Figure $9 \mathrm{~b}$ at $\mathrm{HP}=-40 \mathrm{mV}$ ). The corresponding $\mathrm{I}-\mathrm{V}$ curve (Figure 9 a) shows a single channel conductance of $400 \pm 20 \mathrm{ps}$.

The permeability of the native $\mathrm{SR} \mathrm{Ca}^{2+}$ release channel to $\mathrm{Na}^{+}$ions was also investigated. Figure 10 shows a SR vesicle fusion experiment performed in the same symmetric solution of $250 \mathrm{mM} \mathrm{NaCl}$. Both the purified $106 \mathrm{kDa}$ channel and the native channel (from a fusion experiment) conducts $\mathrm{Na}^{+}$ions. The single channel conductance of the native $\mathrm{Ca}^{2+}$ release channel is $405 \pm 35 \mathrm{ps}$, which agrees with that of $106 \mathrm{kDa}$ protein $(400 \pm 20 \mathrm{ps})$. The voltage dependence of open probability is also evident in native $\mathrm{Ca}^{2+}$ channel.

The other frequently observed feature of the reconstituted $106 \mathrm{kDa}$ channel is the presence of subconducting states. The traces in Figure 11 show the presence of four subconducting states with a conductance of one quarter (102 ps) of the full unitary conductance $(400 \pm 20 \mathrm{pS})$. Note the different kinetics associated with each state. Following reconstitution, about half of the bilayer experiments showed 
A

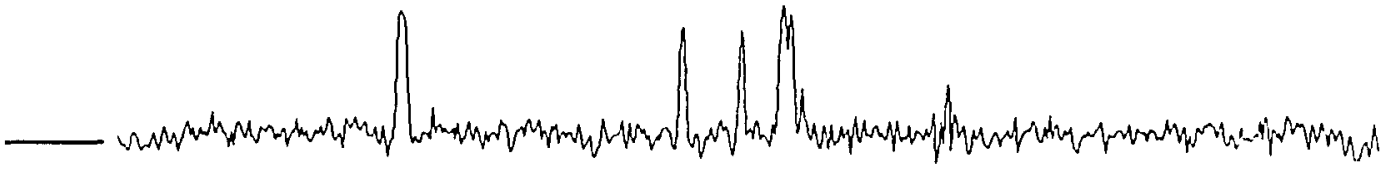

B

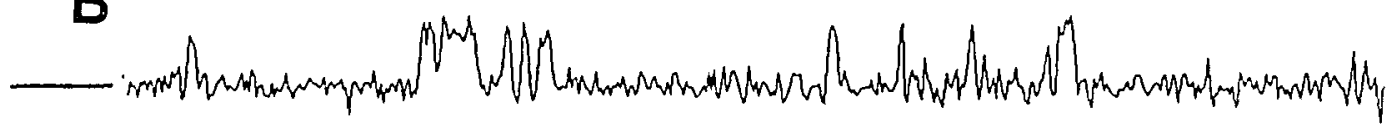

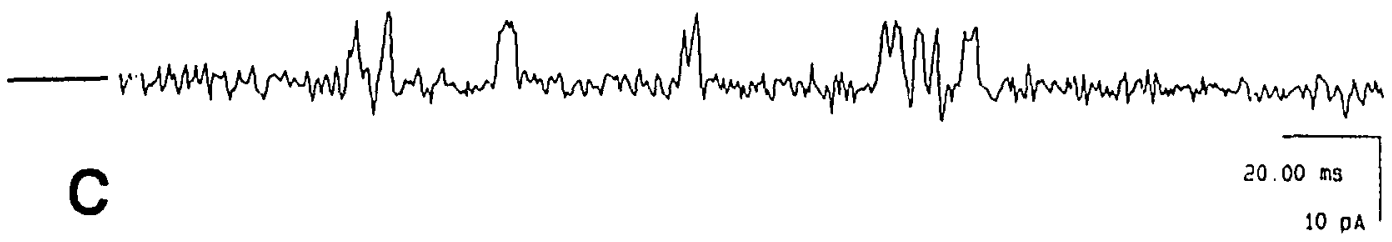

- I

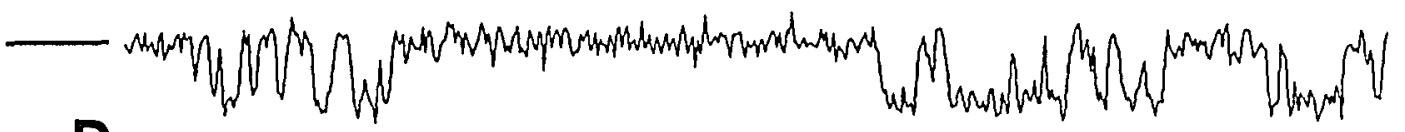

D

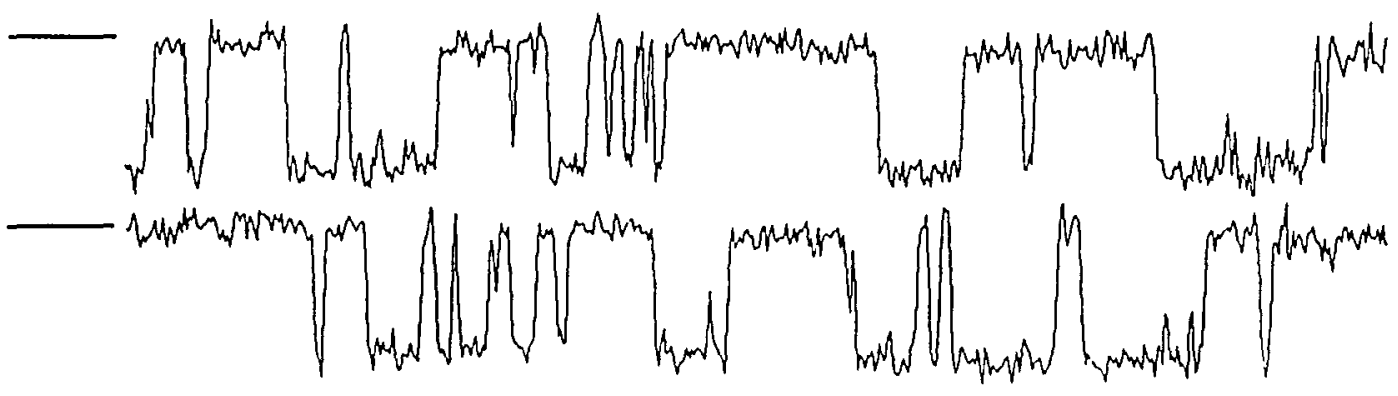

Figure 8. Reconstituted $106 \mathrm{kDa}$ protein shows monovalent cation conductance. Purified protein was incorporated into a bilayer in symmetrical 250 $\mathrm{mM} \mathrm{NaCl}, 10 \mathrm{mM} \mathrm{NaOH} / \mathrm{HEPES}, \mathrm{pH} 7.4$. The four traces are from the same recording of Figure 7 at a shorter time scale. (A) $\mathrm{HP}=40 \mathrm{mV}$. (B) $\mathrm{HP}=20$ $\mathrm{mV}$. (C) $\mathrm{HP}=-20 \mathrm{mV}$. (D) $\mathrm{HP}=-40 \mathrm{mV}$. The bars indicate the closed state of the channel. 
A

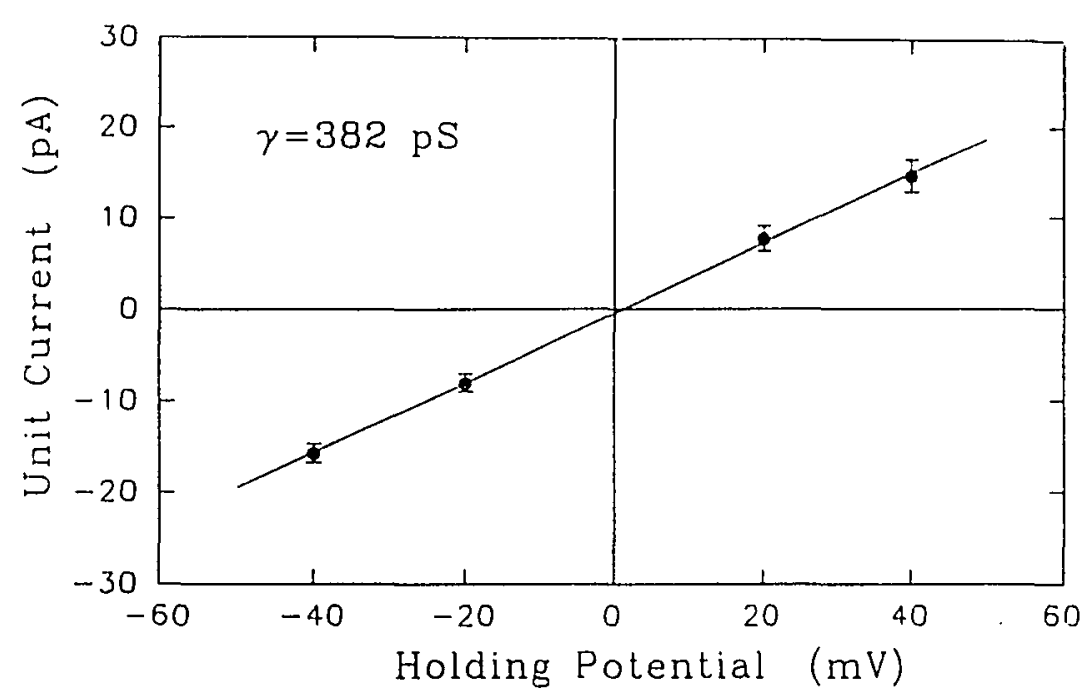

55

B

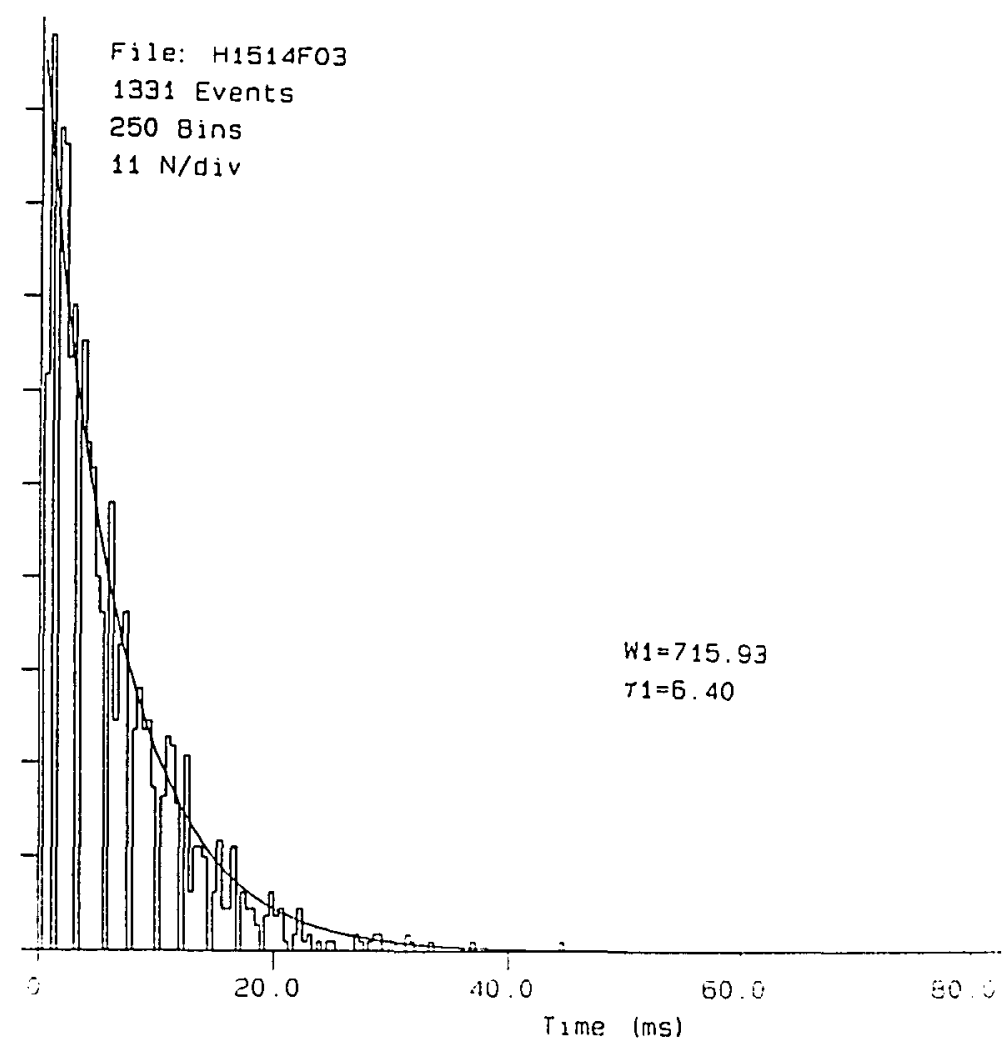

Figure 9. The properties of monovalent conductance of the $106 \mathrm{kDa}$ channel. (A) Current-voltage curve in symmetrical NaCl solution. Data are taken from the same recording as Figure 7 . (B) Open lifetime histogram of the same recording at $H P=-40 \mathrm{mV}$. A single exponential fitting reveals open time constant of $6.4 \mathrm{mS}$. 


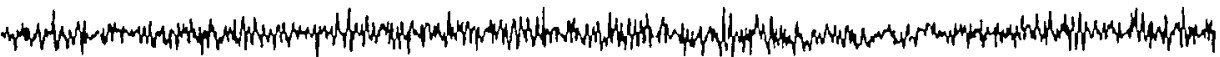

A

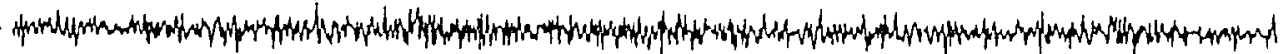

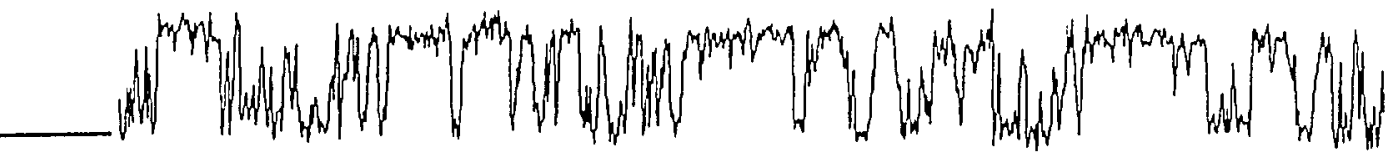

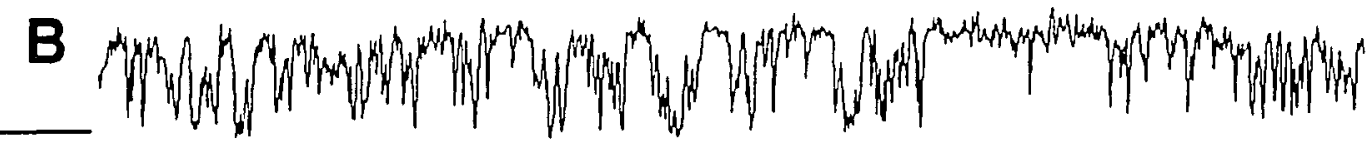

$$
\begin{aligned}
& 40.00 \mathrm{~ms} \\
& 20 \mathrm{mV}
\end{aligned}
$$

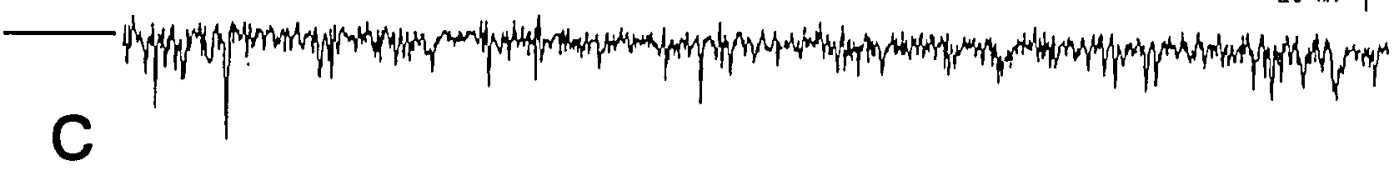

C

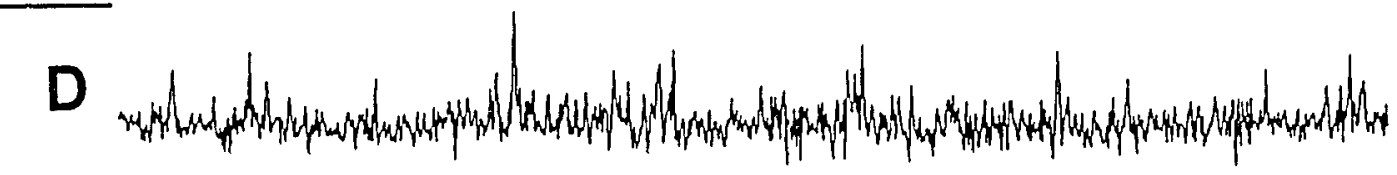

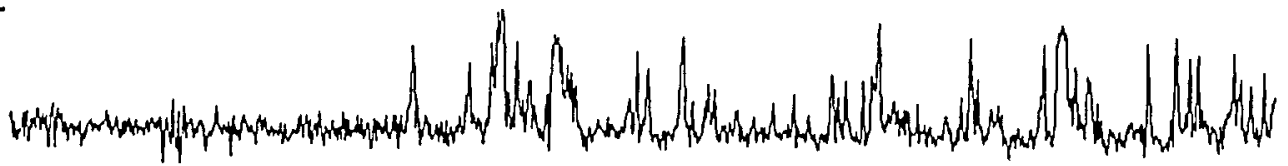

Figure 10. The native $\mathrm{SR} \mathrm{Ca}^{2+}$ release channel conducts monovalent cations. SR vesicles were added to the cis chamber of a bilayer in symmetric solution (250 $\mathrm{mM} \mathrm{NaCl}, 10 \mathrm{mM}$ NaOH/HEPHES, $\mathrm{pH} \mathrm{7.4,}$ with $0.7 \mathrm{mM}$ cis $\mathrm{Ca}^{2+}$ ). Following vesicle fusion the cis chamber was perfused with $250 \mathrm{mM} \mathrm{NaCl}, 10 \mathrm{mM}$ $\mathrm{NaOH} / \mathrm{HEPHES}, \mathrm{pH} 7.4 .\left[\mathrm{Ca}^{2+} \text { free }\right]_{\text {cis }}=10 \mu \mathrm{M}$. (A) HP $=40 \mathrm{mV}, \mathrm{P}_{0}=0 \%$. (C) $\mathrm{HP}=-40 \mathrm{mV}, \mathrm{P}_{0}=1 \%$. Traces $C$ and $d$ were made after the photoactivation of $0.3 \mu M$ rose bengal. (B) $\mathrm{HP}=40 \mathrm{mV}, \mathrm{P}_{0}=87 \%$. (D) $\mathrm{HP}=-40 \mathrm{mV}, \mathrm{P}_{0}=95 \%$. The bars indicate the closed state of the channel. $(n=3)$ 

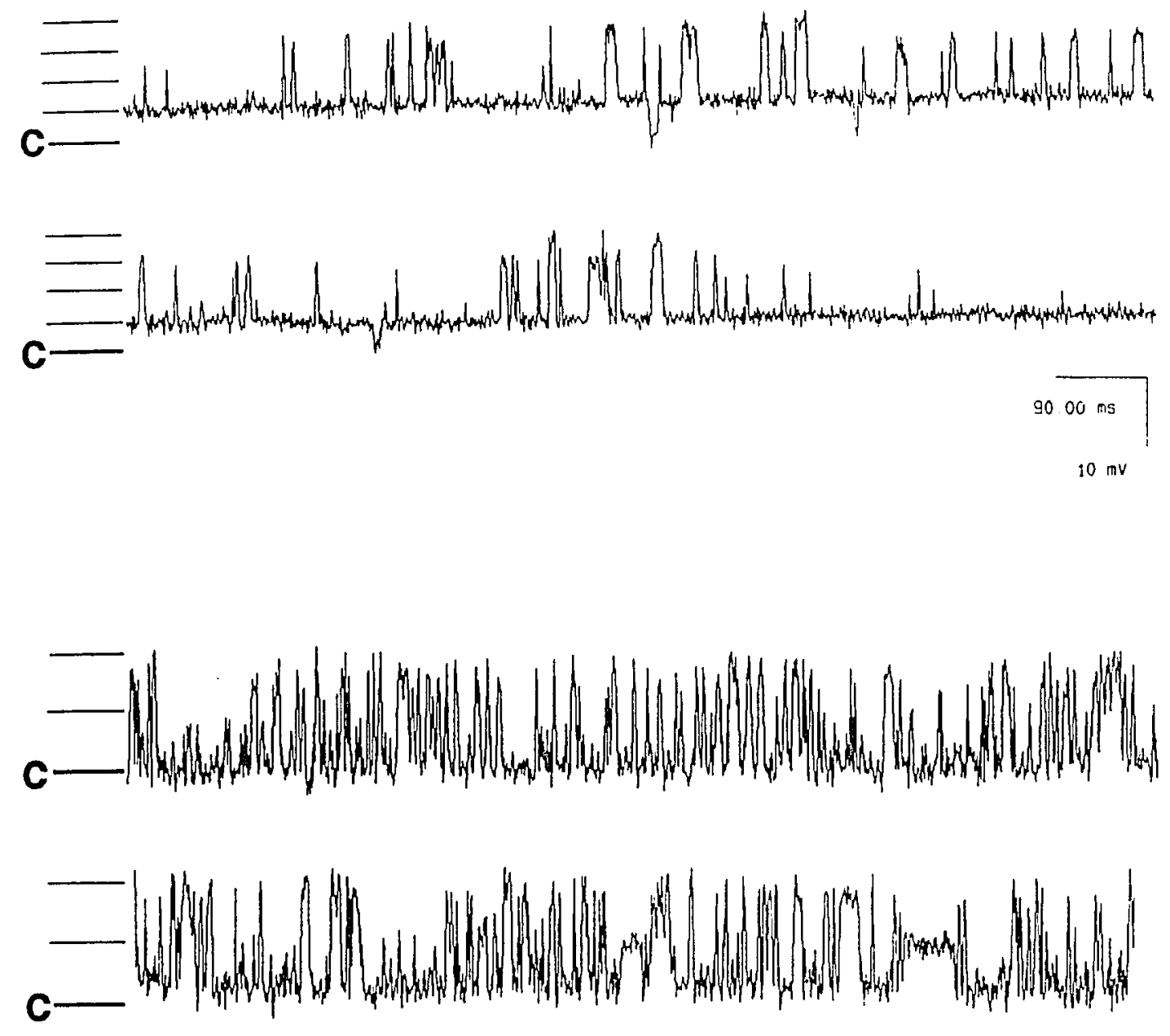

Figure 11. Subconducting states of the reconstituted $106 \mathrm{kDa}$ protein. The recordings were made in $250 \mathrm{mM}$ symmetrical $\mathrm{NaCl}$ solution. The top three traces show quarter states. In the bottom two traces, half-conducting states are evident. The thick bars indicate the closed state of the channel, and the fine bars indicate subconducting states of the channel. $\mathrm{HP}=40 \mathrm{mV}$. 
a full conductance of about $400 \mathrm{ps}$ with no or seldom occurrence of half or quarter states. These types of channels were used to study the ligand sensitivity of the $106 \mathrm{kDa}$ protein. The other half of the reconstituted channels showed behavior that was not reproducible. These channels had single channel conductance other than $400 \mathrm{ps,} \mathrm{very} \mathrm{slow} \mathrm{gating,} \mathrm{or}$ unstable channel activity such as changing unit conductance and unstable gating behavior. Such abnormal channel activity may have resulted from channel molecules which were damaged in the purification procedure, or from channel proteins which were not incorporated into bilayers in a normal conformation.

To establish further the identity of the $106 \mathrm{kDa}$ channel, its ligand sensitivity was tested. A symmetrical $\mathrm{NaCl}$ solution (250 mM NaCl, $10 \mathrm{mM} \mathrm{NaOH} /$ HEPES, $\mathrm{pH} \mathrm{7.4)} \mathrm{was} \mathrm{used} \mathrm{in}$ these studies to simplify the experimental procedure. Figure 12 shows current traces following the incorporation of $106 \mathrm{kDa}$ protein into a bilayer in a symmetrical $\mathrm{NaCl}$ solution. Open events are shown as downward deflections. Addition of $1 \mathrm{mM}$ ATP greatly increased the open probability of the channel, and the subsequent addition of $6 \mu M$ ruthenium red completely inhibited the channel activity. The ligand sensitivity of the reconstituted $106 \mathrm{kDa}$ channel was apparently dependent on the integrity of its structure. If the channel had normal unitary conductance and fast kinetics, there was a larger probability that experiments carried out with it would respond to the ligands added. Of all the $106 \mathrm{kDa}$ channels which showed 


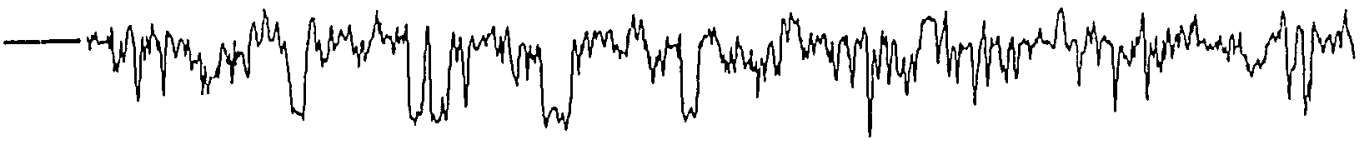

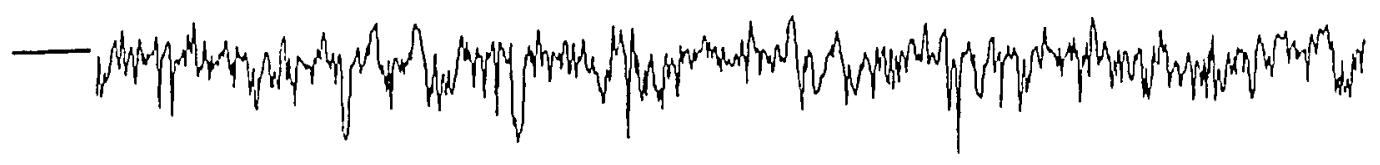

B

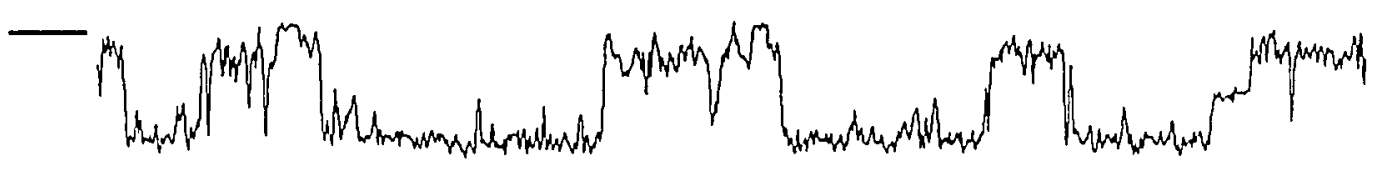

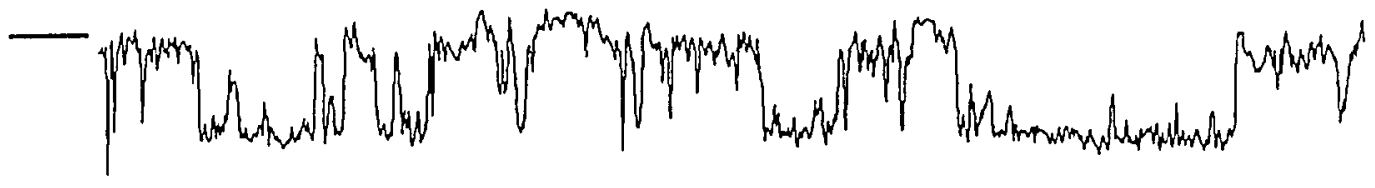

C

$40.00 \mathrm{~ns}$

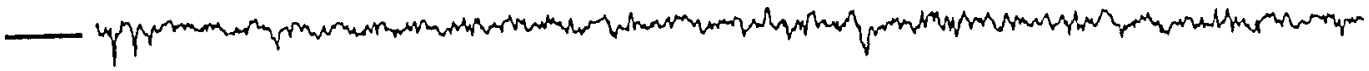

Figure 12. ATP and ruthenium red modification of the reconstituted $106 \mathrm{kDa}$ channel. Recordings were made in $250 \mathrm{mM}$ symmetrical $\mathrm{NaCl}$ solution. (A) Control trace, $\mathrm{P}_{0}=7 \%$. (B) After addition of $1 \mathrm{mM}$ ATP to both chambers, $\mathrm{P}_{0}=33 \%$. (C) After addition of $6 \mu M$ ruthenium red to both chambers, $\mathrm{P}_{0}=0 \%$. $\mathrm{HP}=-40 \mathrm{mV} . \quad \gamma=375 \mathrm{ps}$. The bars indicate the closed state of the channel. $(n=4)$ 
normal conductance, about $50 \%$ were sensitive to the addition of ATP, and about $30 \%$ were sensitive to the addition of ruthenium red. The reconstituted $106 \mathrm{kDa}$ channel was insensitive to $\mathrm{Ca}^{2+}$.

In comparison with the native $\mathrm{SR} \mathrm{Ca}^{2+}$ channel reconstituted in bilayer (Rousseau et al., 1987), the $106 \mathrm{kDa}$ channel had a much greater sensitivity to ryanodine. Figure 13 shows the current fluctuation of a single $106 \mathrm{kDa}$ channel before and after the addition of ryanodine (also see Figure 34 in chapter $V$ ). In trace $A$, the channel is in its full conducting state $(420 \mathrm{pS})$ with an open probability $P_{0}$ of $33 \%$. As shown in Figure 13b, the channel passed into a subconducting state ( $210 \mathrm{ps}$ ) about one minute after addition of $20 \mathrm{nM}$ ryanodine to both sides of the bilayer. The $P_{0}$ of the subconducting state was close to unity.

\section{DISCUSSION}

Reconstitution of the purified, sulfhydryl-activated 106 kDa protein into planar lipid bilayers indicated the presence of a channel with similar characteristics to the native SR $\mathrm{Ca}^{2+}$ release channel. The properties of the native SR $\mathrm{Ca}^{2+}$ channel, the $106 \mathrm{kDa}$ channel, and the purified $400 \mathrm{kDa}$ ryanodine receptor channel are compared in Table IV. The native $\mathrm{Ca}^{2+}$ channel refers to the channel obtained following fusion of $S R$ vesicles to the bilayer. This is a detergent free preparation. The native $\mathrm{SR} \mathrm{Ca}^{2+}$ channel was identified 


\section{A}

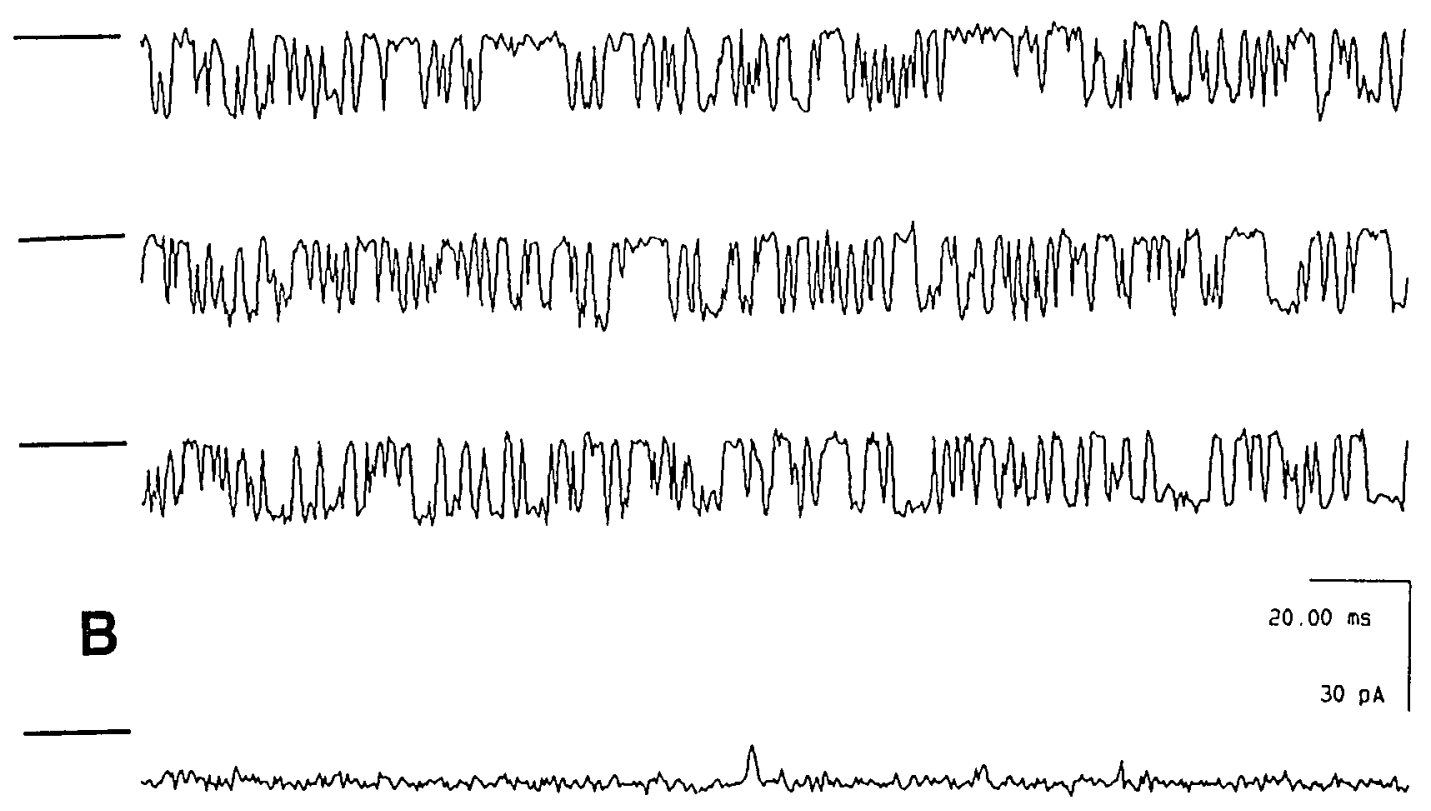

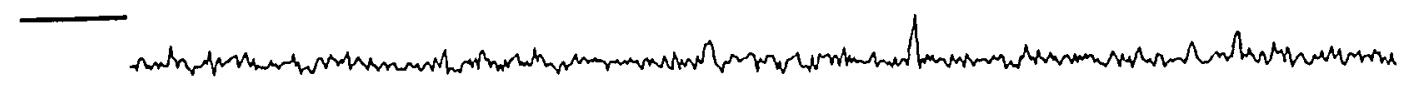

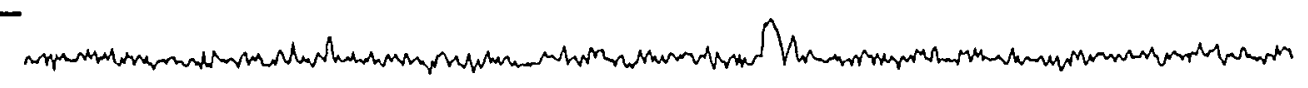

Figure 13. Ryanodine modification of the reconstituted $106 \mathrm{kDa}$ channel. Recordings were made in $250 \mathrm{mM}$ symmetrical $\mathrm{NaCl}$ solution. (A) Control trace, $\mathrm{P}_{0}=33 \%$ ( (B) After addition of 20 $\mathrm{nM}$ of ryanodine to both chambers. $\mathrm{HP}=-40 \mathrm{mV}$. $\gamma=420 \mathrm{ps}$. The bars indicate the closed state of the channel. $(n=4)$ 
THE PROPERTIES OF THE NATIVE SR $\mathrm{Ca}^{2+}$ RELEASE CHANNEL, THE 106 KDA CHANNEL, AND THE 400 KDA CHANNEL IN THE STANDARD ASYMMETRICAL $\mathrm{Ca}^{2+}$ SOLUTION

\begin{tabular}{||l|l|l|l||}
\hline \hline & $\begin{array}{l}\text { Native } \\
\text { channel }\end{array}$ & $\begin{array}{l}106 \mathrm{kDa} \\
\text { channel }\end{array}$ & $\begin{array}{l}400 \mathrm{kDa} \\
\text { channel }\end{array}$ \\
$\begin{array}{l}\text { Unitary conductance }(\mathrm{pS}) \\
\text { Reversal potential } \\
\text { Permeability ratio } \\
\left(\mathrm{P}_{\mathrm{Ca}} \backslash \mathrm{P}_{\text {Tris }}\right)\end{array}$ & $\begin{array}{l}100 \pm 4 \\
30\end{array}$ & $\begin{array}{l}107 \pm 13 \\
-27 \pm 7^{\mathrm{a}}\end{array}$ & $\begin{array}{l}110 \pm 10 \\
7.4\end{array}$ \\
\hline
\end{tabular}

"The sign convention is the opposite of that of the other entries shown.

on the basis of its selectivity for divalent cations, activation by adenine nucleotides and inhibition by ruthenium red. The SR $\mathrm{Ca}^{2+}$ channel was further distinguished from other SR channels by its high unit conductance and by the fact that it does not inactivate (Smith et al., 1986).

To establish the identity of the $106 \mathrm{kDa}$ protein, reconstitution experiments of the isolated protein were carried out with the identical solutions. The protein was found to conduct $\mathrm{Ca}^{2+}$ current, and the unit conductance was $107 \pm 13 \mathrm{ps}$. The current-voltage curve gave a reversal potential of $-27 \pm 7 \mathrm{mV}$. Using an expression derived from constant field electrodiffusion theory (Shamoo and Goldstein, 1977; Lee and Tsien, 1984; see appendix), which considers both divalent and monovalent cation permeability, the permeability ratio of $\mathrm{Ca}^{2+}$ to $\operatorname{Tris}^{+}\left(\mathrm{P}_{\mathrm{Ca}} / \mathrm{P}_{\text {Tris }}\right)$ was found to be $7.4 \pm 3.3$. The result demonstrates an agreement between the $106 \mathrm{kDa}$ channel and the native SR $\mathrm{Ca}^{2+}$ channel. The purified $400 \mathrm{kDa}$ 
protein also showed a similar conductance in the same solution (Smith et al., 1988).

The $106 \mathrm{kDa}$ channel demonstrates large unit conductance for monovalent cations in a solution containing low $\mathrm{Ca}^{2+}$ concentrations $\left(\left[\mathrm{Ca}^{2+}\right]<0.5 \mathrm{mM}\right)$ and a high $\mathrm{Na}^{+}$concentration $(250 \mathrm{mM})$. This may reflect the fact that the $\mathrm{SR} \mathrm{Ca}^{2+}$ release channel is a large pore, which has a much larger unit conductance than $\mathrm{Ca}^{2+}$ channels found in cell surface membranes. It would be difficult for such a large pore to differentiate between monovalent cations and $\mathrm{Ca}^{2+}$ ions. However, this high monovalent cation permeability should not pose problems for the channel under physiological conditions, since in the resting muscle cell, there is only a $\mathrm{Ca}^{2+}$ gradient across the SR membrane. No monovalent cation or anion gradient exists across the SR. Smith et al. (1988) showed a high monovalent cation permeability of the $400 \mathrm{kDa}$ protein. They also showed that in symmetrical $150 \mathrm{mM} \mathrm{KCl}$ solution, the addition of $5 \mathrm{mM} \mathrm{Ca}^{2+}$ to the luminal side resulted in a $60 \%$ reduction of single channel conductance. This implied that there is a competition between $\mathrm{K}^{+}$and $\mathrm{Ca}^{2+}$ for binding sites inside the $400 \mathrm{kDa}$ channel pore.

Both the $106 \mathrm{kDa}$ channel and the native $\mathrm{Ca}^{2+}$ channel show a voltage asymmetry in the channel open probability. This may reflect structural aspects of the release protein. Although the voltage sensitivity of the release channel is unlikely to play a role in EC coupling, it may, however, play a role in 
the release process. It was reported that the $400 \mathrm{kDa}$ protein has a similar voltage dependence at $\mathrm{pH} 7.15$, but not at $\mathrm{pH} 7.4$ (Ma et al., 1988).

The polycationic dye, ruthenium red is the most effective inhibitor of the $\mathrm{Ca}^{2+}$ release channel (Smith et al., 1985). At micromolar concentrations, it completely blocks the $\mathrm{Ca}^{2+}$ release channel. To establish the identity of the purified $106 \mathrm{kDa}$ protein, ruthenium red was also tested. Addition of 5$20 \mu M$ ruthenium red completely closed the $106 \mathrm{kDa}$ release channel. Furthermore, millimolar ATP activates the reconstituted $106 \mathrm{kDa}$ channel by increasing the channel open probability.

Ryanodine exerts its effect on the native release channel by increasing the open probability and locking the channel into a subconducting open state (Rosseau and Meissner, 1987). Ryanodine had a similar effect on the purified $106 \mathrm{kDa}$ release channel. Ryanodine (2-20 nM) changed the kinetics of the 106 kDa channel from a rapid fluctuating full conductance state to a open long-lifetime subconducting state. The effect could be reversed by rose bengal (see chapter $V$ ). There was no inactivation of the channel at ryanodine concentrations ranging from $10 \mathrm{nM}$ to $20 \mu \mathrm{M}$.

The purified protein was isolated in the presence of detergent and is in a different lipid environment than that of the native protein. It is not surprising that the properties of the purified $106 \mathrm{kDa}$ are slightly different than channels 
observed following fusion of $S R$ vesicles to bilayer. Unlike the native channel, the $106 \mathrm{kDa}$ protein is not sensitive to $\mathrm{Ca}^{2+}$ activation. Another very noticeable and frequently observed phenomenon upon the incorporation of the 106kDa protein is the appearance of multiple subconducting levels after an apparent single incorporation event. The characteristic unitary conductance of the native channel may result from simultaneous activation of several coupled sublevels present within one or more $106 \mathrm{kDa}$ protein. In the case of the purified $400 \mathrm{kDa}$ protein, half and quarter subconducting states were also reported (Lui et al., 1989). Combined with the electron microscopic study (Lai et al., 1988), it was concluded that the $400 \mathrm{kDa}$ channel is a tetramer composed of four $400 \mathrm{kDa}$ proteins.

An important issue raised by this work is the relationship between the $400 \mathrm{kDa}$ ryanodine receptor complex and the $106 \mathrm{kDa}$ sulfhydryl activated protein. Despite the lack of cross-reactivity between anti-106 antibodies and the 400 $\mathrm{kDa}$ protein, the $106 \mathrm{kDa}$ protein still may be a fragment of the $400 \mathrm{kDa}$ ryanodine receptor complex. The SR membrane also may have more than one $\mathrm{Ca}^{2+}$ release channel. Important questions remain regarding the role of the $106 \mathrm{kDa} \mathrm{Ca}^{2+}$ release channel protein. Efforts to clone and sequence the CDNA of the $106 \mathrm{kDa}$ protein should enable us to determine if the $106 \mathrm{kDa}$ protein is a distinctly different protein than the $400 \mathrm{kDa}$ foot protein. 
CHAPTER IV

SILVER MODIFICATION OF THE SR CALCIUM RELEASE CHANNEL

SUMMARY

In this chapter, the effect of $\mathrm{Ag}^{+}$on the activity of the reconstituted $\mathrm{SR} \mathrm{Ca}^{2+}$ release channel from skeletal muscle was examined. Experiments were performed by using the vesicle fusion technique in a 5:1 CsCl gradient. The results showed that $\mathrm{Ag}^{+}(0.2-1.0 \mu M)$ activated the $\mathrm{SR} \mathrm{Ca}^{2+}$ release channel. The activation by $\mathrm{Ag}^{+}$did not require the presence of $\mathrm{Ca}^{2+}$, $\mathrm{Mg}^{2+}$, or ATP. $\mathrm{Ag}^{+}$activated the channel activity by increasing the open probability $\mathrm{P}_{0}$. The $\mathrm{Ag}^{+}$activation was always followed (about 10-40 seconds after activation) by a spontaneous inactivation. The channel was still sensitive to ruthenium red after exposure to $\mathrm{Ag}^{+}$. These modifications of channel gating were also observed when $\mathrm{Ag}^{+}$is added to the trans chamber (the luminal face of the SR). At high $\mathrm{Ag}^{+}$ concentration $(>7 \mu M)$, large increases in current were observed which could only be partially inhibited by ruthenium red. $\mathrm{Ag}^{+}$also stimulated the channel activity of the reconstituted $106 \mathrm{kDa}$ protein. However, no spontaneous inactivation was observed with this purified protein. 


\section{INTRODUCTION}

The involvement of sulfhydryl groups in $\mathrm{Ca}^{2+}$ release from the SR was first reported in 1983 by Abramson et al. Various heavy metals cause rapid $\mathrm{Ca}^{2+}$ release from $\mathrm{SR}$ vesicles isolated from rabbit skeletal muscle. The addition of micromolar concentrations of heavy metal (e.g., $\mathrm{Hg}^{2+}, \mathrm{Ag}^{+}$, $\mathrm{Cu}^{2+}$, and $\mathrm{Cd}^{2+}$ ) to $\mathrm{SR}$ vesicles passively loaded with ${ }^{45} \mathrm{Ca}^{2+}$ or actively loaded in the presence of ATP, produces a sudden increase in $\mathrm{Ca}^{2+}$ permeability of the $\mathrm{SR}$ membranes and an almost complete efflux of releasable $\mathrm{Ca}^{2+}$ accumulated inside the SR vesicles. At such low concentrations, heavy metals do not inhibit the ATPase activity of the SR nor do they lyse the $\mathrm{SR}$. The potency of these heavy metals to induce $\mathrm{Ca}^{2+}$ release from $S R$ is similar to their relative binding affinities to sulfhydryl groups. This indicates the possible involvement of sulfhydryl groups in the $\mathrm{Ca}^{2+}$ release mechanism.

To determine whether heavy metal-induced $\mathrm{Ca}^{2+}$ release is a specific interaction with the $\mathrm{Ca}^{2+}$ release protein or a nonspecific interaction with other components of the SR membrane, the action of $\mathrm{Ag}^{+}$, as a sulfhydryl reagent, on isolated $S R$ vesicles was investigated in detail (Salama and Abramson, 1984). Known inhibitors of $\mathrm{Ca}^{2+}$ release such as ruthenium red (micromolar), tetracaine (submillimolar), procaine (millimolar) and $\mathrm{Mg}^{2+}(>1 \mathrm{mM})$ were shown to inhibit $\mathrm{Ag}^{+}$induced $\mathrm{Ca}^{2+}$ release. Adenine-containing nucleotides, which had been shown to stimulate $\mathrm{Ca}^{2+}$ release in a $\mathrm{Ca}^{2+}$ 
dependent manner, were also found to stimulate $\mathrm{Ag}^{+}$induced $\mathrm{Ca}^{2+}$ release. The rates of release were substantially greater (5-6 times) in SR vesicles derived from the terminal cisternae region (HSR) than in those derived from the longitudinal region (LSR). The maximum rate of efflux was observed under physiological conditions, at $\mathrm{pH} 7.0$, and at $1 \mathrm{mM} \mathrm{Mg}^{2+}$. $\mathrm{Ag}^{+}$ also caused the rapid dissociation of $\left[{ }^{3} \mathrm{H}\right]$ ryanodine from isolated SR vesicles (Pessah et al., 1987). The data strongly suggested that $\mathrm{Ag}^{+}$acts at the $\mathrm{Ca}^{2+}$ release protein which appears to be the physiological site for $\mathrm{Ca}^{2+}$ release in $\mathrm{SR}$. As shown in Chapter III, these studies led to the investigation the effect of sulfhydryl oxidation on the SR $\mathrm{Ca}^{2+}$ release channel and finally the isolation of the $106 \mathrm{kDa}$ $\mathrm{Ca}^{2+}$ release channel.

Since $\mathrm{Ag}^{+}$is able to induce rapid $\mathrm{Ca}^{2+}$ release, it is a useful probe of structure and function of the $\mathrm{Ca}^{2+}$ release channel. Dr. Cronin did more detailed efflux measurements and showed that the rate of $\mathrm{Ag}^{+}$induced $\mathrm{Ca}^{2+}$ release was multiphasic (Figure 14). At low $\left[\mathrm{Ag}^{+}\right]\left(\left[\mathrm{Ag}^{+}\right]<10 \mu M\right)$, rapid $\mathrm{Ca}^{2+}$ release was completely inhibited by ruthenium red. At slightly higher $\left[\mathrm{Ag}^{+}\right]\left(10 \mu \mathrm{M}<\left[\mathrm{Ag}^{+}\right]<20 \mu \mathrm{M}\right), \mathrm{Ag}^{+}$induced $\mathrm{Ca}^{2+}$ release rates were greatly diminished. While at high $\left[\mathrm{Ag}^{+}\right]$ $\left(\left[\mathrm{Ag}^{+}\right]>20 \mu M\right), \mathrm{Ca}^{2+}$ release rates were further stimulated, but were only partially inhibited by ruthenium red.

To understand $\mathrm{Ag}^{+}$activation at the single channel level, $\mathrm{Ag}^{+}$regulation of the gating of the $\mathrm{Ca}^{2+}$ release channel was 


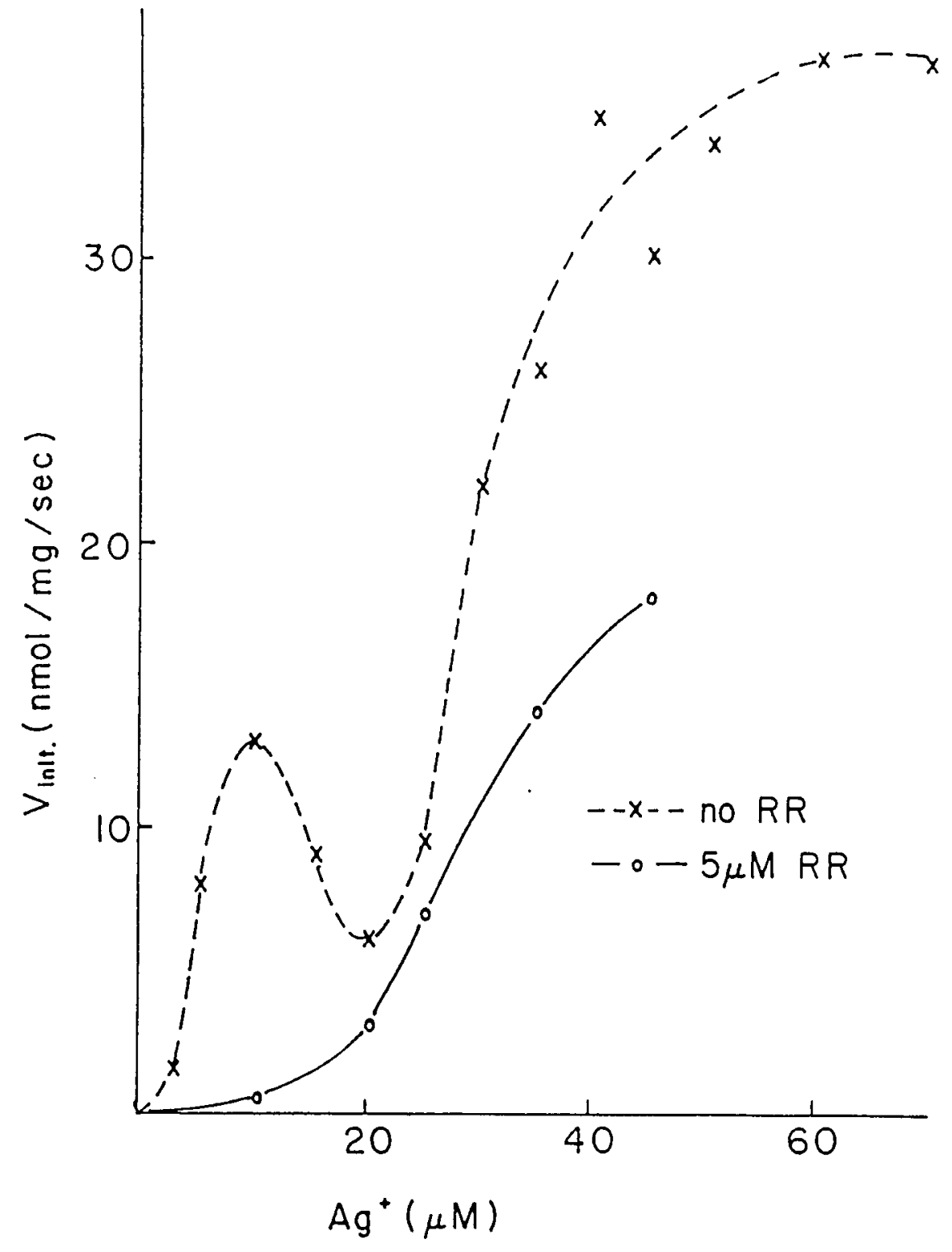

Figure 14. $\mathrm{Ag}^{+}$dependence of $\mathrm{Ca}^{2+}$ release rate of isolated $S R$ vesicles. Efflux measurements were carried out in $100 \mathrm{mM} \mathrm{KNO}, 20 \mathrm{mM}$ HEPES, $5 \mathrm{mM}$ $\mathrm{Mg}\left(\mathrm{NO}_{3}\right)_{2}$, $\mathrm{pH} 7.0$. The $\mathrm{Ca}^{2+}$ was taken up by $\mathrm{SR}$ vesicles actively in the presence of $0.5 \mathrm{mM} \mathrm{Mg}^{2+}$ ATP. After uptake was complete, either $\mathrm{AgNO}_{3}(\mathrm{x})$ or $5 \mu M$ ruthenium red followed by $\mathrm{AgNO}_{3}$ (0) was added to initiate $\mathrm{Ca}^{2+}$ release. Extravesicular $\mathrm{Ca}^{2+}$ concentration was measured by a $\mathrm{Ca}^{2+}$ electrode. Estimation of the error for each point is $\pm 10 \%$. 
investigated with the reconstitution technique. Reconstitution of the native channels was performed in asymmetric 5:1 CSCl gradient with fused $S R$ vesicles, and the purified $106 \mathrm{kDa}$ channel was studied in a symmetric $\mathrm{NaCl}$ solution.

RESULTS

Single channel recording technique was used to study the interaction of $\mathrm{Ag}^{+}$and the $\mathrm{SR} \mathrm{Ca}^{2+}$ release channel following fusion of $S R$ vesicles to planar lipid bilayer membranes (phosphatidylethanolamine / phosphatidyl serine $=5: 3$ ). SR vesicles were added to the cis chamber of an asymmetric 5:1 $\mathrm{Cscl}$ gradient at a final concentration of $2-10 \mu \mathrm{g} / \mathrm{ml}$. The cis chamber contained $500 \mathrm{mM} \mathrm{CsCl}, 10 \mathrm{mM}$ Tris-HEPES, $0.1 \mathrm{mM}$ $\mathrm{CaCl}_{2}, 0.1 \mathrm{mM} \mathrm{EGTA}, \mathrm{pH} 7.2$; the trans chamber contained $100 \mathrm{mM}$ CsCl, $10 \mathrm{mM}$ Tris-HEPES, $\mathrm{pH}$ 7.2). Vesicle fusion was facilitated by addition of $0.35 \mathrm{mM} \mathrm{CaCl}_{2}$ to the cis chamber. A two fold excess of EGTA was added immediately after incorporation of a vesicle to the bilayer, and the solution in the cis chamber was perfused to prevent further fusion events. Figure 15 shows a current-voltage curve of a typical native $\mathrm{SR} \mathrm{Ca}^{2+}$ release channel in a $500 \mathrm{mM}$ to $100 \mathrm{mM} \mathrm{CsCl}$ gradient. It reveals a single channel conductance of $511 \pm 24$ ps and a reversal potential of $-32 \pm 10 \mathrm{mV}$, from which the permeability ratio $\left(\mathrm{P}_{\mathrm{Cs}} / \mathrm{P}_{\mathrm{Cl}}\right)$ is calculated as 11 . As expected, the channels incorporated into bilayers by fusion of $\mathrm{SR}$ 


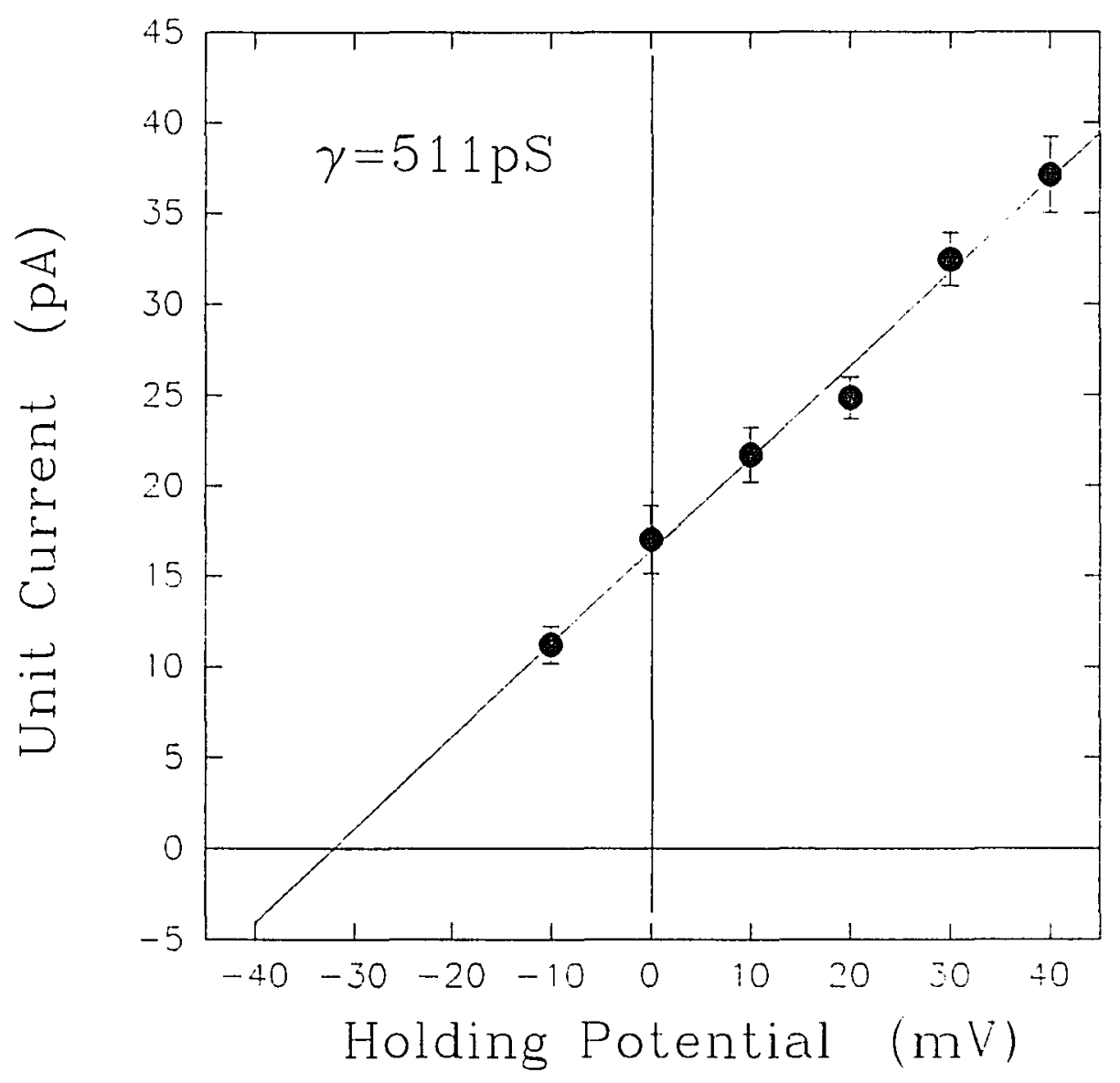

Figure 15. The current-voltage curve of a typical native SR $\mathrm{Ca}^{2+}$ channel in a $500 \mathrm{mM}$ to $100 \mathrm{mM} \mathrm{CsCl}$ gradient. The data represents three independent experiments. The best fit gives single channel conductance of $511 \pm 24 \mathrm{ps}$, and reversal potential of $-32 \pm 10 \mathrm{mV}$ which results in a permeability ratio of $\mathrm{Cs}^{+}$to $\mathrm{Cl}^{*}$ of 11 . 
vesicles in a CsCl gradient were activated by $\mathrm{Ca}^{2+}$ (Figure 19b), ATP (Figure 17b), and inhibited by $\mathrm{Mg}^{2+}$ (Figure 16b). This method of reconstituting the native $\mathrm{SR} \mathrm{Ca}^{2+}$ release channel in 5:1 CsCl gradient proved to be efficient.

Once active channels are incorporated into bilayers routinely, subsequent investigation of channel behavior can be carried out. Figure $16 \mathrm{a}$ shows a typical current trace of $\mathrm{Cs}^{+}$ transport through $\mathrm{SR} \mathrm{Ca}^{2+}$ release channel in the presence of $5 \mu M$ cis (the myoplasmic face of the SR) $\mathrm{CaCl}_{2}$. The addition of $1 \mathrm{mM} \mathrm{MgCl} 2$ to the cis chamber (Figure 16b) decreased the open probability of the channel $\left(P_{0}\right)$, and the subsequent addition of $1 \mathrm{mM}$ of ATP stimulated the channel activity (Figure 16C). This is the optimal condition for $\mathrm{Ag}^{+}$to induce rapid $\mathrm{Ca}^{2+}$ release from isolated $\mathrm{SR}$ vesicles. Addition of $0.7 \mu \mathrm{M} \mathrm{Ag}{ }^{+}$to the cis chamber of the bilayer increased channel activity (Figure 16d). $\mathrm{Ag}^{+}$affects the $\mathrm{Ca}^{2+}$ release channel of SR membrane by increasing its open probability without changing the single channel conductance. It is also concluded that the $\mathrm{Cl}^{-}$conductance was not sensitive to $\mathrm{Ag}^{+}$ based on the fact that the background current is not affected by $\mathrm{Ag}^{+}$(Figure 16). At submicromolar concentration, $\mathrm{Ag}^{+}$ increased the permeability of $S R$ membrane by directly activating the $\mathrm{Ca}^{2+}$ release channel. One distinct feature of $\mathrm{Ag}^{+}$modification was that the activation was transient (10-40 seconds). As demonstrated in Figure 16e, the $\mathrm{Ag}^{+}$activation of the channel was followed by a spontaneous inactivation of 


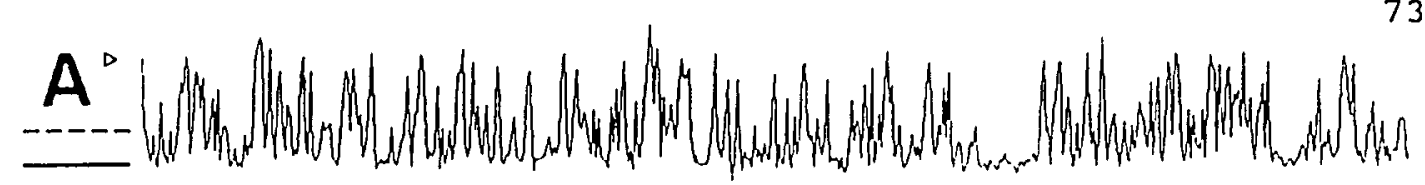

$B^{\circ}$

C. C.
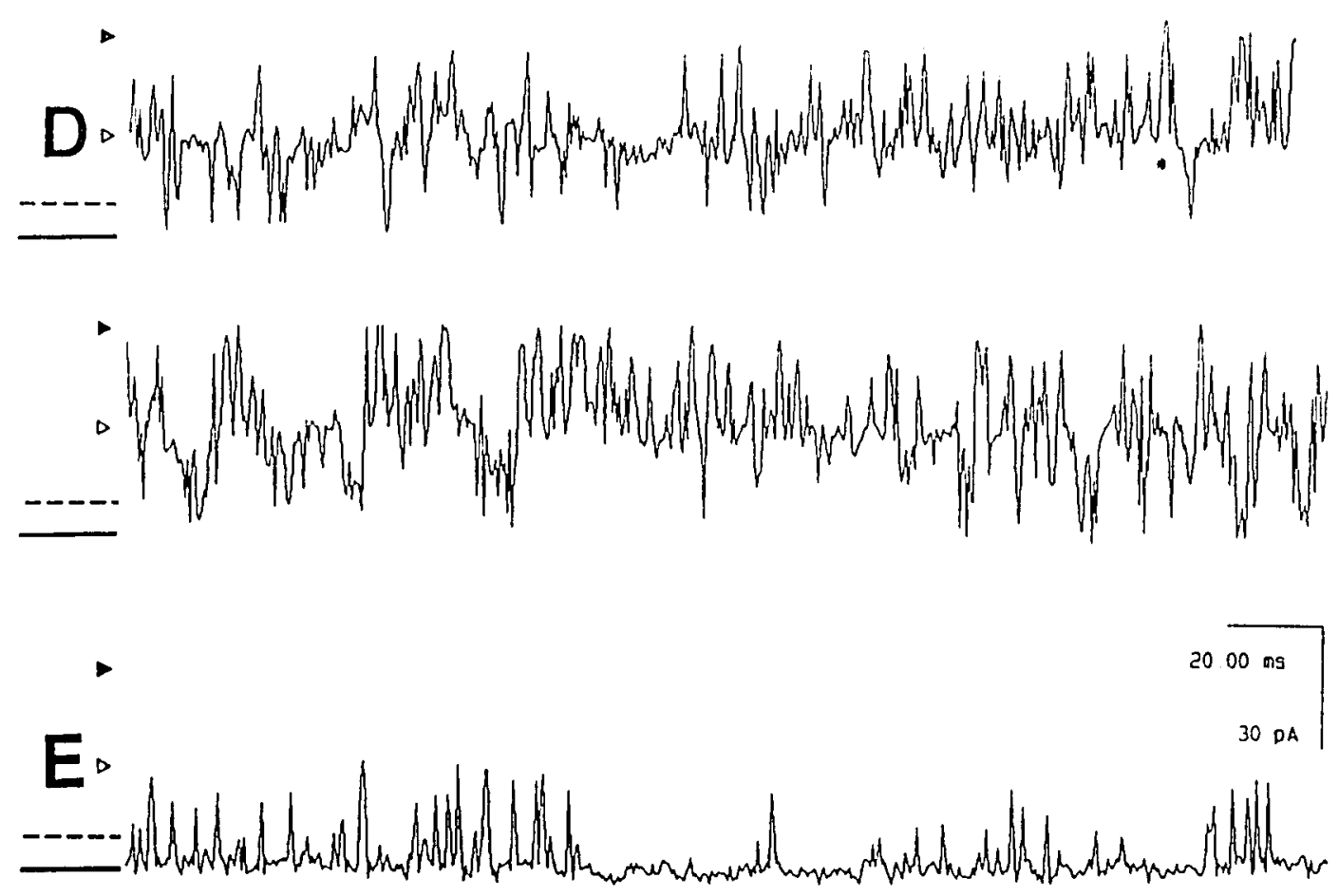

Figure 16. $\mathrm{Ag}^{+}$modification of a native $\mathrm{SR} \mathrm{Ca}^{2+}$ release channel under physiological conditions. single channel current was recorded in 5:1 CsCl gradient after fusion of a $S R$ vesicle with two channels to a bilayer. (A) $\left[\mathrm{Ca}^{2+}\right]_{\text {cis }}=5 \mu M$. (B) After addition of $1.0 \mathrm{mM}$ of $\mathrm{Mg}^{2+}$ to the cis chamber. (C) $1.0 \mathrm{mM}$ of ATP was added to the cis chamber. (D) $0.7 \mu M$ of $\mathrm{Ag}^{+}$was added to the cis side of the channel. (E) 20 seconds after $\mathrm{Ag}^{+}$ activation. $\mathrm{HP}=+20 \mathrm{mV}$. The dash lines indicate zero. The bars indicate the closed state of the channel. The open triangles indicate the current level of one open channel and the filled triangles indicate the current level when two channels open at the same time. $(n=2)$ 
the channel. This inactivation phase of the $\mathrm{Ag}^{+}$effect was observed in all the experiments, and was independent of the SR preparation and experimental conditions (as shown later).

The $\mathrm{Ag}^{+}$modification of the $\mathrm{SR} \mathrm{Ca}^{2+}$ release channel also occurred in the absence of $\mathrm{MgCl}_{2}$. The channel activity (Figure $17 \mathrm{a},\left[\mathrm{Ca}^{2+}\right]_{\mathrm{cis}}=5 \mu M$ ) was increased by the addition of $1 \mathrm{mM}$ ATP to the cis chamber (Figure 17b). The channel activity was increased further by the addition of $0.7 \mu M \mathrm{Ag}^{+}$to the cis chamber (Figure 17c). Spontaneous inactivation was evident following the $\mathrm{Ag}^{+}$activation. The long time scale is chosen to show the inactivation phase.

$\mathrm{Ag}^{+}$activation of the $\mathrm{SR} \mathrm{Ca}^{2+}$ release channel was observed at low myoplasmic $\mathrm{Ca}^{2+}$ concentration. Figure $18 \mathrm{a}$ shows a current trace after vesicle-bilayer fusion in the presence of $160 \mathrm{nM}$ free $\mathrm{Ca}^{2+}$. The channel was opened by the addition of $0.5 \mu M \mathrm{Ag}^{+}$to cis chamber (Figure 18b), and then inactivated spontaneously (Figure 18c).

The SR $\mathrm{Ca}^{2+}$ release channel is still sensitive to ruthenium red after the interaction with $\mathrm{Ag}^{+}$. Figure 19 shows a native $\mathrm{SR} \mathrm{Ca}^{2+}$ release channel in 5:1 $\mathrm{CsCl}$ gradient with $5 \mu M$ free $\mathrm{Ca}^{2+}$ in the cis chamber. It was activated by $50 \mu M$ myoplasmic $\mathrm{Ca}^{2+}$ (Figure 19b), inhibited by $1 \mathrm{mM} \mathrm{Mg}^{2+}$ (Figure 19c), and activated by $0.4 \mu \mathrm{M} \mathrm{Ag}^{+}$added to the cis chamber (Figure 19d). After the spontaneous deactivation (Figure 19e), $6 \mu M$ ruthenium red added to the cis chamber completely inhibited the channel. Following a similar 

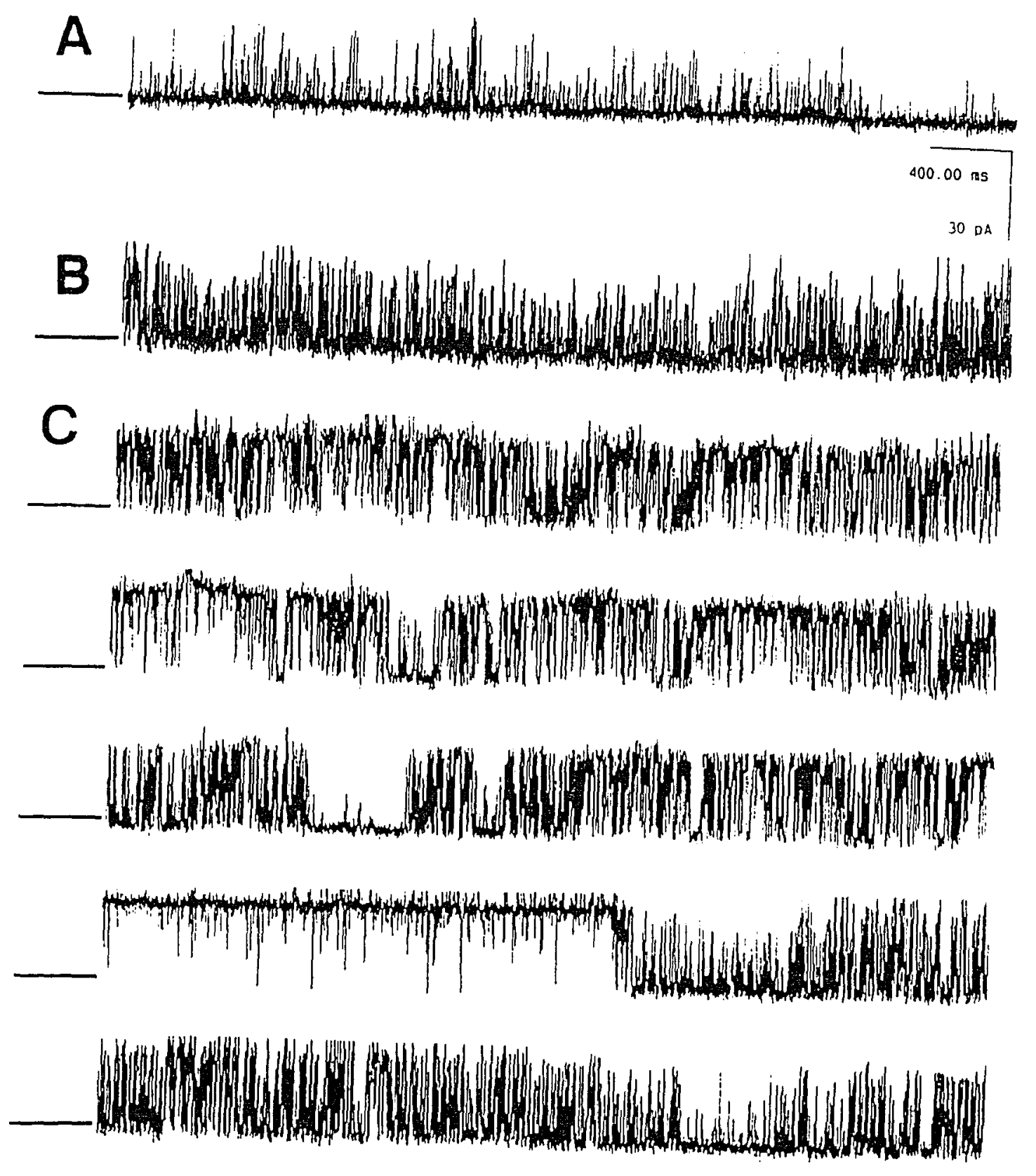

Figure 17. $\mathrm{Ag}^{+}$modification of the $\mathrm{SR} \mathrm{Ca}{ }^{2+}$ channel in the absence of $\mathrm{MgCl}_{2}$. (A) $\left[\mathrm{Ca}^{2+}\right]_{\text {cis }}=5 \mu M$ (0.1 $\mathrm{mM}$ added to the EGTA), $\mathrm{P}_{0}=2 \%$. (B) $1.0 \mathrm{mM}$ of ATP was $\mathrm{Ag}^{+}$was added inactivation). Activation chamber, $P_{0}=74 \%$ (before Long time scale is used lasted about 20 seconds. inactivation. HP $=+20$ used in order to show the closed state of the channei. The bars indicate the 
A

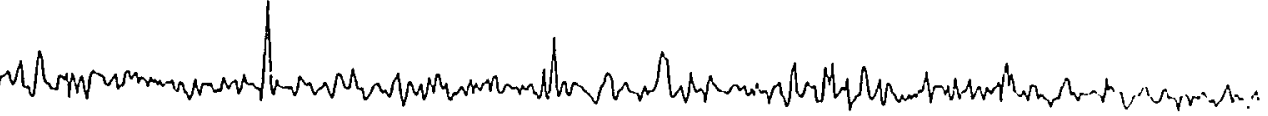

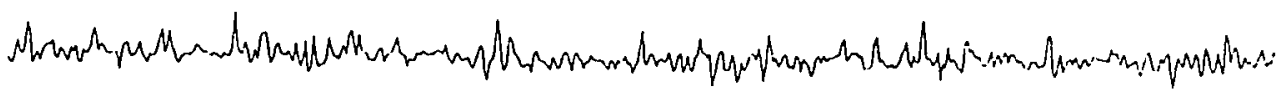

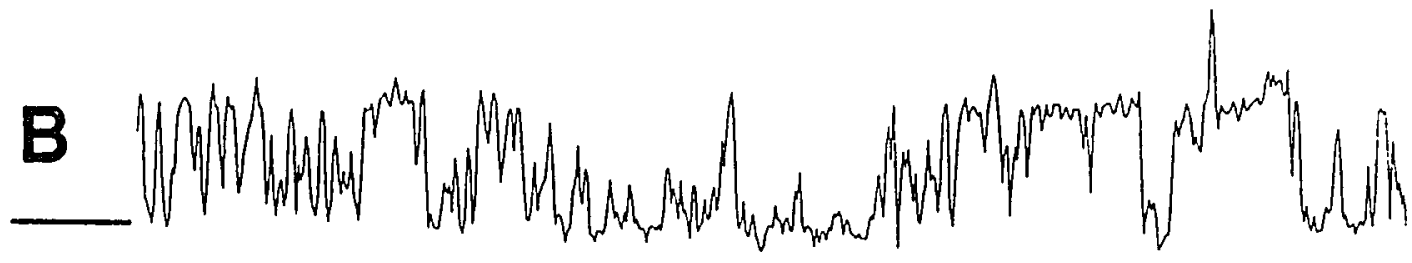

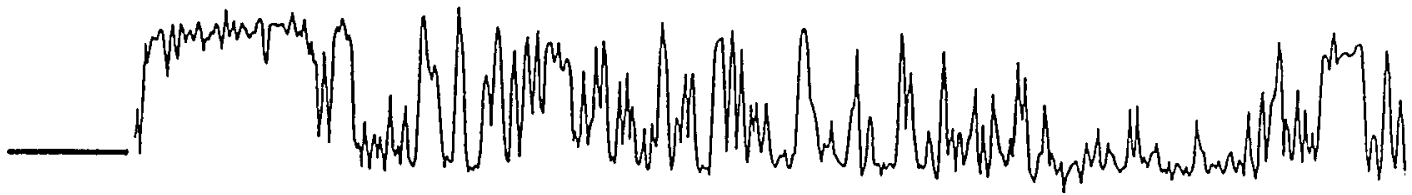

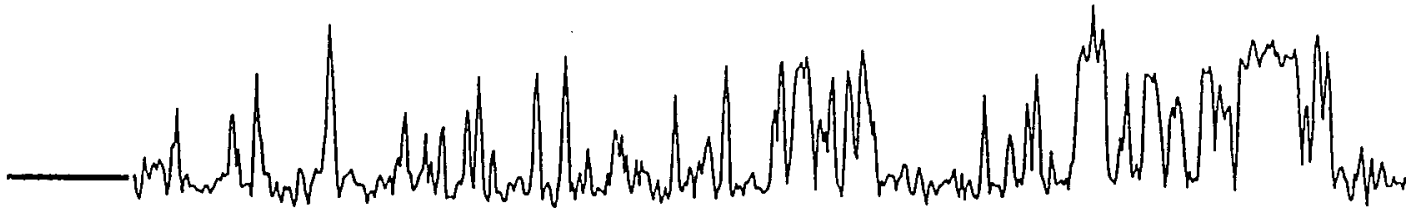

$20.00 \mathrm{~ms}$

$30 \mathrm{DA}$

C

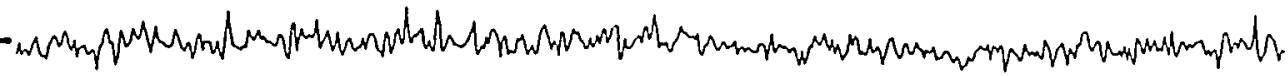

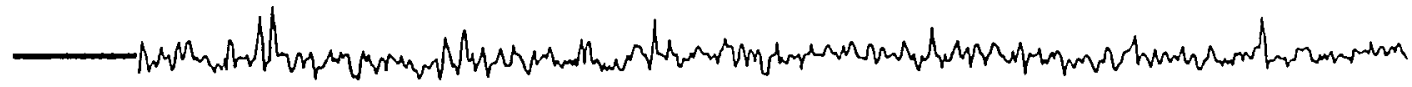

Fiqure 18. $\mathrm{Ag}^{+}$modification of $\mathrm{SR} \mathrm{Ca}^{2+}$ release channel at a low $\mathrm{Ca}^{2+}$ concentration. Following fusion of a SR vesicle to the bilayer with $0.35 \mathrm{mM}$ cis $\mathrm{CaCl}_{2}$, a two fold excess of EGTA was added to the cis chamber to prevent further fusion events and to achieve low $\mathrm{Ca}^{2+}$ concentration. (A) $\left[\mathrm{Ca}^{2+}\right]_{\mathrm{cis}}=$ $160 \mathrm{nM}(0.35 \mathrm{mM} \mathrm{CaCl}, 0.70 \mathrm{mM} \mathrm{EGTA}), \mathrm{P}_{0}=1 \%$. (B) After addition of $0.5 \mu \mathrm{M} \mathrm{Ag}^{+}$to the cis chamber, $\mathrm{P}_{0}$ $=34 \%$ (C) Spontaneous inactivation followed the $\mathrm{Ag}^{+}$ activation (10 seconds), $P_{0}=1 \%$. The bars indicate the closed state of the channel. $\mathrm{HP}=+30 \mathrm{mV} . \quad(\mathrm{n}=4)$ 


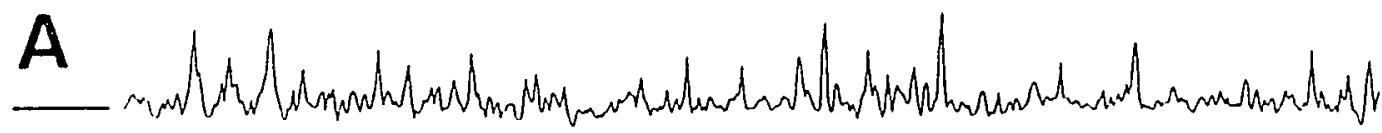

B

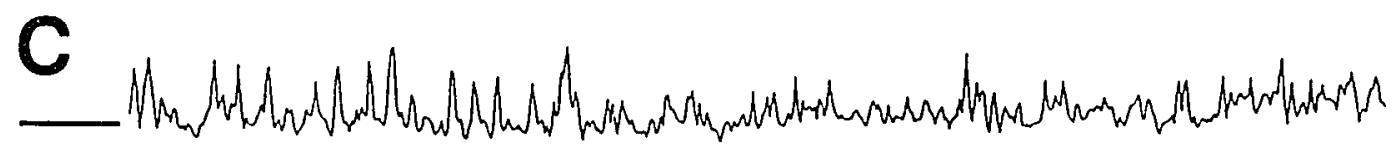

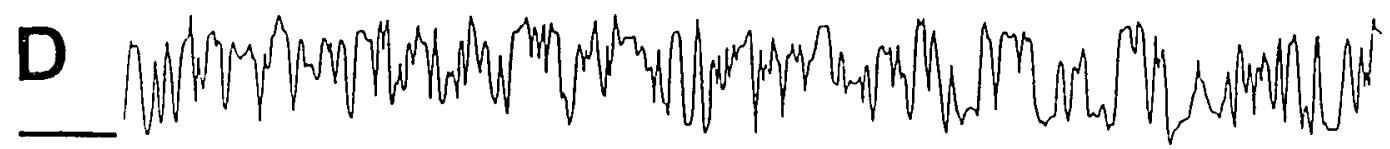

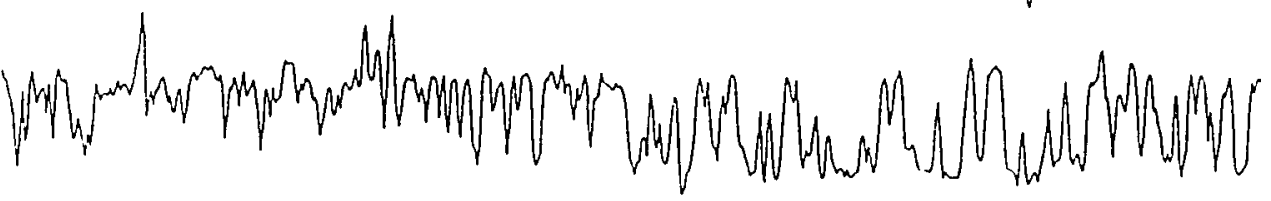

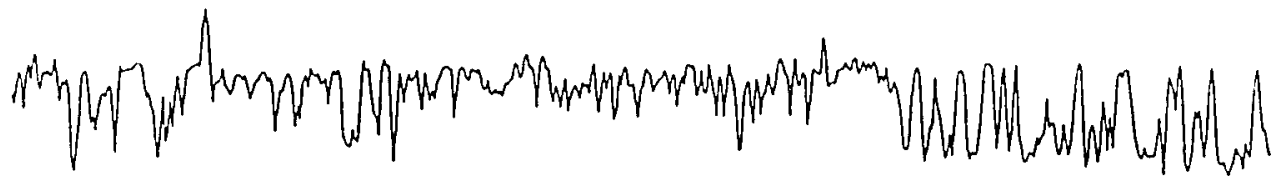

$2000 \mathrm{~ms}$

$30 \mathrm{DA}$

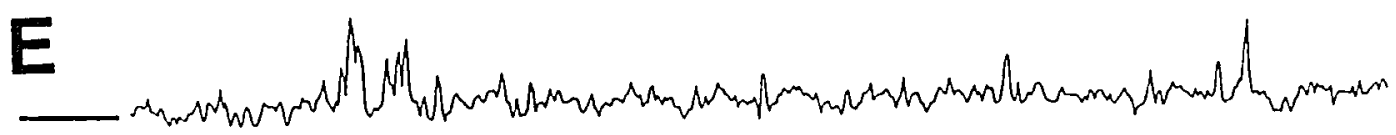

$\mathbf{F}$

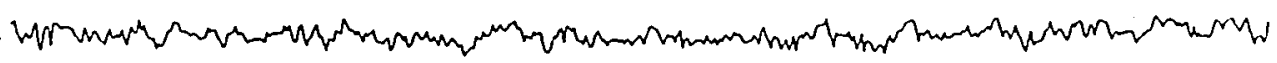

Figure 19. Ruthenium red inhibition of the $\mathrm{SR} \mathrm{Ca}^{2+}$ channel after $\mathrm{Ag}^{+}$modification. (A) $\left[\mathrm{Ca}^{2+}\right]_{\text {cis }}$ $=5 \mu M\left(0.1 \mathrm{mM} \mathrm{CaCl}, 0.1 \mathrm{mM}\right.$ EGTA), $\mathrm{P}_{0}=11 \%$ (B) After the addition of $50 \mu M$ of $\mathrm{Ca}^{2+}$ to the cis chamber, $\mathrm{P}_{0}=23 \%$. (C) $1.0 \mathrm{mM}$ of $\mathrm{MgCl}_{2}$ was added to the cis chamber, $\mathrm{P}_{0}=9 \%$. $\left(\right.$ (D) $0.4 \mu \mathrm{M}$ of $\mathrm{Ag}^{+}$was added to the cis chamber, $P_{0}=78 \%$. (E) Spontaneous inactivation followed the $\mathrm{Ag}^{+}$activation (40 seconds), $\mathrm{P}_{0}=6 \%$. (F) After cis addition of $6 \mu \mathrm{M}$ ruthenium red, $\mathrm{P}_{0}=0 \%$. The bars indicate the closed state of the channel. $\mathrm{HP}=+20 \mathrm{mV} .(\mathrm{n}=4)$ 
protocol, except adding the $0.4 \mu M \mathrm{Ag}^{+}$to the trans chamber, Figure 20 shows that the $\mathrm{Ag}^{+}$is equally effective from luminal face of the $S R$.

As demonstrated in Figure 21, high concentration of $\mathrm{Ag}^{+}$ ( $7 \mu M$ ) causes a large change of membrane permeability. The mean current over a given period of time is partially inhibited by ruthenium red.

The action of $\mathrm{Ag}^{+}$on the purified $106 \mathrm{kDa}$ protein was also investigated. Purified $106 \mathrm{kDa}$ protein was added to both sides of a bilayer in a symmetric $\mathrm{NaCl}$ buffer $\left(250 \mathrm{mM} \text {, [ } \mathrm{Ca}^{2+}\right]_{\text {free }}$ $=100 \mu \mathrm{M}$ ) at a final concentration of 50-500 $\mathrm{ng} / \mathrm{ml}$. As shown in Figure 22, the activity of the reconstituted $106 \mathrm{kDa}$ protein is activated by addition of $0.6 \mu M \mathrm{Ag}^{+}$to both side of bilayer (Figure 22b). No spontaneous inactivation was observed.

\section{DISCUSSION}

Heavy metals such as $\mathrm{Ag}^{+}$and $\mathrm{Hg}^{2+}$ have been reported to increase the $\mathrm{Ca}^{2+}$ permeability of isolated $\mathrm{SR}$ vesicles. The increase of $\mathrm{Ca}^{2+}$ permeability was suggested to be caused by the inhibition of the SR $\mathrm{Ca}^{2+}$ pump molecules (Shamoo and MacLennan, 1975; Gould et al., 1987). However, other studies presented evidence that heavy metals inducing $\mathrm{Ca}^{2+}$ release by acting on the SR $\mathrm{Ca}^{2+}$ release pathway (Salama and Abramson, 1984; Palade, 1987; and Tatsumi et al., 1988). This issue can only be resolved indirectly with isolated vesicle system. The 


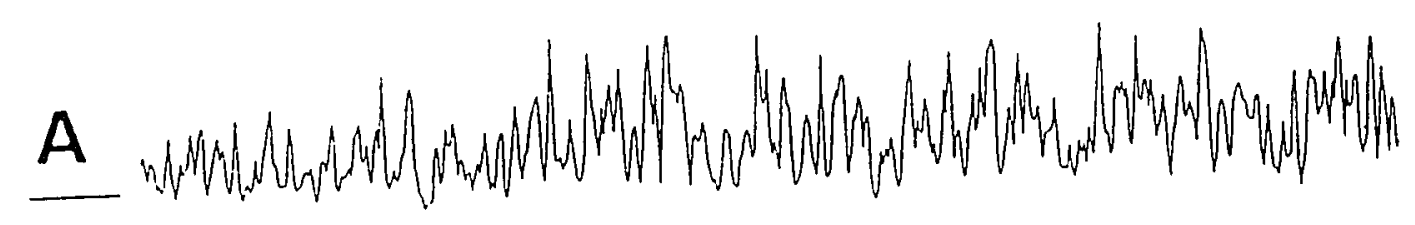

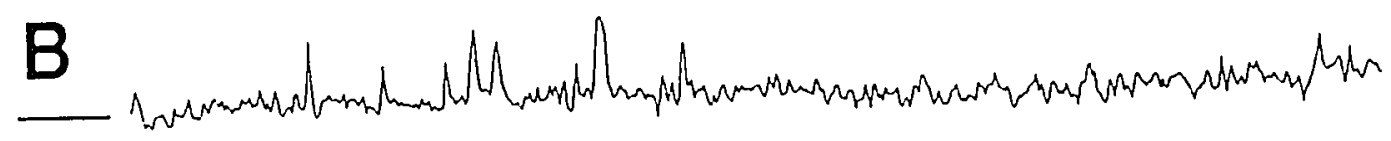

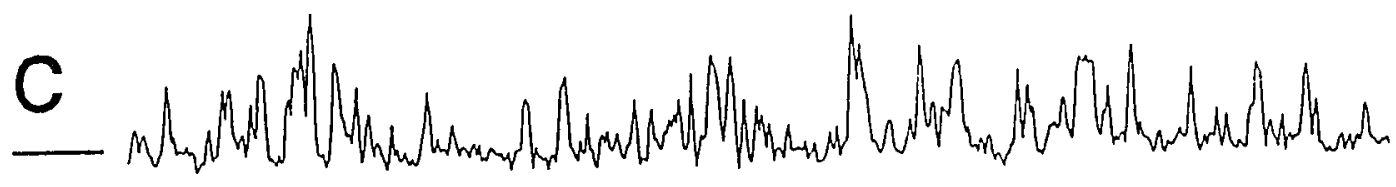

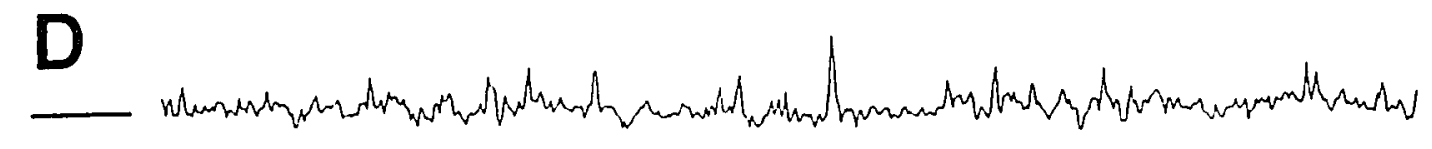

E

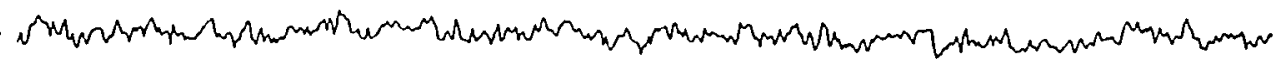

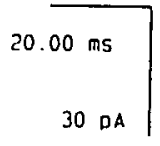

Figure 20. $\mathrm{Ag}^{+}$modification of the $\mathrm{Ca}^{2+}$ channel from the luminal face of the $S R$. (A) $\left[\mathrm{Ca}^{2+}\right]_{\mathrm{cis}}=$ $50 \mu M, \mathrm{P}_{0}=45 \%$. (B) $1.0 \mathrm{mM}$ of $\mathrm{MgCl}_{2}$ was added to the cis chamber, $\mathrm{P}_{0}=1 \%$. (C) $0.4 \mu M$ of $\mathrm{Ag}^{+}$was added to the trans chamber, $\mathrm{P}_{0}=23 \%$. (D) Spontaneous inactivation followed the $\mathrm{Ag}^{+}$activation (10 seconds), $\mathrm{P}_{0}=3 \%$. (E) After cis addition of $6 \mu M$ ruthenium red, $\mathrm{P}_{0}=0 \%$. The bars indicate the closed state of the channel. $\mathrm{HP}=+25 \mathrm{mV} . \quad(\mathrm{n}=2)$ 


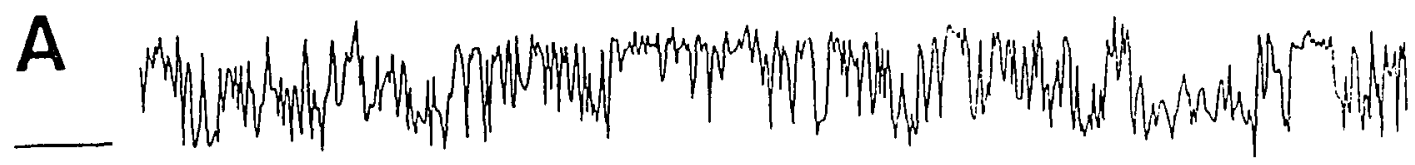

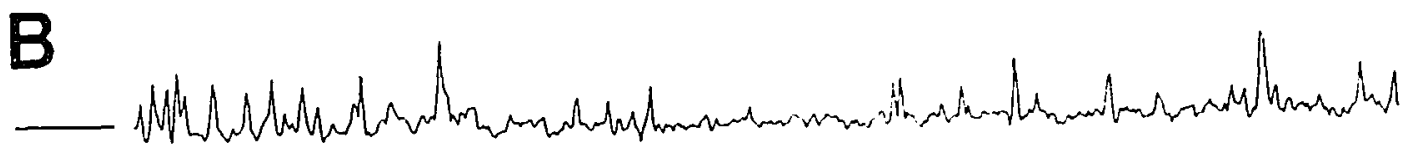

C

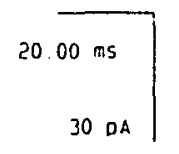

D

$D$

\section{,}
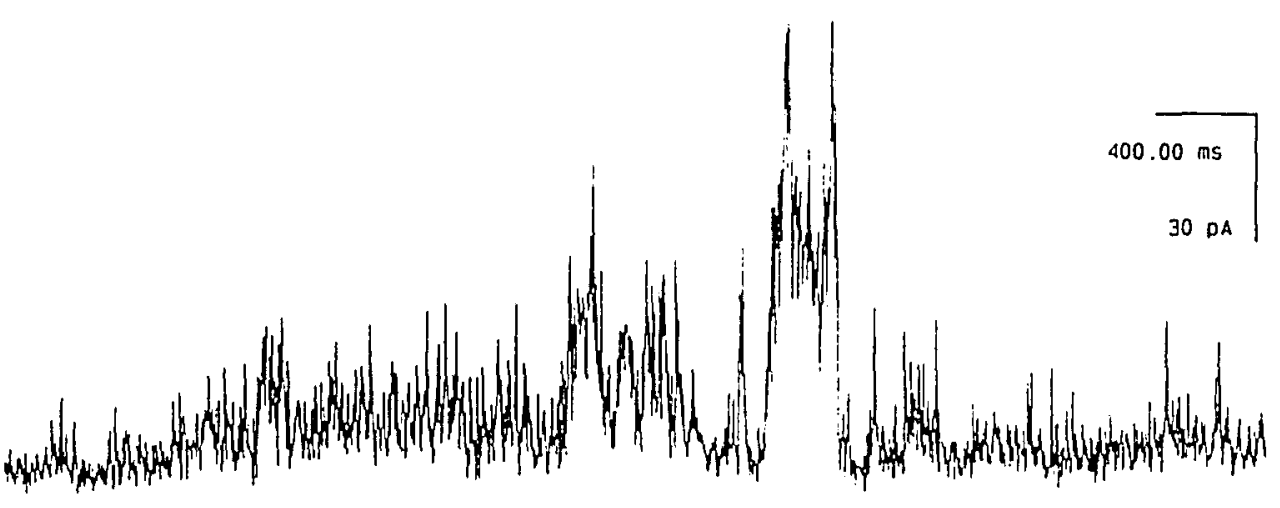

E

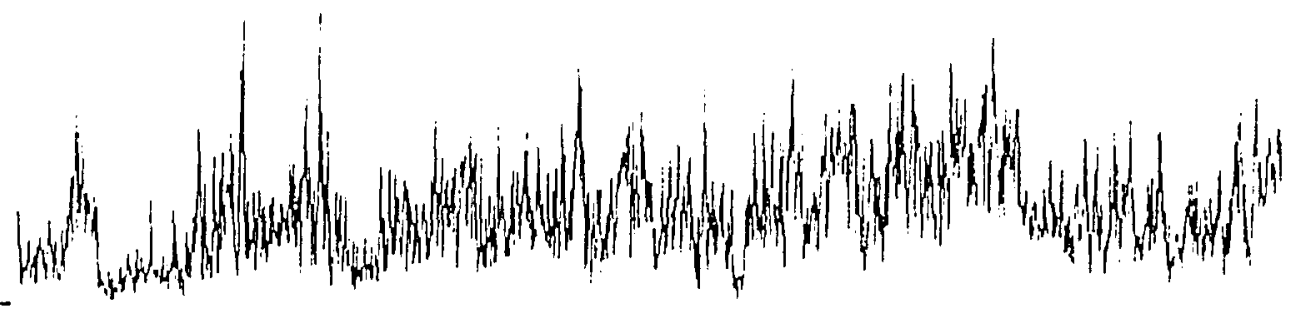

Figure 21. The effect of high concentration of $\mathrm{Ag}^{+}$ on the SR $\mathrm{Ca}^{2+}$ channel. (A) $\left[\mathrm{Ca}^{2+}\right]_{\text {cis }}=50 \mu \mathrm{M}, \mathrm{P}_{0}$ $=82 \%$ (B) $1.0 \mathrm{mM}$ of $\mathrm{MgCl}_{2}$ was added to the $\mathrm{Cis}$ chamber, $\mathrm{P}_{0}=4 \%$. (C) $0.6 \mu \mathrm{M}$ of $\mathrm{Ag}^{+}$was added to the cis chamber, $P_{0}=23 \%$ (D) Subsequently $7 \mu M$ $\mathrm{Ag}^{+}$was added to the cis chamber. (E) After cis addition of $6 \mu M$ ruthenium red. The bars indicate the closed state of the channel. $\mathrm{HP}=+20 \mathrm{mV}$. $(n=5)$ 
A

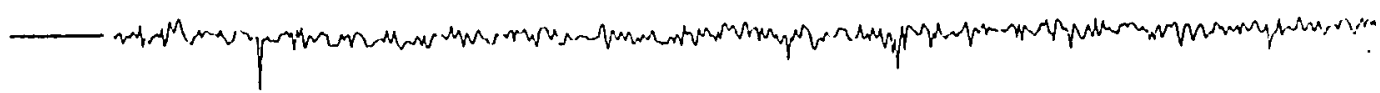

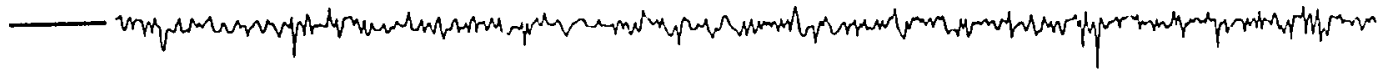

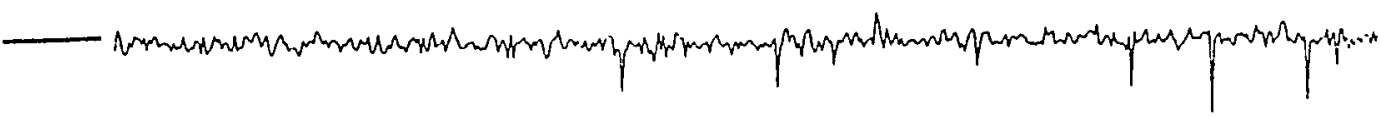

$90.00 \mathrm{~ms}$

B

$10 \mathrm{DA}$

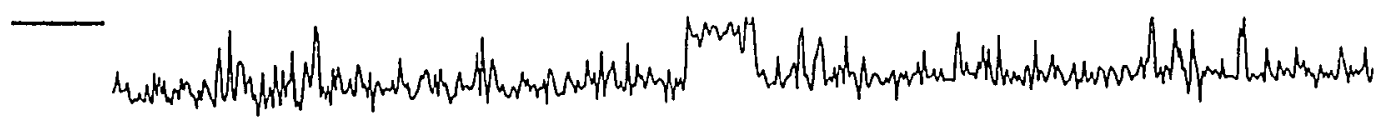

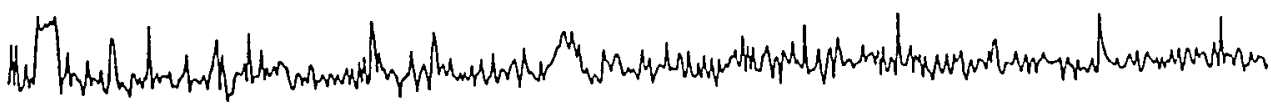

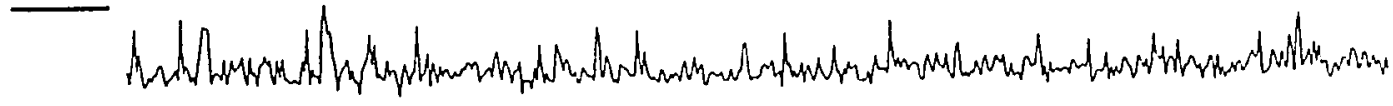

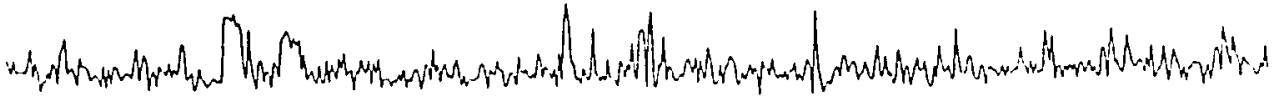

Figure 22. The effect of $\mathrm{Ag}^{+}$on the purified 106

$\mathrm{kDa} \mathrm{SR} \mathrm{Ca}^{2+}$ release channel. Purified $106 \mathrm{kDa}$

protein was incorporated to a bilayer in symmetric $250 \mathrm{mM} \mathrm{NaCl}$ buffer. (A) current fluctuation in the presence of $1 \mu M \quad \mathrm{Ca}^{2+}, \mathrm{P}_{0}=1 \%$ (B) After the addition of $0.6 \mu \mathrm{M} \mathrm{\textrm {Ag } ^ { + }}$ to both sides of the channel, $\mathrm{P}_{0}=88 \%$. $\mathrm{HP}=-20 \mathrm{mV} .(\mathrm{n}=3)$ 
general approach is to examine the distribution of $\mathrm{Ca}^{2+}$ release activity among different $S R$ fraction (i.e. LSR and HSR), and to assess the ability of known $\mathrm{SR} \mathrm{Ca}^{2+}$ channel modulators to modulate the release. Evidences strongly imply that $\mathrm{Ag}^{+}$induces $\mathrm{Ca}^{2+}$ release by interacting directly with the $\mathrm{Ca}^{2+}$ release channel of $\mathrm{SR}$.

The development of the single channel recording technique provides an excellent method to directly study drug action on channel activities. Using the CsCl gradient procedure described in Chapter II, active $\mathrm{Ca}^{2+}$ channels can be observed and characterized easily. The channels are activated by submillimolar $\mathrm{Ca}^{2+}$ millimolar ATP, and inhibited by millimolar $\mathrm{Mg}^{2+}$, and micromolar ruthenium red. The currentvoltage curve reveals a single channel conductance of $511 \pm 24$ $\mathrm{ps}$ and a reversal potential of $-32 \mathrm{mV}\left(\mathrm{P}_{\mathrm{C}_{3}} / \mathrm{P}_{\mathrm{Cl}}=11\right)$. The effect of $\mathrm{Ag}^{+}$on the $\mathrm{SR} \mathrm{Ca}^{2+}$ release channel in the lipid bilayer was investigated. The results of this chapter clearly demonstrate the direct modulation of the $\mathrm{SR} \mathrm{Ca}^{2+}$ release channel by $\mathrm{Ag}^{+}$and explain the $\mathrm{SR} \mathrm{Ca}^{2+}$ permeability increase observed in the SR vesicles experiments. $\mathrm{Ag}^{+}$apparently did not affect the SR $\mathrm{Cl}^{-}$channel.

The $\mathrm{SR} \mathrm{Ca}^{2+}$ release channel is modified by low concentrations of $\mathrm{Ag}^{+}$at physiological condition, and also in the absence of ATP or $\mathrm{Mg}^{2+}$. $\mathrm{Ag}^{+}$modification is equally effective from either side of the channel. There are two possible explanations for this observation. While binding 
sites for $\mathrm{Ag}^{+}$may exist at both sides of the channel, it is likely that the $\mathrm{Ag}^{+}$ions can cross the bilayer through the $\mathrm{Ca}^{2+}$ channel itself to reach the binding sites from either side of the membrane.

Tatsumi et al. (1988) studied the $\mathrm{Ag}^{+}$effect on isolated $\mathrm{SR}$ vesicles at different myoplasmic $\mathrm{Ca}^{2+}$ concentration. They reported that $\mathrm{Ag}^{+}$only stimulated $\mathrm{Ca}^{2+}$ induced $\mathrm{Ca}^{2+}$ release and had no effect beyond the CICR range $\left(\left[\mathrm{Ca}^{2+}\right]=1 \mu M\right.$ to $\left.1 \mathrm{mM}\right)$. Their results would predict that $\mathrm{Ag}^{+}$binds to a site only available when $\mathrm{Ca}^{2+}$ is bound, and $\mathrm{Ag}^{+}$increases the open probability of an channel already partially activated by $\mathrm{Ca}^{2+}$. However, Moutin et al. (1989) suggest that $\mathrm{Ag}^{+}$is more effective at stimulating $\mathrm{Ca}^{2+}$ release at low $\mathrm{Ca}^{2+}$ concentrations. The results presented in this chapter indicate that $\mathrm{Ag}^{+}$is also able to activate a channel at low $\mathrm{Ca}^{2+}$ concentration.

While it is difficult to generate a reproducible doseresponse curve with a bilayer system, my results at different $\mathrm{Ag}^{+}$concentrations do qualitatively agree with the results of vesicle flux experiments. At low concentration $(<1 \mu M), \mathrm{Ag}^{+}$ increases the permeability of $\mathrm{SR}$ by activating the $\mathrm{Ca}^{2+}$ release channel. At high concentration ( $>5 \mu M$ ), $\mathrm{Ag}^{+}$induces large current through bilayers and no discrete channels can be easily resolved. The current is only partially inhibited by ruthenium red. This indicates that at high concentrations $\mathrm{Ag}^{+}$ may not specifically interact with the $\mathrm{Ca}^{2+}$ release channel. 
One of the advantages to study single channel behavior is its high time resolution. It allows us to observe the behavior of individual channels and resolve events according to the sequence in which they occur. In efflux measurements with the isolated $\mathrm{SR}$ vesicle system, at intermediate $\mathrm{Ag}^{+}$ concentrations, below that of causing the nonspecific interaction and above that needed to cause rapid specific $\mathrm{Ca}^{2+}$ release, a slower release rate was observed (Figure 14). Brunder et al (1988) made the same observation and suggested that $\mathrm{Ag}^{+}$binds to a second activation site with a lower affinity to $\mathrm{Ag}^{+}$. When $\mathrm{Ag}^{+}$interacts with $\mathrm{SR}$ following fusion to a bilayer, a spontaneous inactivation was observed following $\mathrm{Ag}^{+}$activation at all $\mathrm{Ag}^{+}$concentration tested. Even at high $\mathrm{Ag}^{+}$concentration that causing nonspecific interaction partial inactivation was always evident. Generally, $\mathrm{Ag}^{+}$activation lasted between a few seconds to half a minute before the inactivation occurred. The fact that the inactivation was not complete and occasional gating was further inhibited by ruthenium red indicates that the inactivation was not due to denaturation of the channel. one possible interpretation of this observation is that $\mathrm{Ag}^{+}$binds to an inhibitory site of the channel which has lower affinity to $\mathrm{Ag}^{+}$. Thus, the spontaneous inactivation seen with $\mathrm{Ag}^{+}$is likely due to a specific reaction between $\mathrm{Ag}^{+}$and an endogenous SH which closes the channel. This hypothesis 
readily explains the action of intermediate concentrations of $\mathrm{Ag}^{+}$on isolated $\mathrm{SR}$ vesicles.

Any agent that causes $\mathrm{Ca}^{2+}$ release from $\mathrm{SR}$ could in principle yield some clues about the nature of EC coupling. $\mathrm{Ag}^{+}$induces rapid $\mathrm{Ca}^{2+}$ release from isolated heavy $\mathrm{SR}$ vesicles, and causes contracture in skinned muscle fibers (Aoki et al., 1986; Pike et al., 1987). $\mathrm{Ag}^{+}$is the most potent of a number of $\mathrm{Ca}^{2+}$-releasing drugs (Palade, 1987). Even though $\mathrm{Ag}^{+}$is not a physiological trigger for $\mathrm{Ca}^{2+}$ release from $\mathrm{SR}$, the SHs to which $\mathrm{Ag}^{+}$binds, can be oxidized, and open the $\mathrm{Ca}^{2+}$ release channel. It is possibly the physiological target site for opening the release channel. A large number of proteins contain SH groups that undergo oxidation-reduction reactions on a millisecond time scale (Williams, 1976). The $\mathrm{Ca}^{2+}$ permeability of human platelets (Adunyah and Dean, 1986), insulinoma cells (Erlichman et al., 1979), and liver microsomes (Thor et al., 1985) have all been shown to be regulated by $\mathrm{SH}$ interactions. $\mathrm{SH}$ group oxidation-reduction may play a general role in controlling the state of many membrane-bound transport proteins. Trimm et al. (1986) showed that oxidation induced $\mathrm{Ca}^{2+}$ release from $\mathrm{SR}$ vesicles (stimulated by $\mathrm{Cu}^{2+} /$ cysteine) could be reversed by addition of the reducing agent DTT. It is believed that DTT closed the $\mathrm{Ca}^{2+}$ channel by reducing the disulfide bond between cysteine and the endogenous critical SH group. Brunde et al (1988) showed that both reducing agents glutathione (GSH) and DTT 
prevented the rapid $\mathrm{Ca}^{2+}$ release induced by $\mathrm{Ag}^{+}$( $1 \mu M$ ) on HSR, while neither of the agents had an effect on $\mathrm{Ca}^{2+}$ release induced by caffeine, alkalinization or $\mathrm{Cl}^{\circ}$. They also showed that GSH and DTT at millimolar concentration prevented contracture of skinned muscle fibers. In an effort to study the physiological relevance of this observation and to evaluate the role of sulfhydryl oxidation in EC coupling, the voltage clamped cut frog skeletal muscle fibers were used to test whether depolarization fail to cause $\mathrm{Ca}^{2+}$ release from SR in the presence of DTT and GSH. The results was ambiguous, although it was interpreted that $\mathrm{SH}$ oxidation may not interfere with physiological $\mathrm{SR} \mathrm{Ca}^{2+}$ release. Clearly, more careful studies need to be done regarding to the intriguing role of sulxhydryl oxidation in EC coupling.

The single channel data of this chapter shows that $\mathrm{Ag}^{+}$ interacts directly with the $\mathrm{SR} \mathrm{Ca}^{2+}$ release channel of skeletal muscle. $\mathrm{Ag}^{+}$activates the channel by increasing the open probability. The spontaneous inactivation caused by $\mathrm{Ag}^{+}$ is likely due to the binding of $\mathrm{Ag}^{+}$to an endogenous $\mathrm{SH}$ group which closes the channel. 


\section{CHAPTER V}

PHOTOOXIDATION OF THE SR CALCIUM RELEASE CHANNEL

\section{SUMMMARY}

In this chapter, the effect of photooxidation of rose bengal on the gating characteristics of the reconstituted $\mathrm{Ca}^{2+}$ release channel from skeletal muscle SR is examined. To study the native SR channel, a series of experiments were performed by using the vesicle fusion technique in a 5:1 $\mathrm{cscl}$ gradient. The results showed that rose bengal activated the $\mathrm{Ca}^{2+}$ release channel in the presence of light. The photooxidation of the channel increased the channel open probability and left the single channel conductance unchanged. This photoactivation was independent of the myoplasmic $\mathrm{Ca}^{2+}$ concentration, and could be achieved from either side of the membrane. In addition, the effect was inhibited by addition of 10-20 $\mu \mathrm{M}$ ruthenium red. If the $\mathrm{Ca}^{2+}$ release channel was in its subconducting state induced by ryanodine, subsequent addition of rose bengal reactivated the channel to its rapidly fluctuating full conducting state. Rose bengal also stimulated the channel activity of the reconstituted $106 \mathrm{kDa}$ protein. Furthermore, rose bengal could reverse the modification of the $106 \mathrm{kDa}$ protein by ryanodine. 


\section{INTRODUCTION}

The lethal effect of light and oxygen on microbes in the presence of certain dyes was discovered at the turn of the century. This effect, termed photodynamic action, was later shown to result from the sensitized photooxidation of certain amino acid residues in protein molecules. The dyes act as photosensitizers in these reactions. Photosensitizers absorb light and produce chemical reactions which would not occur in their absence. A photosensitizer has two electronically excited states, the singlet and the triplet. The short-lived singlet state is the initial product of light absorption. It rapidly decays by fluorescence to the ground state or by electronic intersystem crossing to a long-lived triplet state. It is the triplet state of a photosensitizer that participates in photooxidation of protein molecules. The most effective sensitizers are therefore those that have a high quantum yield of a long-lived triplet state.

There are two major classes of reaction for the sensitizer triplet. In Type $I$, the sensitizer triplet state undergoes a chemical interaction with a substrate in the system. This reaction results in the formation of a free radical pair through electron or hydrogen atom transfer. subsequently the radicals react with oxygen to form peroxy radicals or superoxide radicals. In TYpe II, the sensitizer triplet state transfers energy to oxygen $\left({ }^{3} \mathrm{O}_{2}\right)$, resulting in the generation of excited singlet oxygen $\left({ }^{1} \mathrm{O}_{2}\right)$. Photosensitized 
oxidations of many biomolecules have been shown to involve the Type II pathway with the formation of singlet oxygen. High concentrations of sensitizer may switch the photooxidation process to a Type I pathway.

The xanthene dye rose bengal (Figure 23) is a well known photosensitizer, and has been used as a photosensitizer for ${ }^{\prime} \mathrm{O}_{2}$ formation (reviewed by Neckers, 1987; 1989). In their study,<smiles>O=C(O)c1c(Cl)c(Cl)c(Cl)c(Cl)c1-c1c2cc(I)c(=O)c(I)c-2oc2c(I)c(O)c(I)cc12</smiles>

Figure 23. The structure of rose bengal as $\mathrm{C}-2$ ', C-6 potassium salt. The maximum absorbance $\lambda$ max is $549.0 \mathrm{~nm}$ in $\mathrm{H}_{2} \mathrm{O}$, and the quantum yield of singlet oxygen formation in $\mathrm{H}_{2} \mathrm{O}$ at $20^{\circ} \mathrm{C}$ is 0.75 (Neckers, 1989).

Lee and Rodgers (1987) showed that photooxidation of rose bengal in aqueous solution produces about $75 \%{ }^{1} \mathrm{O}_{2}$ and about $20 \%$ superoxide $\left(\mathrm{O}_{2}^{-}\right)$. This study indicates the relative participation of each process in the photooxidation of rose bengal, with the Type II pathway as the dominant process. photooxidation of rose bengal has been studied in some biological model systems. It was reported that photooxidation of SR vesicles with rose bengal resulted in inhibition of 
$\mathrm{Ca}^{2+}-\mathrm{ATP}$ ase activity and inhibition of active $\mathrm{Ca}^{2+}$ uptake (Yu et al., 1974). This photooxidation was proposed to involve either histidyl, or tryptophan residues (Kondo et al., 1974). Watson and Haynes (1982) reported a increase in passive $\mathrm{Ca}^{2+}$ permeability of SR vesicles photosensitized by rose bengal and suggested functional damage to $\mathrm{Ca}^{2+}$ pumps.

Photooxidation, sensitized by rose bengal, increases the $\mathrm{Ca}^{2+}$ permeability of the SR vesicles. While previous work has focused on the $\mathrm{Ca}^{2+}$ pump, investigation in our laboratory indicates that the rapid increase of the $\mathrm{Ca}^{2+}$ permeability is primarily due to photooxidation of the $\mathrm{Ca}^{2+}$ release pathway (Stuart et al., 1991). At low concentration (10 nM to $1 \mu M$ ), rose bengal causes rapid $\mathrm{Ca}^{2+}$ efflux from actively loaded SR vesicles when irradiated with a light source. At concentration of $5 \mu M$ or greater, rose bengal causes $\mathrm{Ca}^{2+}$ release without direct irradiation (Figure 24). Rose bengal, at nanomolar concentrations, inhibits high affinity $\left[{ }^{3} \mathrm{H}\right]$ ryanodine binding to its receptor on the $\mathrm{SR}$ in a light dependent manner. At a rose bengal concentration of $0.1 \mu M$, $\mathrm{Ca}^{2+}$-ATPase activity is less than 50\% inhibited after 1 minute of light exposure, yet all the $\mathrm{Ca}^{2+}$ has exited from the SR vesicles with less than 30 seconds of exposure. These evidence suggest the involvement the of $\mathrm{SR} \mathrm{Ca}^{2+}$ release channel in the process of photooxidation.

The photooxidation site on the SR appears to be a histidyl residue (stuart et al., 1991). This suggestion is 


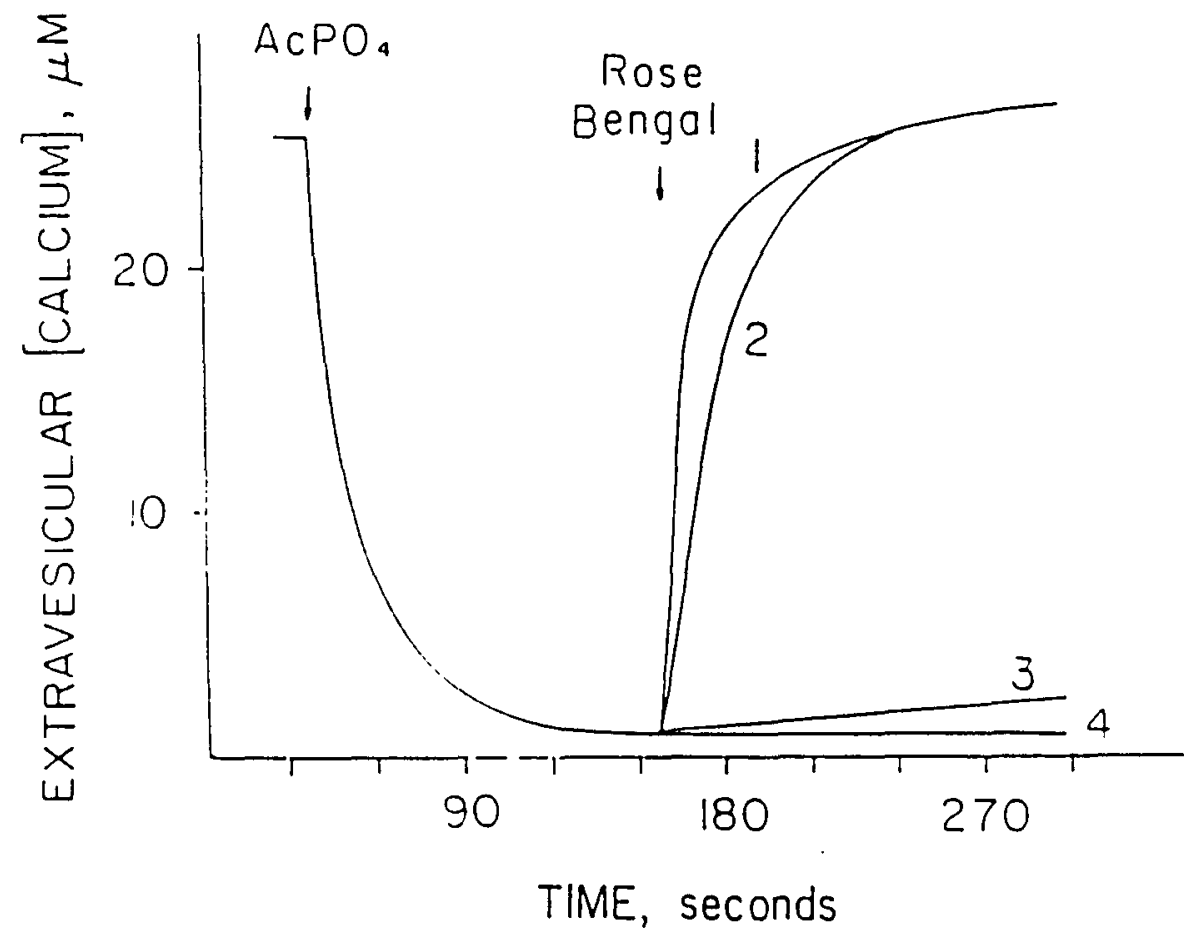

Figure 24. Rose bengal induced $\mathrm{Ca}^{2+}$ efflux from actively loaded $S R$ vesicles. Efflux measurements were carried out in $100 \mathrm{mM} \mathrm{KCl}, 3 \mathrm{mM} \mathrm{MgCl}, 50 \mathrm{mM}$ HEPES, $\mathrm{pH} 7.0$. The $\mathrm{Ca}^{2+}$ was taken up in the presence of $2.0 \mathrm{mM} \mathrm{ACPO}$. Afte accumulation of the added $\mathrm{Ca}^{2+}$, efflux was initiated by the addition of (1) $5 \mu M$ rose bengal in the dark, (2) $1 \mu M$ rose bengal with irradiation from a $360 \mathrm{~W}$ light source, and (3) $1 \mu M$ rose bengal in the dark. In (4), no reagent was added. Extravesicular $\mathrm{Ca}^{2+}$ concentration was monitored using a $\mathrm{Ca}^{2+}$ selective electrode. 
supported by the observation that excess histidine in the reaction buffer decreases $\mathrm{Ca}^{2+}$ efflux rates induced by rose bengal by about $40 \%$. Cysteine or lysine in the reaction buffer had no effect on the release rates. Also, when SR residues are photooxidized in the presence of rose bengal for 1 minute, a strong absorbance maximum appears at $250 \mathrm{~nm}$ which is attributed to the photooxidation of histidine. At longer illuminations times tryptophan residues are also modified. since photooxidation induced $\mathrm{Ca}^{2+}$ efflux is essentially complete within 30 seconds, it is unlikely that the oxidation of the tryptophanyl residues is responsible for inducing rapid $\mathrm{Ca}^{2+}$ efflux. This is further supported by the observation that ethoxyformic anhydride (EFA), a known histidyl modifying reagent also is effective in inducing $\mathrm{Ca}^{2+}$ release from $\mathrm{SR}$ vesicles. Furthermore, EFA induced release responds to modulators of $\mathrm{Ca}^{2+}$ release in the same manner as that of rose bengal induced release. Therefore it is concluded that photooxidation target on the $S R$ is likely to involve modification of histidyl residues.

While some data suggest the involvement of the $\mathrm{Ca}^{2+}$ release channel in the rose bengal sensitized photooxidation of the SR, rose bengal-induced $\mathrm{Ca}^{2+}$ release shows unexpected ligand sensitivity. Unlike $\mathrm{Ca}^{2+}$-induced $\mathrm{Ca}^{2+}$ release or sulfhydryl oxidation-induced $\mathrm{Ca}^{2+}$ release, rose bengal-induced $\mathrm{Ca}^{2+}$ release is independent of $\mathrm{Ca}^{2+}$ or $\mathrm{Mg}^{2+}$. It is inhibited by ATP, and only partially inhibited by ruthenium red. 
Furthermore, HSR is only about $40 \%$ more sensitive to rose bengal than is LSR. The reconstituted $\mathrm{Ca}^{2+}$ release channel is an ideal system to verify that whether the channel is a target for rose bengal sensitized photooxidation. The effect of photooxidation was shown first on native $\mathrm{SR} \mathrm{Ca}^{2+}$ channel's, and then the study was carried further to the purified $106 \mathrm{kDa}$ $\mathrm{Ca}^{2+}$ channel.

\section{RESULTS}

The single channel recording technique was used tol study the effect of photooxidation on the native SR $\mathrm{Ca}^{2+}$ release channel following fusion of $S R$ vesicles to planar lipid bilayer membranes (phosphatidylethanolamine / phosphatidyl serine $=5: 3)$. SR vesicles were added to the cis chamber of an asymmetric 5:1 CsCl gradient at a final concentration of 2$10 \mathrm{\mu g} / \mathrm{ml}$. The cis chamber contained $500 \mathrm{mM} \mathrm{CsCl,} 10 \mathrm{mM} / \mathrm{Tr}$ isHEPES, $0.1 \mathrm{mM} \mathrm{CaCl} 2,0.1 \mathrm{mM} \mathrm{EGTA,} \mathrm{pH} 7.2$; the trans chamber contained $100 \mathrm{mM} \mathrm{CsCl,} 10 \mathrm{mM}$ Tris-HEPES, pH 7.2. Ifter addition of $0.35 \mathrm{mM} \mathrm{CaCl} \mathrm{Cl}_{2}$ to the cis chamber, and fusion of a SR vesicle, a two fold excess of EGTA was added, and the solution in the cis chamber was changed to prevent further fusion events. Figure 25 a shows a typical current trace of $\mathrm{Cs}^{+}$transport through a single SR $\mathrm{Ca}^{2+}$ channel $\left(\left[\mathrm{Ca}^{2+}\right.\right.$ free $_{\text {is }}=$ $5 \mu M)$. As demonstrated in Figure 25b, addition of $0.5 \mu M$ rose bengal in the presence of light increases the probability of finding the $\mathrm{Ca}^{2+}$ channel in its open state $\left(P_{0}\right)$. Subsequent 
A
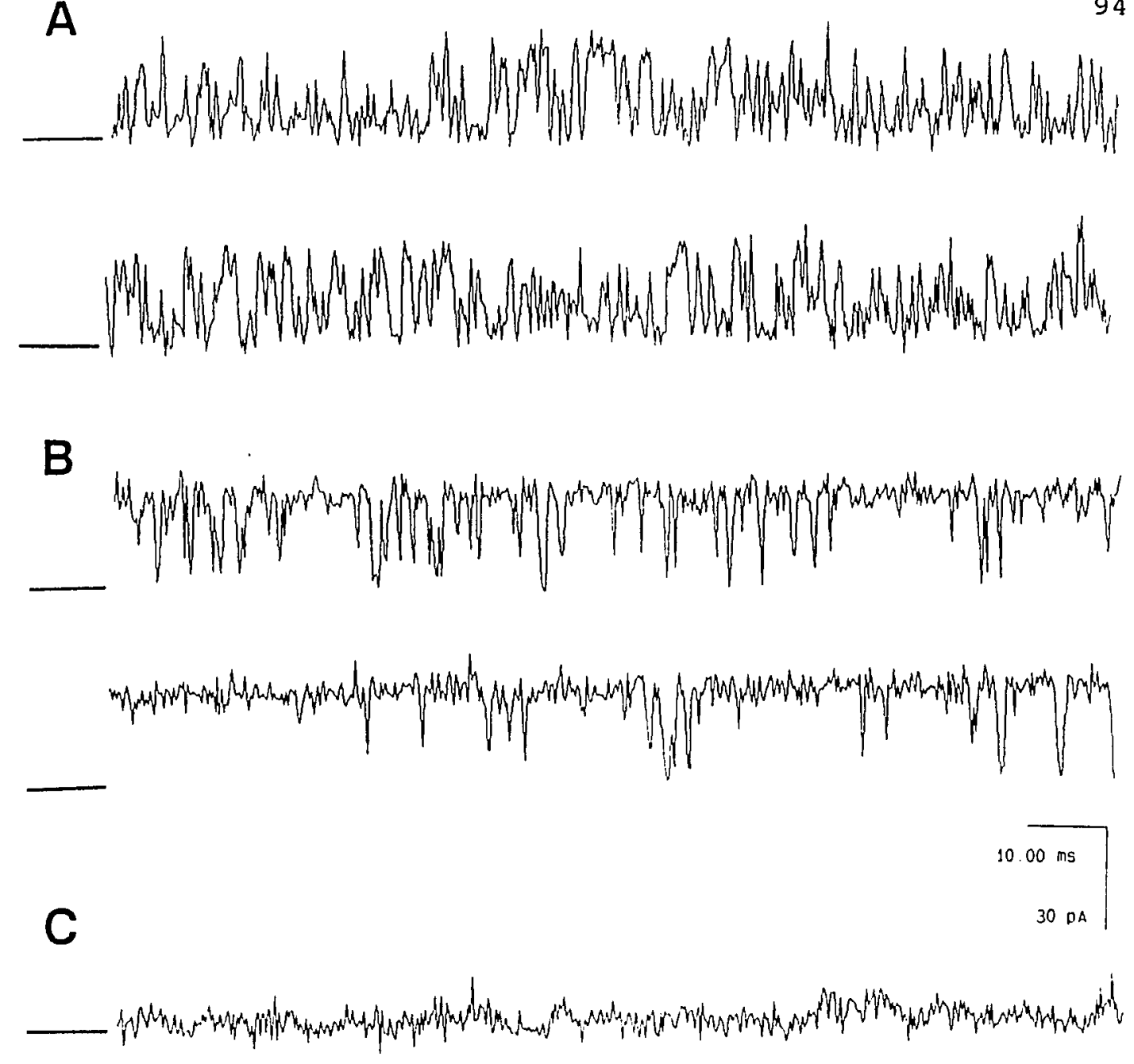

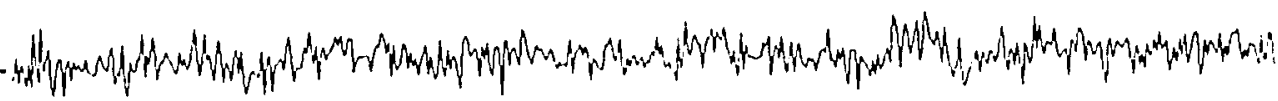

Figure 25. Rose bengal activation and ruthenium red inhibition of the $\mathrm{SR} \mathrm{Ca}^{2+}$ release channel. Single channel current in $5: 1 \mathrm{cscl}$ gradient after fusion of a SR vesicle to phospholipid bilayer. (A) $\left[\mathrm{Ca}^{2+}\right]_{\text {cis }}=5 \mu \mathrm{M}\left(0.1 \mathrm{mM} \mathrm{CaCl} \mathrm{C}_{2}, 0.1 \mathrm{mM} \mathrm{EGTA}\right), \mathrm{P}_{0}$ $=29 \%$ (B) Addition of $0.5 \mu \mathrm{M}$ of rose bengal to the $\mathrm{cis}$ chamber in the presence of light $(8000$ lux). $\mathrm{P}_{0}=88 \%$ (C) Addition of $10 \mu \mathrm{M}$ of ruthenium red to the cis chamber after the activation of rose bengal. $P_{0}=2 \%$. Holding potential (HP) was $+20 \mathrm{mV}$. The horizontal bars indicate the closed state of the channel. Number of independent bilayer experiments $(n)$ is 5 . 
addition of $10 \mu \mathrm{M}$ ruthenium red to the cis chamber greatly inhibits the channel activity (Figure 25c).

Although the channel activity was stimulated by photooxidation, the single channel conductance $(479 \pm 31 \mathrm{pS})$ and the selectivity of the channel remains unaffected (Figure 26). The reversal potential of $-33 \mathrm{mV}$ yields a permeability ratio $\left(\mathrm{P}_{\mathrm{Cs}} / \mathrm{P}_{\mathrm{Cl}}\right)$ of 13 . The relative abundance of $\mathrm{Cl}^{-}$channels was found to vary among $S R$ preparations. Most of the experiments described were carried out with SR preparations containing a relatively low number of $\mathrm{Cl}^{-}$channels. The background current, including the $\mathrm{Cl}^{-}$current, of the bilayer was not affected by photooxidation.

Figure 27 and 28 display the lifetime histogram for the recordings of channel activity from which the traces in figure 25 were taken. For the open lifetimes (Figure 27), the best fit was obtained with a single exponential. The fitting reveals open time constant (mean open lifetime) of $1.1 \pm 0.1$ $\mathrm{ms}$ and $7.3 \pm 0.8 \mathrm{~ms}$ before and after photooxidation respectively. The analysis of the closed lifetime (Figure 28) reveals a time constant (mean closed time) of $3.5 \pm 0.8 \mathrm{~ms}$ for the control trace and $0.82 \pm 0.04 \mathrm{~ms}$ after addition of $0.5 \mu \mathrm{M}$ rose bengal and exposure to light. Thus, photooxidation causes the $\mathrm{Ca}^{2+}$ channel to stay open longer. The data was filtered at $1,500 \mathrm{~Hz}$ and digitalized at $4,000 \mathrm{~Hz}$.

In a similar experiment to that shown in Figure 25, rose bengal was added in the darkness before exposure to light. As 


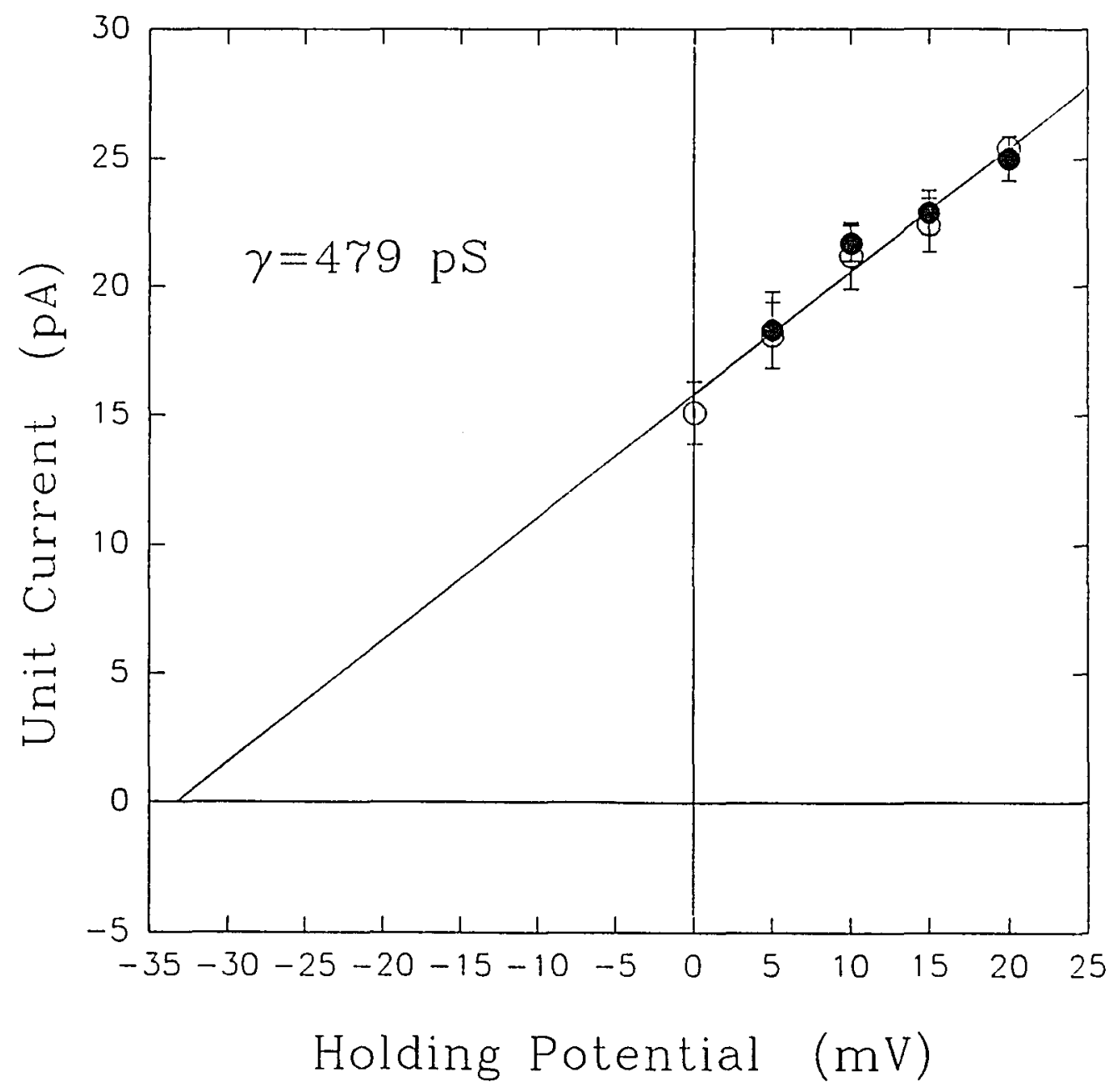

Figure 26. Current-voltage curve of a single $\mathrm{Ca}^{2+}$ channel in the absence and presence of $0.5 \mu \mathrm{M}$ rose bengal with illumination. The data are taken from the experiment showed in Figure 25. Currentvoltage curve of a typical native $\mathrm{Ca}^{2+}$ release channel in the absence (0) and presence of rose bengal with illumination ( $\bullet$ ). The least-square fit of all points yields a slope of $479 \mathrm{ps}$, and an $X$ interception of $-33 \mathrm{mV}$. 

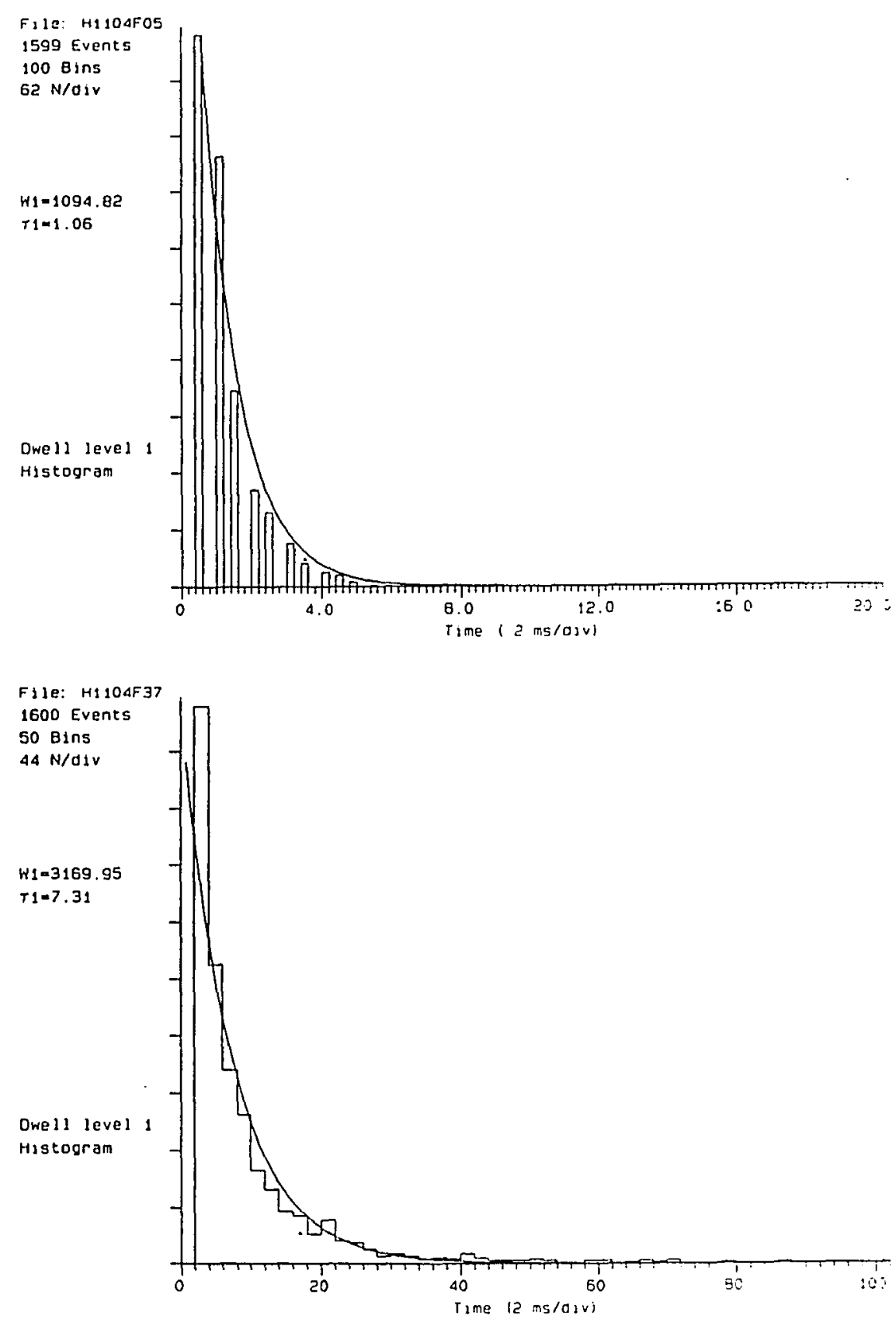

Figure 27. Open lifetime analysis of a SR Ca'+ release channel upon photooxidation. The analysis was done with the data from recordings of Figure 25. Open lifetime histograms before (top panel) and after (bottom panel) the addition of $0.5 \mu \mathrm{M}$ cis rose bengal with illumination. 

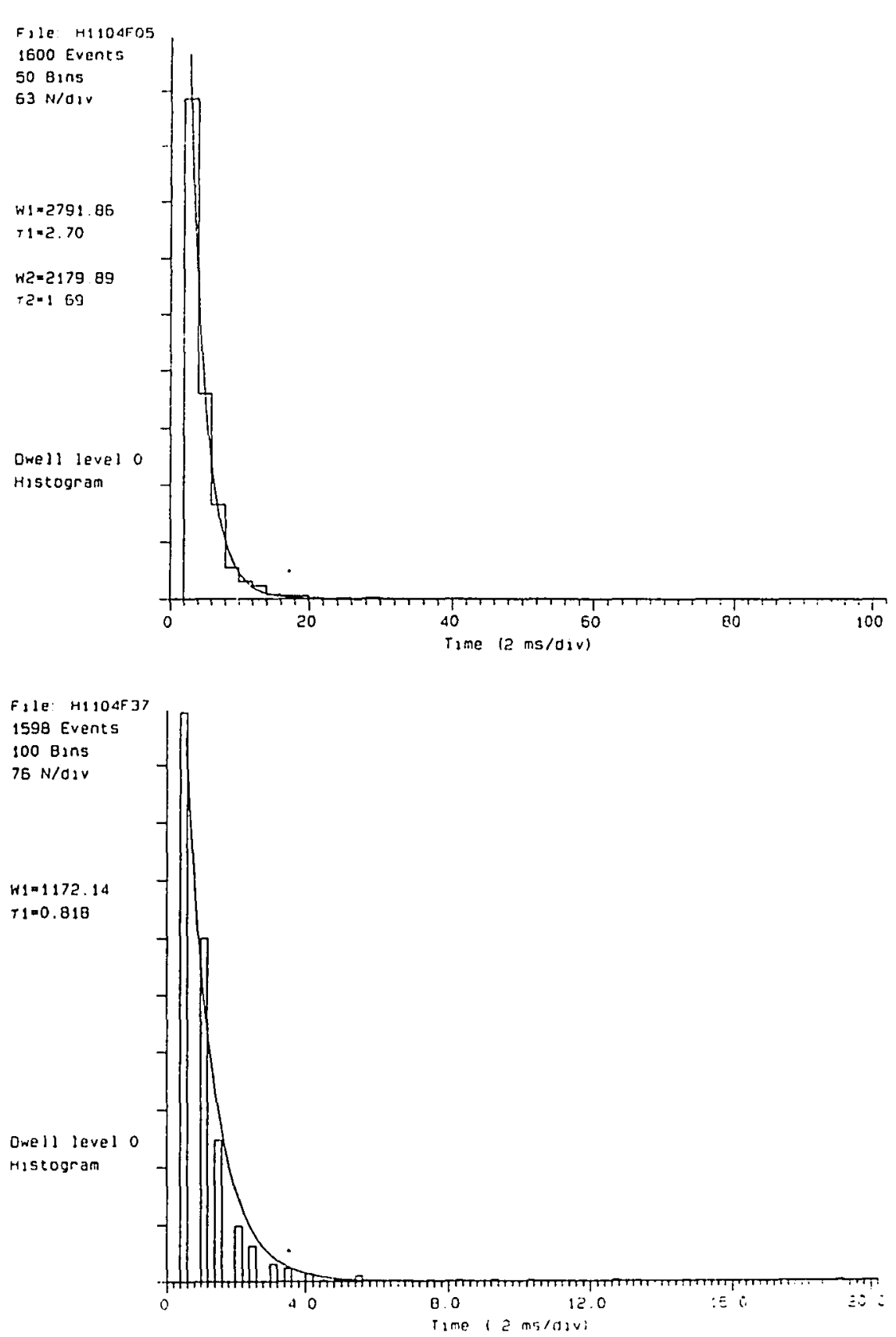

Figure 28. Closed lifetime analysis of a SR $\mathrm{Ca}^{2+}$ release channel upon photooxidation. The analysis was done with the data from recordings of Figure 25. Close lifetime histograms before (top panel) and after (bottom panel) the addition of $0.5 \mu \mathrm{M}$ cis rose bengal with illumination. 
shown in Figure $29 \mathrm{~b}, 1 \mu M$ rose bengal had no effect in the dark. Immediately after illumination for a few seconds, the $\mathrm{Ca}^{2+}$ channel activity was greatly increased (Figure 29c). Higher rose bengal concentrations ( $5 \mu M$ ) were needed to stimulate $\mathrm{SR} \mathrm{Ca}^{2+}$ release channel activity in the dark.

In $\mathrm{Ca}^{2+}$ flux measurements, rose bengal stimulated $\mathrm{Ca}^{2+}$ release from $S R$ vesicles is insensitive to extravesicular free $\mathrm{Ca}^{2+}$ concentration. This observation is in contrast to $\mathrm{Ca}^{2+}$ release induced by other activators which shows a marked dependence on myoplasmic $\mathrm{Ca}^{2+}$ concentration. As shown in Figure 30 , channel activity was stimulated by photooxidation even at low $\mathrm{Ca}^{2+}$ concentration (18 $\mathrm{nM}$ ).

As shown in Figure 31 , addition of $1 \mu M$ rose bengal to either side of the bilayer results in similar activation of channel activity upon exposure to light. Light dependent stimulation of channel activity is presumably caused by singlet oxygen production. Singlet oxygen can readily diffuse across biological membranes, and therefore one might expect $\mathrm{Ca}^{2+}$ channel activity to be activated by rose bengal added to either the cis or trans chamber.

It has previously been shown with the bilayer fusion technique that micromolar concentrations of ryanodine lock the native $\mathrm{SR} \mathrm{Ca}^{2+}$ release channel in a half conductance state (Rousseau et al., 1987). As shown in Figure 32, addition of $0.7 \mu M$ ryanodine to the cis chamber modified the channel (479 ps) to a long open subconducting state (about $250 \mathrm{ps}$ ). 
A

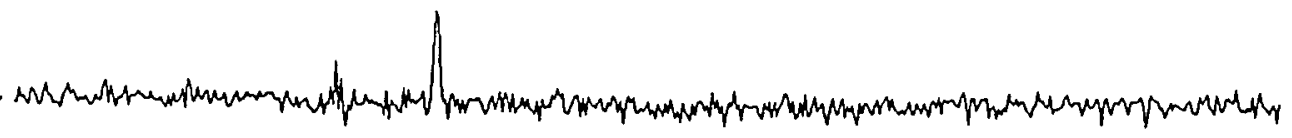

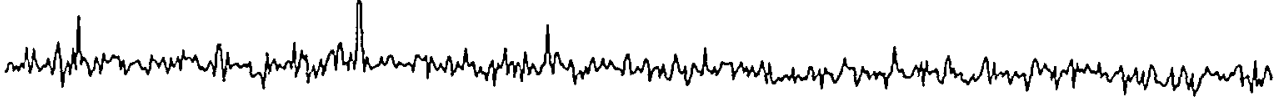

B

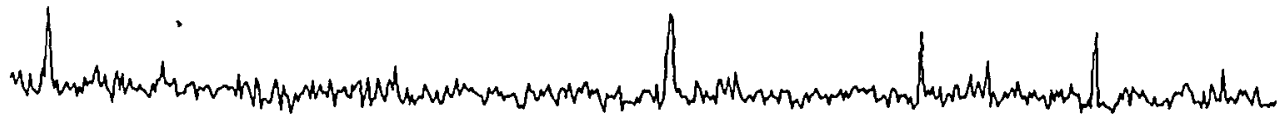

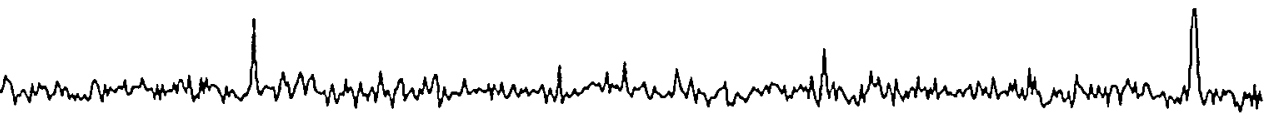

C

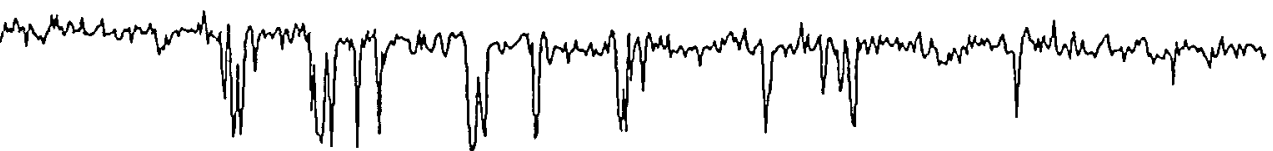

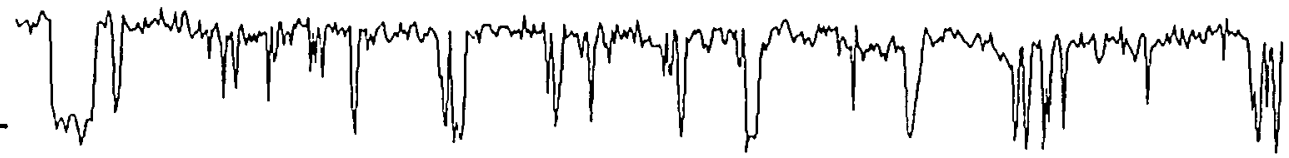

$2000 \mathrm{~ms}$

$30 \mathrm{DA}$

Figure 29. Light dependence of the rose bengal effect. Single channel current was recorded in 5:1 Cscl gradient after fusion of a SR vesicle to phospholipid bilayer. (A) $\left[\mathrm{Ca}^{2+}\right]_{\text {cis }}=5 \mu M(0.1 \mathrm{mM}$ $\mathrm{CaCl}_{2}, 0.1 \mathrm{mM}$ EGTA), $\mathrm{P}_{0}=1 \%$. (B) addition of $1.0 \mu M$ of rose bengal to the $c$ is chamber in the absence of light. $P_{0}=1 \%$ (C) Immediate after exposure to light. $P_{0}=95 \% . \mathrm{HP}=+20 \mathrm{mV} \cdot(n=5)$ 
A

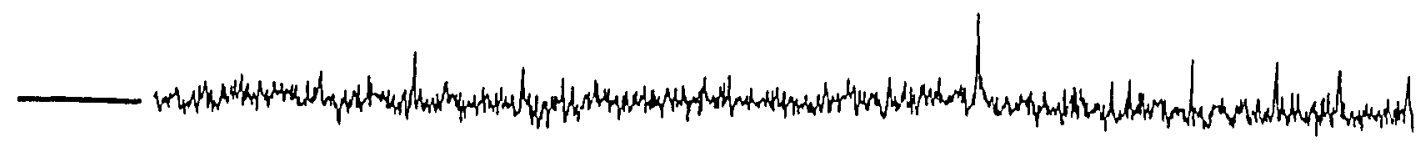

B

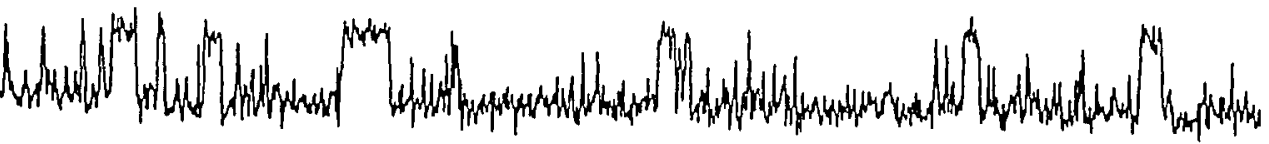

$40 \mathrm{~ms}$

$30 \mathrm{pA}$

Figure 30. Rose bengal activation of $\mathrm{SR} \mathrm{Ca}^{2+}$ release channel at low $\mathrm{Ca}^{2+}$ concentration. Following fusion of a SR vesicle to the bilayer with $0.35 \mathrm{mM}$ cis $\mathrm{CaCl}_{2}$, a ten fold excess of EGTA was added to the cis chamber to prevent further fusion events and to achieve low $\mathrm{Ca}^{2+}$ concentration. (A) $\left[\mathrm{Ca}^{2+}\right]_{\text {cis }}=18 \mathrm{nM}\left(0.35 \mathrm{mM} \mathrm{CaCl}_{2}, 3.5 \mathrm{mM}\right.$ EGTA $)$. (B) After addition of $0.6 \mu \mathrm{M}$ rose bengal to the cis chamber and activation by light. $\mathrm{HP}=+20 \mathrm{mV}$. $(n=5)$ 
A

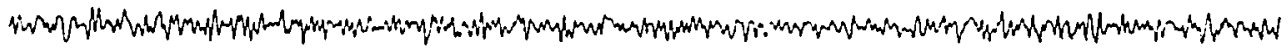

B

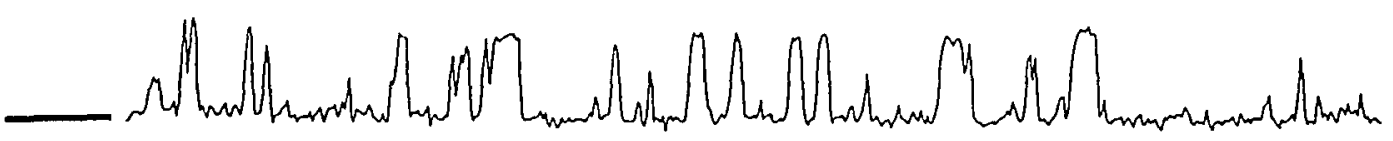

C

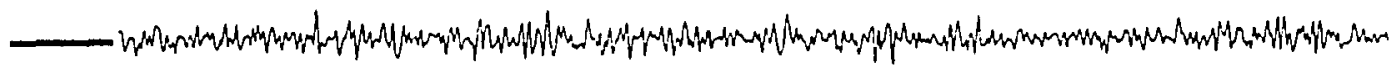

D

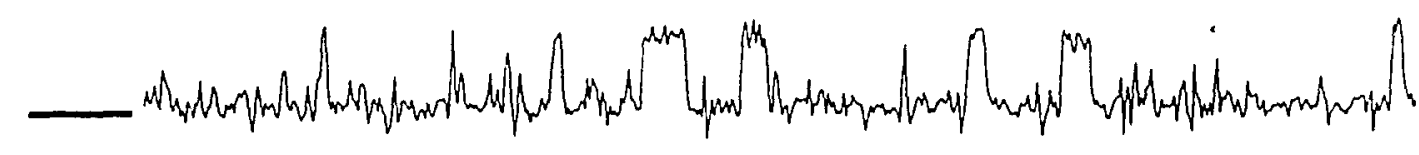

$20 \mathrm{~ms}$

$30 \mathrm{pA}$

Figure 31. Rose bengal activation of channel activity is side independent. Following fusion of a $S R$ vesicle to the bilayer with $0.35 \mathrm{mM}$ cis $\mathrm{CaCl}_{2}$, a two fold excess of EGTA was added to the cis chamber $\left(\left[\mathrm{Ca}^{2+}\right]_{\text {cis }}=160 \mathrm{nM}\right)$ to prevent further fusion events. (A) Control trace. (B) Addition of $1.0 \mu M$ rose bengal to the trans chamber and activation by light. $\mathrm{HP}=+20 \mathrm{mV} .(\mathrm{n}=3)$. (C) Control cis with a new bilayer. (D) Addition of $1.0 \mu M$ rose bengal to the trans chamber and activation by light. $\mathrm{HP}=+20 \mathrm{mV} . \quad(\mathrm{n}=6)$ 


\section{A}

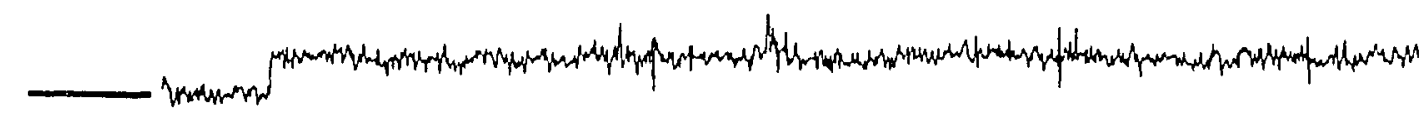

B

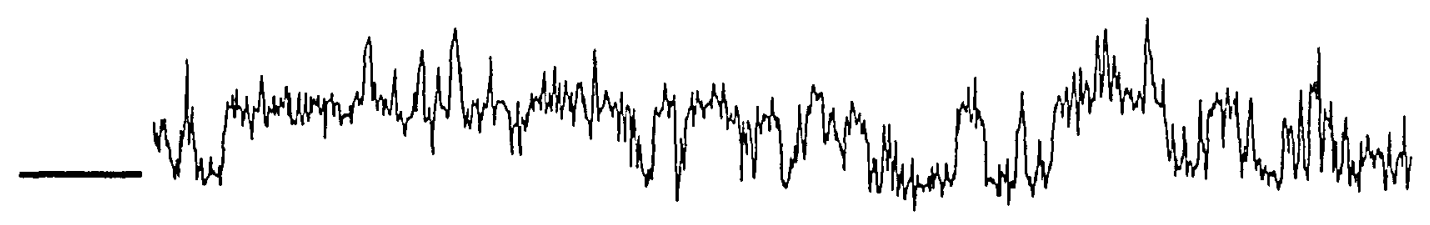

$40 \mathrm{~ms}$

30pA

Figure 32. Ryanodine modification of the $\mathrm{Ca}^{2+}$ release channel is reversed by rose bengal. After incorporation of a SR vesicle and changing the cis solution, $100 \mu \mathrm{M}$ of $\mathrm{Ca}^{2+}$ was added to the cis chamber. (A) $0.7 \mu \mathrm{M}$ ryanodine was added to the cis chamber. (B) After addition of $0.6 \mu \mathrm{M}$ rose bengal to the cis chamber and activation by light. $\mathrm{HP}=+20 \mathrm{mV} .(\mathrm{n}=5)$ 
Subsequent addition of $0.6 \mu M$ rose bengal in the presence of light reversed the effect of ryanodine. The channel returns to a rapidly fluctuating full conductance state. This implies that rose bengal can displace bound ryanodine from its receptor. Dr. Pessah in collaboration with this laboratory examined the interaction between ryanodine and rose bengal using a ryanodine binding assay (Figure 33 ). His results

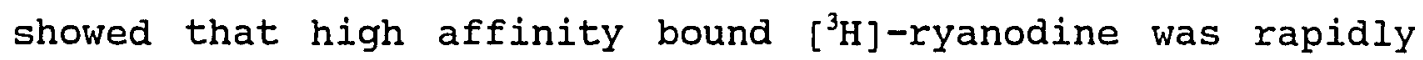
displaced by addition of rose bengal. Displacement of bound $\left[{ }^{3} \mathrm{H}\right]$-ryanodine is shown to be rose bengal concentration dependent and requires the presence of light (Xiong et al., 1991).

Photooxidation of the purified $106 \mathrm{kDa}$ protein was also investigated. The purified $106 \mathrm{kDa}$ protein was added to both sides of a bilayer in a symmetric $\mathrm{NaCl}$ buffer $\left(250 \mathrm{mM},\left[\mathrm{Ca}^{2+}\right]_{\text {free }}\right.$ $=100 \mu \mathrm{M}$ ) at a final protein concentration of 50-500 $\mathrm{ng} / \mathrm{ml}$. As shown in Figure 34, the activity of the reconstituted 106 $k D a$ protein is also stimulated by addition of $500 \mathrm{nM}$ rose bengal (Figure $34 \mathrm{~b}$ ). Channel activity is further increased by exposure to light (Figure 34c). Activation by rose bengal was partially reversed by the subsequent addition of $10 \mathrm{nM}$ ryanodine (Figure $34 d$ ).

Similar to the observation on the native channel (Figure 32), photooxidation with $500 \mathrm{nM}$ rose bengal reactivated the ryanodine modified channel. Figure 35 shows the modification by ryanodine of the reconstituted $106 \mathrm{kDa}$ channel, and the 


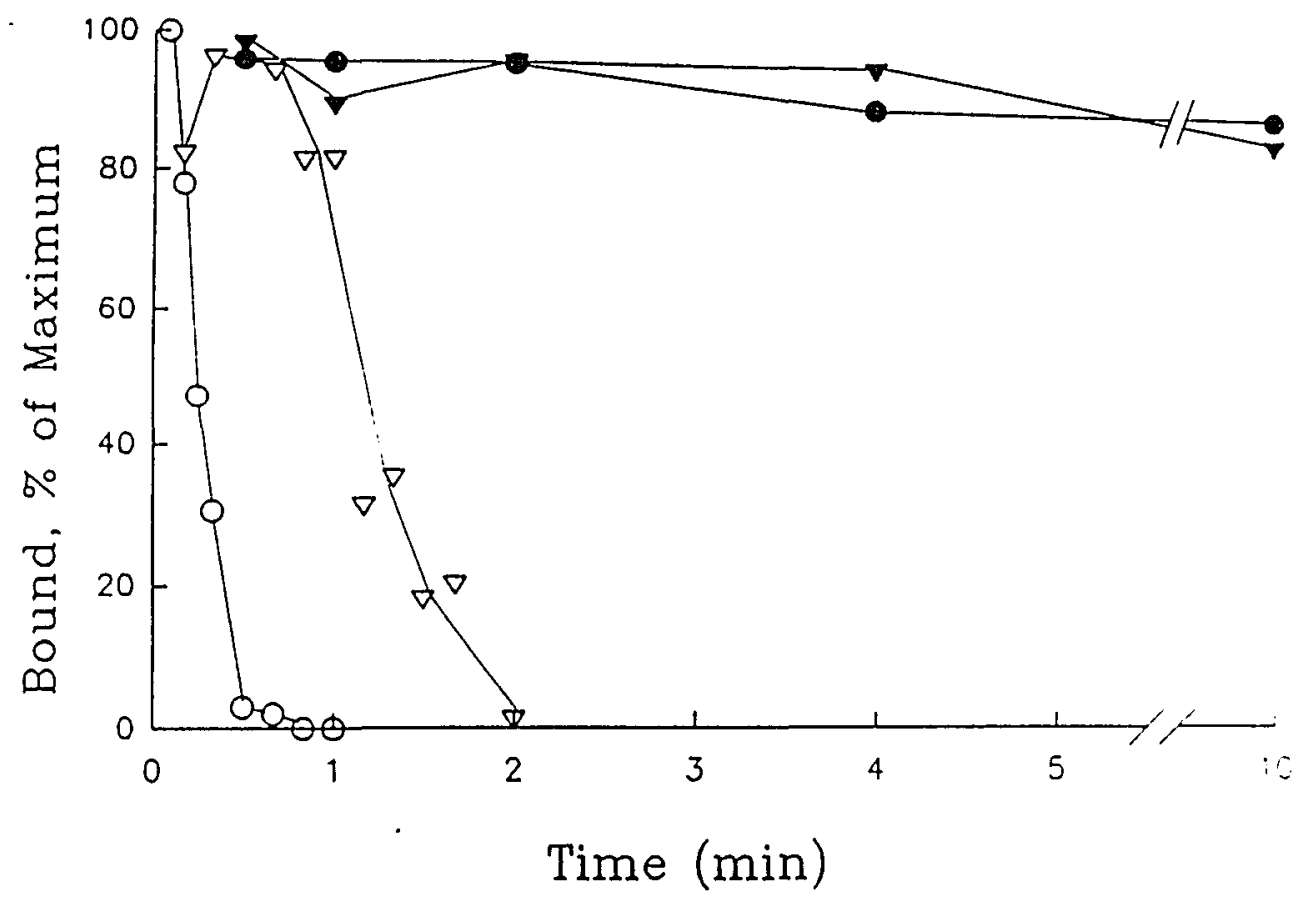

Figure 33. Light dependent displacement of $\left[{ }^{3} \mathrm{H}\right]-$ ryanodine from its binding sites by rose bengal. Junctional $S R$ vesicles $(30 \mu g)$ were equilibrated with $1 \mathrm{nM}\left[{ }^{3} \mathrm{H}\right]$-ryanodine for 3 hours. The samples were then exposed to either $50 \mathrm{nM}(\nabla, \nabla)$ or $500 \mathrm{nM}$ $(\bullet, 0)$ rose bengal in the dark $(0, \nabla)$ or in the presence of white light of $6500 \operatorname{lux}(0, \nabla)$ for various amounts of time. The assays were terminated with ice-cold wash buffer and radioactivity of the samples was measured by scintillation spectroscopy. 
A

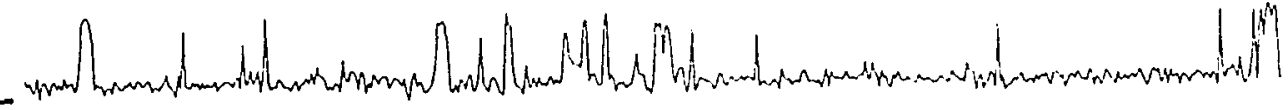

90.00 ติ

B

10 DA

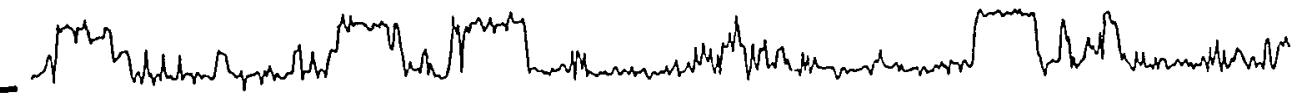

C

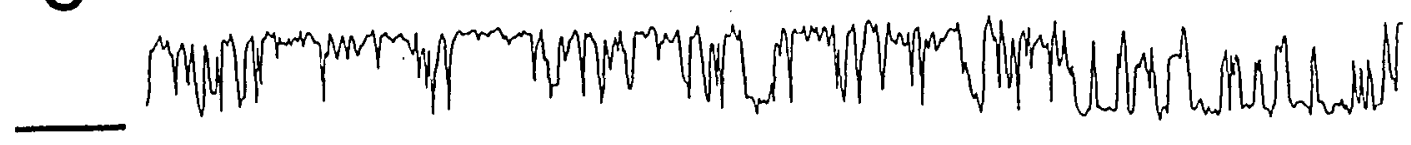

D

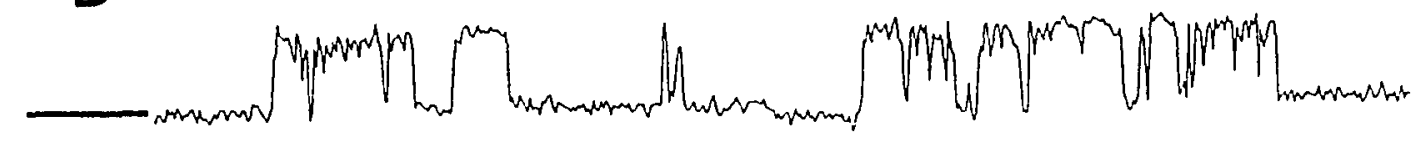

Figure 34. Rose bengal activation of the purified $\mathrm{Ca}^{2+}$ release channel and subsequent modification by ryanodine. Purified $106 \mathrm{kDa}$ protein was incorporated to a bilayer in symmetric $250 \mathrm{mM} \mathrm{NaCl}$ buffer $\left(\left[\mathrm{Ca}^{2+}\right]_{\text {frec }}=100 \mu M\right)$. (A) Control trace $\left(\left[\mathrm{Ca}^{2+}\right]_{\text {frec }}=100 \mu M\right) \cdot \mathrm{P}_{0}=9 \%$. (B) $0.5 \mu \mathrm{M}$ rose bengal was added to both chamber. $P_{0}=20 \%$. (C) Immediately following exposure to light. $\mathrm{P}_{0}=71 \%$. (D) $10 \mathrm{nM}$ ryanodine was added to both chamber. $\mathrm{P}_{0}$ $=62 \%$ HP $=+20 \mathrm{mV} \cdot(\mathrm{n}=3)$ 


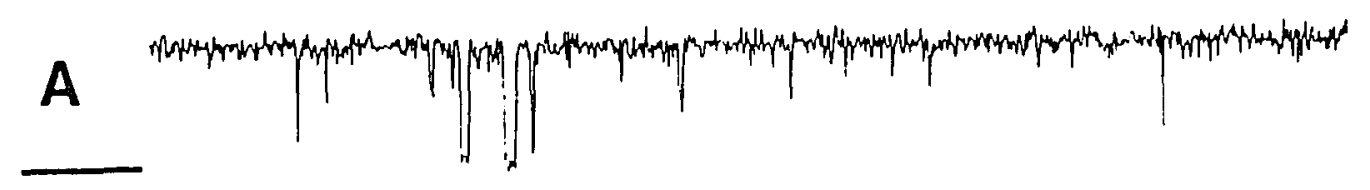

B

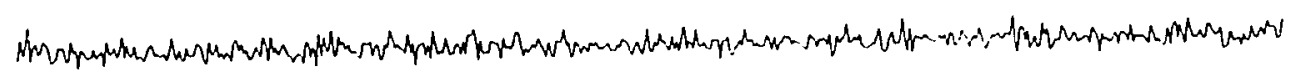

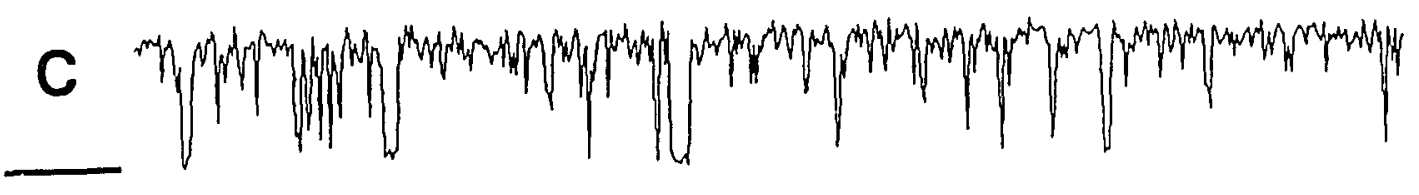

$90 \mathrm{~ms}$

D 10pA
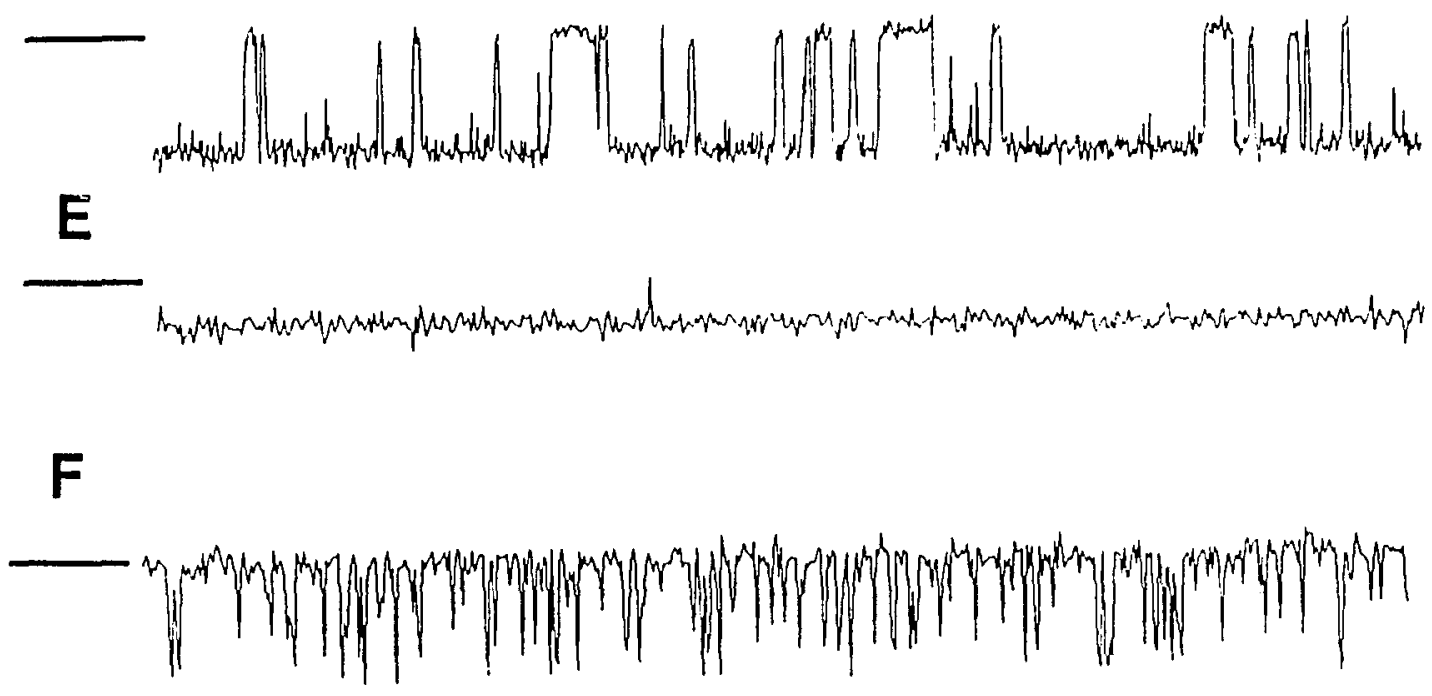

Figure 35. Rose bengal activation of ryanodine modified $106 \mathrm{kDa} \mathrm{Ca}{ }^{2+}$ release channel. Purified 106 $\mathrm{kDa}$ protein was incorporated to a bilayer in symmetric $250 \mathrm{mM} \mathrm{NaCl}$ buffer $\left(\left[\mathrm{Ca}^{2+}\right]_{\text {frec }}=100 \mu \mathrm{M}\right)$. (A) Control trace at $+40 \mathrm{mV} . \mathrm{P}_{0}=99 \%$ (B) Same as in (A), $\mathrm{HP}=-40 \mathrm{mV}, \mathrm{P}_{0}=92 \%$ (C) After addition of $10 \mathrm{nM}$ ryanodine. $\mathrm{HP}=+40 \mathrm{mV}$. (D) Same as in (C), $\mathrm{HP}=-40 \mathrm{mV}$. (E) $0.5 \mu \mathrm{M}$ rose bengal was added to both chamber in the presence of light. $P_{0}$ $=93 \%$. (F) Same as in (E), $\mathrm{HP}=-40 \mathrm{mV}, \mathrm{P}_{0}=12 \%$. The bars indicate the closed state of the channel. $(n=3)$ 
subsequent reversal of the effect by photooxidation. Also note the voltage dependence of the open channel probability $\left(P_{0}\right)$. After rose bengal activation, this voltage asymmetry is still evident.

\section{DISCUSSION}

Exposure of the photosensitizer rose bengal to light results in the production of ${ }^{1} \mathrm{O}_{2}$ and the activation of rapid $\mathrm{Ca}^{2+}$ release from skeletal muscle $\mathrm{SR}$ vesicles. Evidence presented in this chapter shows that the $\mathrm{Ca}^{2+}$ release channel from $S R$ is activated by rose bengal $(<1 \mu M)$ in the presence of light. Photooxidation of the $\mathrm{SR} \mathrm{Ca}^{2+}$ release channel increases the open probability $\left(\mathrm{P}_{0}\right)$ of the channel, and does not affect the single channel conductance. The selectivity of the channel $\left(\mathrm{P}_{\mathrm{Cs}} / \mathrm{P}_{\mathrm{Cl}}\right)$ is unaffected by photooxidation. Results indicate that the $\mathrm{SR} \mathrm{Cl}^{-}$channels do not respond to photooxidation. The photooxidation of $\mathrm{SR} \mathrm{K}^{+}$channel was also investigated with planar lipid bilayer technique. A fellow student, Ed Buck, showed that rose bengal, in the presence of light, had no effect on $\mathrm{SR}^{+}$channels.

Photooxidative modification of the $\mathrm{Ca}^{2+}$ release channel is independent of the side to which rose bengal is added. The life time of singlet oxygen in water is 2-5 $\mu \mathrm{sec}$ (Perez, 1985). Given the high diffusion coefficient of $\mathrm{O}_{2}$ in water (D $\left.=10^{-9} \mathrm{~m}^{2} \mathrm{~s}^{-1}\right)$, it is likely that ${ }^{\prime} \mathrm{O}_{2}$ diffuses at least ten times the thickness of the bilayer before decaying. It is therefore 
not surprising that photooxidation of the $\mathrm{Ca}^{2+}$ release channel is independent of the side to which rose bengal is added.

The activity of the SR $\mathrm{Ca}^{2+}$ release channel is $\mathrm{Ca}^{2+}$ dependent (Smith et al, 1986$)$. Activation of channel activity by adenine nucleotides (Meissner, 1984), ryanodine (Rousseau et al., 1987), and doxorubicin (Abramson et al. 1988; Ondrias et al., 1990) is also $\mathrm{Ca}^{2+}$ dependent. Maximal channel activity activation occurs at about $100 \mu \mathrm{M} \mathrm{Ca}^{2+}$. At $\mathrm{Ca}^{2+}$ concentrations as low as $20 \mathrm{nM}$, the channel is completely inhibited. However, $\mathrm{Ca}^{2+}$ release induced by rose bengal and the $\mathrm{Ca}^{2+}$ channel activity stimulated by rose bengal are both observed to be insensitive to $\mathrm{Ca}^{2+}$ (stuart et al.,1991; Figure 27). This indicates that the molecular mechanism underlying stimulation of $\mathrm{Ca}^{2+}$ channel activity by photooxidation is likely different than previous observed with other activators.

The other distinguishing feature of photooxidation is the fast response time. When rose bengal is added in the dark, the SR $\mathrm{Ca}^{2+}$ channel is opened immediately after light illumination. Unlike the isolated $S R$ vesicle system, $a$ reconstituted $\mathrm{Ca}^{2+}$ release channel in a bilayer responds more slowly to any added reagent. This is partly due to the mixing time. In the case of photooxidation, the channel is not affected after the addition and mixing of rose bengal. It opens up as soon as a light is switching on.

The sarcoplasmic reticulum has previously been implicated as a site of action for oxygen free radical damage. However, 
previous studies have focused on the $\mathrm{Ca}^{2+}, \mathrm{Mg}^{2+}-\mathrm{ATPase}$ as the primary target. Studies in our laboratory demonstrated that the $\mathrm{Ca}^{2+}$ release pathway is more sensitive to photooxidation than the $\mathrm{Ca}^{2+}$ pump. This study indicates that photooxidation of rose bengal stimulates $\mathrm{Ca}^{2+}$ release from $\mathrm{SR}$ by directly interacting with the $\mathrm{Ca}^{2+}$ release protein.

Although this study has been carried out with skeletal muscle SR, it may enhance our understanding of reperfusion damage of the myocardium. It has been reported that photooxidation of rose bengal in rat heart results in the rapid development of various arrhythmias (Hearse et al., 1988). The electrophysiological changes induced in the heart by reactive oxygen intermediates are similar to those associated with severe ischemia-reperfusion injury. Free radical scavengers, such as glutathione and superoxide dismutase reduce reperfusion damage. Intracellular $\mathrm{Ca}^{2+}$ overload has been proposed as a general pathogenic mechanism of reperfusion damage, and two membrane systems (SR and the sarcolemma) are the principal targets of reactive oxygen intermediates. My results imply that in skeletal muscle the intracellular $\mathrm{Ca}^{2+}$ overload is a direct result of an interaction between reactive oxygen intermediates and the SR $\mathrm{Ca}^{2+}$ release channel. A recent abstract indicates that the photooxidation of rose bengal modifies the sheep cardiac SR $\mathrm{Ca}^{2+}$ release channel (Cumming et al., 1990). Whether or not the cardiac $\mathrm{SR} \mathrm{Ca} \mathrm{Ca}^{2+}$ release protein is the primary site of 
action of singlet oxygen during reperfusion of cardiac muscle will require further detailed studies. 
CHAPTER VI

\section{CONCLUSION}

This research examined several aspects of the $\mathrm{SR} \mathrm{Ca}^{2+}$ release channel from skeletal muscle. When this work started in the summer of 1986, the investigation of the gating characteristics of the SR $\mathrm{Ca}^{2+}$ release channel had just begun. The planar lipid bilayer technique had successfully been used to examine channel behavior following fusion of SR vesicles to lipid bilayers. The activity of individual channels under electrically and chemically well defined conditions could be examined. The initial phase of my research involved setting up a planar lipid bilayer system in our laboratory. The establishment of this system was a great extension of the research capability in this laboratory. Combined with three other $\mathrm{Ca}^{2+}$ flux measurement systems, the single channel recording system has aided us in our effort to understand the $\mathrm{SR} \mathrm{Ca}^{2+}$ release mechanism.

At this same time attempts were being made to purified the $\mathrm{Ca}^{2+}$ channel protein. The ryanodine receptor complex was purified in 1987, and, using the bilayer technique, it was identified and characterized as a $\mathrm{Ca}^{2+}$ channel with similar properties to the native $\mathrm{SR} \mathrm{Ca}^{2+}$ release channel. The sulfhydryl activated $\mathrm{Ca}^{2+}$ channel protein was purified in 1989. However, this protein appeared not to be the same 
protein as the ryanodine receptor complex isolated by others. As described in Chapter III, the sulfhydryl activated $106 \mathrm{kDa}$ protein also showed similar channel properties in the artificial bilayer to the native $\mathrm{SR} \mathrm{Ca}^{2+}$ release channel. Further experiments will be needed to clarify the relationship between the high molecular mass ryanodine receptor and the 106 kDa sulfhydryl activated $\mathrm{Ca}^{2+}$ channel protein.

The work presented in Chapter IV is a continuation of our investigation into the interaction of sulfhydryl reagents and the SR $\mathrm{Ca}^{2+}$ release mechanism. $\mathrm{Ag}^{+}$activation of the $\mathrm{Ca}^{2+}$ release channel was studied at the single channel level. $\mathrm{Ag}^{+}$ activates the channel by increasing its open probability. The spontaneous inactivation following $\mathrm{Ag}^{+}$activation is likely due to a specific interaction between $\mathrm{Ag}^{+}$and an endogenous sulfhydryl group which closes the channel. Single channel data helped explain the interesting multiphasic $\mathrm{Ag}^{+}$dependence of the $\mathrm{Ca}^{2+}$ release rate from $\mathrm{SR}$ vesicles.

The work presented in Chapter $\mathrm{V}$ is a extension of $\mathrm{Dr}$. Janice stuart's work on modification of the $\mathrm{SR} \mathrm{Ca}^{2+}$ release mechanism with the photosensitizing dye, rose bengal. The discrepancy between the $\mathrm{pK}$ of a free cysteine and the optimal $\mathrm{pH}$ of sulfhydryl oxidation-induced $\mathrm{Ca}^{2+}$ release led Dr. Stuart's research on the possible involvement of histidyl residues in the $\mathrm{Ca}^{2+}$ release process. In the presence of light, nanomolar concentrations rose bengal induced $\mathrm{Ca}^{2+}$ release from isolated SR vesicles. Detailed studies could not 
determine whether the target of rose bengal sensitized photooxidation was the $\mathrm{Ca}^{2+}$ release channel. one possible reason for the rose bengal-increased $\mathrm{Ca}^{2+}$ permeability of the SR membrane was that other channels present in the SR were being modified in such a way as to conduct $\mathrm{Ca}^{2+}$. Assays carried out by Dr. Stuart could not rule out this possibility. Bilayer experiments described in chapter $V$ demonstrated that the target of rose bengal sensitized photooxidation is the SR $\mathrm{Ca}^{2+}$ release channel.

Data presented in this dissertation provide a new and valuable molecular description of the $\mathrm{SR} \mathrm{Ca}^{2+}$ release channel from skeletal muscle. 


\section{REFERENCES}

Abramson, J.J., Trimm, J.L., Weden, L., and Salama, G. (1983) "Heavy metal induce rapid calcium release from sarcoplasmic reticulum vesicles isolated from skeletal muscle," Proc. Natl. Acad. Sci. USA 80, 1526-1530.

Abramson, J.J., and Salama, G. (1987) "Critical sulfhydryls regulate calcium release from sarcoplasmic reticulum," (1989) J. Bioenerg. Biomembr. 21: 283-294.

Arreola, J., Calvo, J., Garcia, M.C., and Sanchez, J.A. (1987) "Modulation of calcium channels of twitch skeletal muscle fibers of the frog by adrenaline and cyclic adenosine monophosphate," J. Physiol. 393: 307-330.

Baylor, S.M. (1983) "Optical studies of excitation-contraction coupling using voltage-sensitive probes," In: Handbook of physiology. Skeletal Muscle, Bethesda, MD:Am. Physiol. Soc., vol. 10, p.355-379.

Baylor, S.M., and Hollingworth, S. (1988) "Fura-2 calcium transients in frog skeletal muscle fibres," J. Physiol. Lond., $403: 151-192$.

Beam, K.G., Knudson, C.M. (1988a) "Calcium currents in embryonic and neonatal mammalian skeletal muscle," J. Gen. Physiol. 91: 781-798.

Beam, K.G., Knudson, C.M. (1988b) "Effect of postnatal development on calcium currents and slow charge movement on mammalian skeletal muscle," J. Gen. Physiol. 91: 799815 .

Bean, B.P. (1989) "Classes of calcium channels in vertebrate cells," Annu. Rev. Physiol. 51: 367-384.

Beaty, G.N., Cota, G., Nicola Siri, L., Sanchez, J.A., and Stefani, E. (1987) "Skeletal muscle $\mathrm{Ca}^{2+}$ channels," In: structure and Physiology of the slow Inward calcium Channke, edited by Triggle, D.J., and Venter, J.C., Yew York: liss, 1: 123-140.

Berridge, M.J. (1987) "Inositol trisphosphate and diacylglycerol: two interacting second messengers," Ann. Rev. Biochem. 56: 159-193. 
Blinks, J.R., Wier, W.G. and Prendergast, F.G. (1982) "Measurements of $\mathrm{Ca}^{2+}$ concentrations in living cells," prog. Biophys. Mol. Biol., 40:1-114.

Block, B.A., Imagawa, T., Campbell, K.P., Franzini-Armstrong, C. (1988) "Structural evidence for direct interaction between the molecular components of the transverse tubule/sarcoplasmic reticulum junction in skeletal muscle," J. Cell Biol. 107: 2587-2600.

Borsotto,M., Barhanin,J., Norman, R. I., and Lazdunski, M. (1984) "Purification of the dihydropyridine receptor of the voltage-dependent $\mathrm{Ca}^{2+}$ channel from skeletal muscle transverse tubules," Biochem. Biophys. Res. Commun. 122: 1357-1366.

Brandt, N.R., Caswell, A.H., Wen, S.R., and Talvenheimo, J.A. (1990) "Molecular interactions or the junctional foot protein and dihydropyridine receptor in skeletal muscle triads," J. Membr. Biol. 113: 237-251.

Brunder, D.G., Dettbarn, C., and Palade, P. (1988) "Heavy metal-induced $\mathrm{Ca}^{2+}$ release from sarcoplasmic reticulum," J. Biol. Chem. 263: 18785-18792.

Cambell, K.P., Franzini-Armstrong, C., and Shamoo, A.E. (1980) "further characterization of light and heavy sarcoplasmic reticulum vesicles: identification of the 'sarcoplasmic reticulum feet' associated with heavy sarcoplasmic reticulum vesicles," Biochim. Biophys. Acta 602: 97-116.

Caswell, A.H., Lau, Y.H., and Brunschwig, J.P. (1976) "Ouabain binding vesicles from skeletal muscle," Arch. Biochem. Biophys. 176: 417-430.

Caswell, A.H., Lau, Y.H., and Brunschwig, J.P. (1979) "Recognition and junction formation by isolated transverse tubules and terminal cisternae of skeletal muscle," J. Biol. Chem. 254: 202-208.

Caswell, A.H. and Brandt N.R. (1981) "Correlation of $\mathrm{Ca}^{2+}$ release from terminal cisternae with integrity of triad junction," In: The Mechanism of Gated Calcium Transport Across Biological Membranes edited by S.T. Ohnish and M. Endo. New Youk: Academic. p. 219-226.

Chandler, W.K., Rakowski, F.R., Schneider, M.F. (1976) "Effects of glycerol treatment and maintained depolarization on charge movement in skeletal muscle," J. Physiol. 254: 285-316. 
Corbett, A.M., Caswell, A.H., Brandt N.R., and Brunschwig, J.P. (1985) "Determinants of triad junction reformation: Identification and isolation of an endogenous promotor for junction reformation in skeletal muscle," J. Membr. Biol. 86: 267-276.

Coronado, R., Rosenberg, R.L., and Miller, C. (1980) "Ionic selectivity, saturation, and block in a $\mathrm{K}^{+}$-selective channel from sarcoplasmic reticulum," I. Gen. Physiol. 76: $425-446$.

Costanin, L.L., and Podolsky, R.J. (1967) "Depolarization of the internal membrane system in the activation of frog skeletal muscle," J. Gen. Physiol. 50:1101-1124.

Cumming, D., Holmberg, S., Kusama, Y., Shattock, M. and Williams, A. (1990) "Effects of reactive oxygen species of the structure and function of the calcium release channel from isolated sheep cardiac sarcoplasmic reticulum," J Physiol. Abstr. 420: 88P.

Curtis, B.M., Catterall, W.A. (1984) "Purification of the calcium antagonist receptor of the voltage-sensitive calcium channel from skeletal muscle transverse tubules," Biochemistry 23:2113-2118.

Donaldson, S.K. (1985) "Peeled mammalian skeletal muscle fibers: possible stimulation of $\mathrm{Ca}^{2+}$ release via a TT-SR mechanism," J.Gen. Physiol. 86:501-525.

Ebashi, S. (1975) "Regulatory mechanism of muscle contraction with special reference to the ca-troponin-tropomyosin system," Essays Biochem. 10: 1-36.

Eisenberg, R.S. (1987) "Membranes, calcium and coupling," Can. J. Physiol. Pharmacol. 65: 686-690.

Endo, M., Tanaka, M., and Ogawa, Y. (1970) "Calcium induced release of calcium from the sarcoplasmic reticulum of skinned skeletal muscle fibers," Nature 228: 34-36.

Endo, M. (1977) "Calcium release from the sarcoplasmic reticulum," Physiol. Rev. 57: 71-108.

Endo, M. (1985) "Calcium release from sarcoplasmic reticulum," Curr. Top. Membr. Transp. 25: 181-230.

Endo, M. and Iino, M. (1988) "Measurement of $\mathrm{Ca}^{2+}$ release in skinned fibers from skeletal muscle," In:Methods in Enzymology, Vol 157, p.12-26. 
Fill, M., Coronado, R., Mickelson, J.R., Vilven, J., and Ma, $\mathrm{J}$. et al. (1990) "Ábnormal ryanodine receptor channels in malignant hyperthermia muscle," J. Biophys. 50: 471-475.

Fleischer S., Inui, M. (1989) "Biochemistry and biophysics of excitation-contraction coupling," Annu. Rev. Biophys. Biophys. Chem. 18: 333-364.

Ford, L.E., and Podolsky, R.J. (1970) "Regenerative calcium release within muscle cells," Science 167: 58-59.

Fox, A.P., Nowycky, M.C., and Tsien, R.W. (1987) "Kinetic and pharmacological properties distinguishing three types of calcium currents in chick sensory neurones," J. Physiol. 394: $149-172$.

Franzini-Armstrong, C. (1975) "Membrane particles and transmission at the triad," Federation Proc. 34: 13821389 .

Franzini-Armstrong, c. (1980) "structure of sarcoplasmic reticulum," Federation Proc. 39: 2403-2409.

Garcia, J., and Stefani, E. (1987) "Appropriate conditions to record activation of fast $\mathrm{Ca}^{2+}$ channels in frog skeletal muscle," Pflugers Arch. 408: 646-648.

Gould, G.W., Colyer, J., East, J.M., and Lee, A.G. (1987) "Silver ions trigger $\mathrm{Ca}^{2+}$ release by interaction with the $\left(\mathrm{Ca}^{2+}-\mathrm{Mg}^{2+}-\mathrm{ATPase}\right.$ in reconstituted systems," J. Biol. Chem. 262: 7676-7679.

Hagiwara, S. (1983) Membrane Potential-Dependent Ion Channels in Cell Membrane. New York: Raven. p. 5-47.

Hagiwara, N., Irisawa, H., and Kameyama, M. (1988) "Contribution of two types of calcium currents to the pacemaker potentials of rabbit sino-atrial note cells," J. Physiol. 359: 233-253.

Hearse, D.J., Kusama, Y., and Bernier, M. (1988) "Rapid electrophysiological changes leading to arrhythmias in the aerobic rat heart," Circulation Research 65: 146-153.

Hodgkin, A.L., and Horowicz, P. (1957) "The differential action of hypertonic solution on the twitch and action potential of a muscle fibre," J. Physiol. London 153: 386-403. 
Ikemoto, N., Antoniu, B., and Kim, D.H. (1984) "Rapid calcium release from the isolated sarcoplasmic reticulucm is triggered via the attached transverse tubular system," J. Biol. Chem. 259: 13151-13158.

Ikemoto, N., Antoniu, B., and Meszaros, L.G. (1985) "Rapid flow calcium quench studies of calcium release from isolated sarcoplasmic reticulum," I. Biol. Chem. 260: 14096-14100.

Imagawa, T., Smith, J.S., Coronado, R., and Campbell, K.P. (1987) "Purified ryanodine receptor from skeletal muscle sarcoplasmic reticulum is the $\mathrm{Ca}^{2+}$ permeable pore of the calcium release channel," J. Biol. Chem. 262: 1663616643 .

Inui, M., Saito, A., and Fleischer, S. (1987) "Purification of the ryanodine receptor and identity with feet structure of junctional terminal cisternae of sarcoplasmic reticulum from fast skeletal muscle," J. Biol. Chem. 262: $1740-1747$.

Jorgensen, A.O., Shen, A.C.Y., Campbell, K.P., and Maclennan, D.H. (1983) "Ultrastructural localization of calsequestrin in rat skeletal muscle by immunoferritin labeling of ultrathin frozen sections," J. Cell Biol. 97: 1573-1581.

Kelly, A.M. (1980) "T tubules in neonatal rat soleus and extensor digitorum longus muscles," Dev. Biol. 80: 501505 .

Kim, D.H., Ohnishi, S.T., and Ikemoto, N. (1983) "Kinetic studies of calcium release from sarcoplasmic reticulum in vitro," I. Biol. Chem. 258: 9662-9668.

Kometani, T., and Kasai,M. (1978) "Ion permeability of sarcoplasmic reticulum vesicles measured by light scattering method," J. Membr. Biol. 41: 295-304.

Kondo, M., and Kasai, M. (1974) "Photodynamic inactivation of sarcoplasmic reticulum vesicle membranes by xanthene dyes," Photochem. Photobiol. 19: 35-41.

Lee, K.S., and Tsien, R.W. (1984) "High selectivity of calcim channels in single dialysed heart cells of the guineapig," J. Physiol. 354: 253-272.

Lee, P.C., and Rodgers M.A. (1987) "Laser flash photokinetic studies of rose bengal sensitized photodynamic interactions of nucleotides and DNA," Photochem. Photobiol. 45: 79-86. 
Lai, F.A. Ericksen, H.P. Rousseau E., Liu, Q.Y., and Meissner G. (1988) "Purification and reconstitution of the calcium release channel from skeletal muscle," Nature 331: 315319 .

Luff, A.R., and Atwood, H.L. (1971) "Changes in the sarcoplasmic reticulum and transverse tubule system of fast and slow skeletal muscles of the mouse during postnatal development," J. Cell Biol. 51: 369-383.

Liu, Q.Y., Lai, F.A., Rousseau, E. Jones, R.V. and Meissner, $G$ (1989) "Multiple conductance states of the purified calcium release channel complex from skeletal sarcoplasmic reticulum," Biophys. J. 55: 415-424.

Ma, J.J., Fill, M., Knudson, C.M., Campbell, K.P., and Coronado, R. (1988) "Ryanodine receptor of skeletal muscle is a gap junction type channel," Science 242: 99102 .

MacLennan, D.H. (1970) "Purification and properties of an adenosine triphosphatase from sarcoplasmic reticulum," I. Biol. Chem. 245: 4508-4518.

Maclennan, D.H. and Wong, P.T. (1971) "Isolation of a culcium sequestering protein from sarcoplasmic reticulum," Proc. Natl. Acad. Sci. U.S.A. 68: 1231-1235.

Maclennan, D.H., Campbell, K.P., and Reithmeier, R.A.F. (1983) "Calsequestrin," In: Calcium and Cell Function edited by Cheung, W., Academic Press, Yew York, Vol 4: 151-179.

Mathias, R.T., Levis, R. A., and Eisenberg, S. (1980) " Electrical models of excitation contraction coupling and charge movement in skeletal muscle," J. Gen. Physiol. 76: $1-13$.

Martonosi, A. and Feretos, R. (1964) "Sarcoplasmic reticulum I. The uptake of $\mathrm{Ca}^{2+}$ by sarcoplasmic reticulum fragments," J. Biol. Chem. 239: 648-653.

Martonosi, A.N. (1984) "Mechanisms of $\mathrm{Ca}^{2+}$ release from sarcoplasmic reticulum of skeletal muscle, " Physiol. Rev. 64: $1240-1320$. 
McCleskey, E.W. (1985) "Calcium channels and intracellular calcium release are pharmacologically different in frog skeletal muscle," I. Physiol. 361:231-249.

McCleskey, E.W. "Fox, A.P., and Tsien, R.W. (1986) "Different types of calcium channels," J. Experim. Biol. 124: 177190.

McCleskey,E.W., Fox, A.P., Feldman, D.H., Cruz, L.J., Olivera, B.M., et al. (1987) "' $\omega$ - conotoxin: direct and persistent blockade of specific typos of calcium channels in neurons but not muscle," Proc. Natl. Acad. Sci. USA 84: 43274331 .

Meissner, G. (1975) "Isolation and characterization of two types of sarcoplasmic reticulum vesicles," Biochim. Biophys. Acta 389: 51-68.

Meissner, G., and Mckinley, D., (1976) "Permeability of sarcoplasmic reticulum membrane- the effect of changed ionic envirconments on $\mathrm{Ca}^{2+}$ release," J. Memb. Biol. 30: 79-98.

Meissner, G. (1984) "Adenine nucleotide stimulation of $\mathrm{Ca}^{2+}$ induced $\mathrm{Ca}^{2+}$ release in sarcoplasmic reticulum," J. Biol. Chem. 259: 2365-2374.

Meissner, G. (1986) "Permeability of sarcoplasmic reticulum to monovalent ions," In: Sarcoplasmic Reticulum in Muscle Physiology edited by Entman, M.L., and Barry Van Winkle, W., CRC Press, Vol 2: 21-29

Miller, C., and Racker h E. (1976) " $\mathrm{Ca}^{2+}$-induced fusion of fragmented sarcoplalsmic reticulum with artificial planar bilayers," J. Membr. Biol. 30: 283-300.

Miller, C. (1978) "Voltage-gated cation conductance channel from fragmented sarcoplasmic reticulum: steady-state electrical properties," I. Membr. Biol. 40: 1-23.

Miller, C. Bell, J.E., and Garcia, A.M. (1984) "The potassium channel of sarcoplasmic reticulum," In: current Topics in Membranes and Transport edited by stein,W.D., Acad. Press Inc., New lork, Vol 21:99-132.

Mitchell, R.D., Palade, P., and Fleischer, S. (1983) "Purification of morphologically intact triad structures from skeletal muscle," J.Cell Biol. 96: 1008-1016.

Miyamoto, H., and Racker E. (1982) "Mechanism of calcium release from skeletal sarcoplasmic reticulum," J. Membr. Biol. 66: 1.93-201. 
Moutin, M.J., Abramson, J.J., Salama, G. and Dupont, Y. (1989) "Rapid $\mathrm{Ag}^{+}$-induced release of $\mathrm{Ca}^{2+}$ from sarcoplasmic reticulum vesicles of skeletal muscle: a rapid filtration study," Biochim. Biophys. Acta. 984: 289-292.

Nagasaki, K. and Fleischer, S. (1989) "Modulation of the calcium release channel of sarcoplasmic reticulum by adriamycin and other drugs," Cell calcium 10: 63-70.

Neckers, D.C. (1987) "The indian happiness wart in the development of photodynamic action," J. Chem. Educ. $64: 649-656$.

Neckers, D.C. (1989) "Rose bengal," J. Photochem. Photobiol. A47: $1-29$.

Notori, R. (1954) "The role of myofibrils, sarcoplasma and sarcolemma in muscle contraction," Jikeikai Med. J., $1: 18-20$.

Notori, R. (1965) "Effects of $\mathrm{Na}$ and $\mathrm{Ca}$ ions on the excitability of isolated myofibrils," In:Molecular Biology of Muscular Contraction, Elsevier, Amsterdam, p.190-196.

Ohnishi, S.T. (1981) "Calcium induced calcium release as a gated calcium transport," In: The Mechanism of Gated calcium Transport Across Biological Membranes edited by Ohnishi, S.T., and Endo, M. New Youk: Academic, p. 275293 .

Ondrias, K., Borgatta, L., Kim, D.H., and Ehrlich, B.E. (1990) "Biphasic effect of doxorubicin on the calcium release from sarcoplasmic reticulum of cardiac muscle," circ. Res. 67: 272-283.

Palade, P. (1987) "Drug-induced $\mathrm{Ca}^{2+}$ release from isolated asrcoplasmic reticulum," J. Biol. Chem. 262: 6142-6148.

Pape, P.C., Konishi, M., Baylor, S.M., and Somlyo, A.P. (1988) "Excitation-contraction coupling in skeletal muscle fiber injected with the InsP ${ }_{3}$ blocker, heparin," FEBS Lett. 235: 57-62.

Peachey, L.D. (1965) "The sarcoplasmic reticulum and transverse tubules of the frog sartorious," J. Cell Biol. 25: 209-231. 
Peachey, L.D., and Franzini-Armstrong, C. (1983) "structure and function of membrane systems of skeletal muscle cells," In: Handbook of Physiology--Skeletal Muscle, edited by Peachey, L.D., and Adrian, R.H., American Physiological Society. p. 23-71.

Perez, H.D. (1985) In: Handbook of Methods for Oxygen Radical Research, edited by Greenwald, R.A., CRC Press, Boca Raton, FI, pp. 111-113.

Pessah, I. N., Stambuk, R. A., and Casida, J. E. (1987) "Ca2+activated ryanodine binding: mechanisms of sensitivity and intensity modulation by $\mathrm{Mg}^{2+}$, caffeine, and adenine nucleotides," Mol. Pharmacol. 31: 232-238.

Rios E., Brum, G. (1987) "Involvement of dihydropyridine receptors in excitation-contraction coupling, " Nature 325: 717-720.

Rios, E., and Pizarro, G. (1991) "Voltage sensor of excitation-contraction coupling in skeletal muscle," Physiol. Rev. 71: 849-908.

Rosseau, E., Smith, J.S. and Meissner, G. (1987) "Ryanodine modifies conductance and gating behavior of single $\mathrm{Ca}^{2+}$ release channel," Am. J. Physiol. 253: C364-C368.

Rousseau, E., Roberson, M., and Meissner, G. (1988) "Properties of single chloride selectj.ve channel from sarcoplasmic reticulum," European Biophys. J. 16: 143151 .

Salama, G., and Abramson, J.J. (1984) "Silver ions trigger $\mathrm{Ca}^{2+}$ release by acting at the apparent physiological release site in sarcoplasmic reticulum," I. Biol. Chem. 259: $13363-1336$

Schneider, M.F., and Chandler, W.K. (1973) "Voltage dependent charge movement in skeletal muscle: a possible step in excitation-contraction coupling," Nature 242:244-246.

Schwartz, L.M., McCleskey, E.W., and Almers, W. (1985) "Dihydropyridine receptors in muscle are voltagedependent but most are not functional calcium channels," Nature 314: 747-751.

Selser, J.C., Yeh, Y., and Baskin, R.J. (1976) "A lightscattering measurement of membrane vesicle permeability," Biophys. J. 16: 1357-1365. 
Shamoo, A.E. and MacLennan, D.H. (1975) "Separate effects of mercurial compounds on the ionophoric and hydrolytic function of the $\mathrm{Ca}^{2+}+\mathrm{Mg}^{2+}$-ATPase of sarcoplasmic reticulum," J. Membr. Biol. 25: 67-74.

Shamoo, A.E., and Goldstein, D.A. (1977) "Isolation of ionophores from ion transport systems and their role in energy transduction," Biochim. Biophys. Acta 427: 13-53.

Smith, J.S., Coronado, R., and Meissner, G. (1985) "Sarcoplasmic reticulum contains adenine nucleotideactivated calcium channel," Nature 316: 446-449.

Smith, J.S., Coronado, R., and Meissner, G. (1986) "Single channel measurements of the calcium release channel from skeletal muscle sarcoplasmic reticulum," I. Gen. Physol. 88: 573-588.

Smith, J.S., Imagawa, T., Ma, J.J., fill, M., Campbell, K.P., and Caronado, R. (1988) "Purified ryanodine receptor from rabbit skeletal muscle is the calcium release channel of sarcoplasmic reticulum," J.Gen. Physol. 92: 1-26.

Somlyo, A.V., Gonzalez-Serratos, H. Shuman, H., Mcclellan, G., and Somlyo, A.P. (1981) "Calcium release and ionic changes in the sarcoplasmic reticulum of tetanized muscle," J. Cell Biol. 90: 577-594

Somlyo, A.P., and Somlyo, A.V. (1986) "Smooth muscle structure and function," In: The Heart and Cardiovascular System, edited by Fozzard, H., Jennings, R., Haber, E., Katz, A., Morgan, H., Yew York: Raven, pp. 845-864.

Stephenson, E.W. (1981) "Activation of fast skeletal muscle: contributions of studies on skinned fibers," Am. J. Physiol. 240: C1-C19.

Stuart, J., Pessah, I. N., Favero, T.G., and Abramson, J.J. (1991) "Photooxidation of skeletal muscle sarcoplasmic reticulum induces rapid calcium release," Arch. Biochem. Biophys. In press.

Suarez-Isla, A.B., Irribarra A.V., oberhauser, A., Larralde,L., Bull, R., Hidalgo, C., and Jaimovich, E. (1988) "Inosito 1,4,5-trisphosphate activates a calcium channel in isolated sarcoplasmic reticulum membranes." Biophys. J. 54: 737-741. 
Takeshima, H., Nishimura, S., Matsumoto, T., Ishida, H., Kangawa, K., Minamino, N., Matsuo, H., Ueda, M. , Hanaoka, M., Hirose, T. and Numa, S. (1989) "Primary structure and expression from complementary DNA of skeletal muscle ryanodine receptor," Nature 339, 439-445.

Tanabe, T., Takeshima, H., Midami, A., Flokerzi, V. et al. (1987) "Primary structure of the receptor for calcium channel blockers from skeletal muscle," Nature 328: 313318 .

Tanabe, T., Beam, K.G., Powell, J.A., and Numa, S. (1988) " Restoration of excitation-contraction coupling and slow calcium current in dysgenic muscle by dihydropyridine receptor complementary DNA," Nature 336: 134-139.

Tatsumi, S., Suzuno, M., Takahias, T., and Kasai, M. (1988) "Effects of silver ion on the calcium-induced calcium release channel in isolated sarcoplasmic reticulum," J. Biochem. 104: 279-284.

Tsien R.W. (1983) "Calcium channels in excitable cell membranes, " Annu Rev. Physiol. 45: 341-358.

Trimm, J.L., Salama, G., and Abramson, J.J. (1986) "Sulfhydryl oxidation induces rapid calcium release from sarcoplasmic reticulum vesicles," J. Biol. Chem. 261: 16092-16098.

Vergara, J., Tsien, R.Y., and Delay, M. (1985) "Inosito 1,4,5trisphosphate: a possible chemical link in excitationcontraction coupling in muscle," Proc. Natl. Acad. Sci. USA 82: 6352-6356.

Volpe, P., Salviati, G., DiVirgilio,F, and Pozzan, T. (1985) "Inositol 1,4,5-trisphosphate induces calcium release from sarcoplasmic reticulum of skeletal muscle, " Nature 316: $347-349$.

Walker, J.W., Somlyo, A.V., Goldmen, Y.E., Somlyo, A.P., and Trentham, D.R. (1987) "Kinetics of smooth and skeletal muscle activation by laser pulse photolysis of caged inositol 1,4,5-trisphosphate," Nature 327: 249-252.

Watson, B.D. and Haynes, D.H. (1982) "Structural and functional degradation of $\mathrm{Ca}^{2+}: \mathrm{Mg}^{2+}$-APTase rich sarcoplasmic reticulum vesicles photosensitized by erythrosin B," Chem. Biol. Interact. 41: 313-325.

White, S.H. (1986) "The physical nature of planar bilayer membranes," In: Ion Channel Reconstitution, edited by Miller, c. Plenum. pp.3-35. 
Winegred, S. (1968) "Intracellular calcium movements of frog skeletal muscle during recovery from tetanus," J.Gen. Physiol. 51: 65-83.

Winegred, S. (1970) "The intracellular site of calcium activation of contraction of frog skeletal muscle," J. Gen. Physiol. 55: 77-88.

Xiong, H., Buck, E., Stuart, J., Pessah, I.N., Salama, G. and Abramson, J. J. (1991) "Rose bengal activates the $\mathrm{Ca}^{2+}$ release channel from skeletal muscle sarcoplasmic reticulum," Arch. Biochem. Biophys. In press.

Xiong, H., Salama, G. (Abst.) (1991) Biophys. J. 59:103a

Yu, B.P. Masoro, E.J., and Bertrand, H.A. (1974) "The functioning of histidine residues of sarcoplasmic reticulum in $\mathrm{Ca}^{2+}$ transport and related activities," Biochem. 25: 5083-5087.

Zaidi, N.F., Lagenaur, C.F., Abramson, J.J., Pessah, I., and Salama, G. (1989a) "Disulfide linkage of biotin identifies a $106 \mathrm{kDa} \mathrm{Ca}{ }^{2+}$ release channel in sarcoplasmic reticulum," J. Biol. Chem. 264: 21725-21736.

Zaidi, N.F., Lagenaur, C.F., Hilkert, R.J., Xiong, H., Abramson, J.J., and Salama, G. (1989b) "Reactive disulfides trigger $\mathrm{Ca}^{2+}$ release from sarcoplasmic reticulum via an oxidation reaction," J.Biol. Chem. 264 : 21737-21747. 


\section{APPENDIX \\ THE CALCULATION OF PERMEABILTY RATIO}

To obtain the relationship between the membrane potential and the membrane permeability in a bilayer system, we begin with the Goldman equation:

$$
J_{i}=\frac{Z_{i} \theta P_{i}\left(C_{i, c}-C_{i, t} e^{z_{i} \theta}\right)}{\left(1-e^{z_{i} \theta}\right)}
$$

Where

$$
J_{i}=\text { flux of the } i \text { th substance in } \mathrm{mol} \cdot \mathrm{Cm}^{-2} \mathrm{~s}^{-1} \text {. } J \text { is positive }
$$
when the flux is from the cis side of the membrane to the trans side.

$$
\theta=(F V) /(R T) \text { where } F \text { is the Faraday; } R \text { is the gas constant; }
$$$$
\text { and } T \text { is the absolute temperature. } V \text { is the membrane }
$$$$
\text { potential. } V=V_{c i s}-V_{\text {trans }} \text {. }
$$

$$
P_{i}=\text { the permeability of the } i \text { th substance in } \mathrm{cm} \cdot \mathrm{s}^{-1} \text {. }
$$$$
C_{1}=\text { concentration of } i \text { th substance in } \mathrm{mol} \cdot \mathrm{cm}^{-3} \text {. }
$$$$
Z_{i}=\text { valence of the } i \text { th substance. }
$$

Applying the steady-state condition ( $I=0) \sum_{i} z_{i} J_{i}=0$, we obtain

$$
\alpha \xi^{2}+\beta \xi-\gamma=0
$$




\section{Where}

$$
\begin{aligned}
& \xi=e^{\frac{V F}{R T}} \quad\left(V=E_{r e v}\right. \text { for the above condition) } \\
& \alpha=\sum_{i(-1)} P_{i} C_{1, t}+\sum_{i(+1)} P_{i} C_{i, c}+4 \sum_{i(+2)} P_{i} C_{i, c} \\
& \beta=-\sum_{i(-1)} P_{i} C_{i, c^{+}} \sum_{i(+1)} P_{i} C_{i, c^{-}}-\sum_{i(+1)} P_{i} C_{i, t} \\
& \gamma=\sum_{i(-1)} P_{i} C_{i, c^{+}} \sum_{i(+1)} P_{i} C_{i, t}+4 \sum_{i(+2)} P_{i} C_{i, t} \\
& \text { Solving the quadratic equation, we obtain } \\
& E_{r e v}=\frac{R T}{F} \text { In }\left\{\frac{\left.\sqrt{\beta^{2}+4 \alpha \gamma}-\beta\right\}}{2 \alpha}\right.
\end{aligned}
$$

A. In 5:1 Cscl Solution, from equation (1) we have:

$$
E_{r Q V}=\frac{R T}{F} \ln \left\{\frac{5+\left(\frac{P_{C S}}{P_{C 1}}\right)}{1+5\left(\frac{P_{C S}}{P_{C 1}}\right)}\right.
$$

B. In the standard asymmetrical $\mathrm{Ca}^{2+}$ solution, if we assume that HEPES is impermeate, from equation (1) we have:

$$
E_{r \theta V}=\frac{R T}{F} \ln \left\{\frac{\sqrt{1+16 \frac{P_{C a}}{P_{T r i s}} \cdot \frac{\left[\mathrm{Ca}^{2+}\right]}{\left[T r i S^{+}\right]}+1}}{8 \frac{P_{C a}}{P_{T r i s}} \cdot \frac{\left[\mathrm{Ca}^{2+}\right]}{\left[T r i s^{+}\right]}}\right\}
$$

